FORSCHUNGSERGEBNISSE DER WIRTSCHAFTSUNIVERSITÄT WIEN

Anne-Katrin Neyer

Multinational teams

in the European

Commission and the

European Parliament 
FORSCHUNGSERGEBNISSE DER

WIRTSCHAFTSUNIVERSITÄT WIEN

Anne-Katrin Neyer

\section{Multinational teams in the European Commission and the European Parliament}

International public organizations, as the European Commission and the European Parliament, are under almost permanent political pressure to improve efficiency. While teamwork is considered to be a possible remedy, so far little research on effectiveness of multinational teams was undertaken in international public organizations. The purpose of this book is to identify the distinctive characteristics that influence multinational team performance in a public management context. Based on a qualitative research approach a complexity model of multinational team performance was developed. This model can be used as a checklist to identify possible problems in multinational teams. Additionally, managerial implications of how to deal with the inherent complexity of multinational teams are given.

Anne-Katrin Neyer, born in 1978, received her PhD in International Management from the University of Economics and Business Adminstration (WU) in Vienna in 2004. During her PhD she worked as research fellow at the Ludwig-Boltzmann Institute for Contemporary Research on Central Europe in Vienna. She is lecturing at the Europe Institute (WU), the University of Aarhus (Denmark) and the University of Applied Sciences in Fulda (Germany). She currently holds a position as Advanced Institute of Management postdoctoral research fellow at London Business School. 
Multinational teams in the European Commission and the European Parliament 


\section{Forschungsergebnisse der Wirtschaftsuniversität Wien}

\section{Band 10}

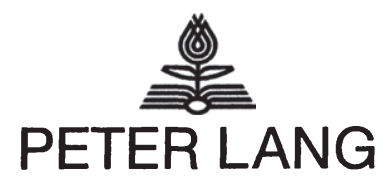

Frankfurt am Main · Berlin · Bern · Bruxelles · New York · Oxford · Wien 


\section{Anne-Katrin Neyer}

\section{Multinational teams in the European Commission and the European Parliament}

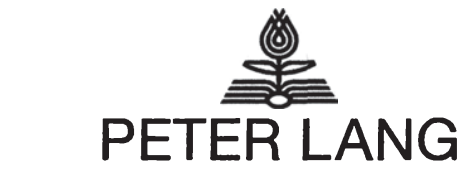

Europäischer Verlag der Wissenschaften 
Bibliographic Information published by Die Deutsche Bibliothek

Die Deutsche Bibliothek lists this publication in the Deutsche Nationalbibliografie; detailed bibliographic data is available in the internet at <http://dnb.ddb.de>.

Open Access: The online version of this publication is published on www.peterlang.com and www.econstor.eu under the international Creative Commons License CC-BY 4.0. Learn more on how you can use and share this work: http://creativecommons. org/licenses/by/4.0.

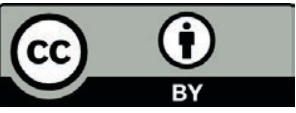

This book is available Open Access thanks to the kind support of ZBW - Leibniz-Informationszentrum Wirtschaft.

Zugl.: Wien, Wirtschaftsuniv., Diss., 2004

Gefördert durch die

Wirtschaftsuniversität Wien.

\author{
ISSN 1613-3056 \\ ISBN 3-631-54332-8 \\ US-ISBN 0-8204-7769-9 \\ ISBN 978-3-631-75440-5 (eBook) \\ (C) Peter Lang $\mathrm{GmbH}$ \\ Europäischer Verlag der Wissenschaften \\ Frankfurt am Main 2005 \\ All rights reserved.
}

All parts of this publication are protected by copyright. Any utilisation outside the strict limits of the copyright law, without the permission of the publisher, is forbidden and liable to prosecution. This applies in particular to reproductions, translations, microfilming, and storage and processing in electronic retrieval systems.

Printed in Germany 123457

www.peterlang.de 


\section{To Jörg}

Anne-Katrin Neyer - 978-3-631-75440-5

Downloaded from PubFactory at 01/11/2019 04:49:55AM

via free access 
Anne-Katrin Neyer - 978-3-631-75440-5

Downloaded from PubFactory at 01/11/2019 04:49:55AM

via free access 


\section{Preface}

This book presents a theoretical and empirical analysis of multinational teams in an international public organization context, i.e. the European Commission and the European Parliament. Working in a multinational environment means working in an environment of complexity. I believe that the main element of managing this complexity is to understand the key factor in this complex environment: the people. Therefore, it is the aim of this book to analyze how people work together in a complex multinational environment and which distinctive characteristics influence their team work.

This book is the outcome of my doctoral dissertation at the Europe Institute of the University of Economics and Business Administration in Vienna. I would like to thank my supervisor Univ.-Prof. Dr. Gerhard Fink for his scientific support, stimulating ideas and the time he invested in challenging discussions during two and a half years of being my supervisor.

I always had a very lively discussion with my academic colleague and now very good friend Dr. Marcus Kölling. I am grateful for his dedication and great interest in my work and his efforts to help me when I was lost in my data analysis. Particularly, I would like to thank him for the experience that science can be great fun.

I am grateful to all members of the Europe Institute for creating an environment I was happy to work in and helped with a lot of smaller and bigger issues.

Dedicating much time and energy to a project like a dissertation always bears the risk of loosing sight of the non-scientific world. Fortunately, I was always surrounded by people who effectively prevented that. I am grateful for your friendship: Jörg Hackermüller, Maria, Helmut and Holger Neyer, Sophia and Anton Behre, Alois, Christina and Lucia Hackermüller, Stefan Duda, Susanne and Bennet Handtmann, Judith Hofer, Lisi Hangl and Gerald Pizzini, Daniela Jézdinska.

The findings of this book are based on interviews with people from the European Commission and the European Parliament. I would like to thank my interview partners for their willingness to participate in the survey.

Vienna, September 2005

The author 
Anne-Katrin Neyer - 978-3-631-75440-5

Downloaded from PubFactory at 01/11/2019 04:49:55AM

via free access 


\section{Table of contents}

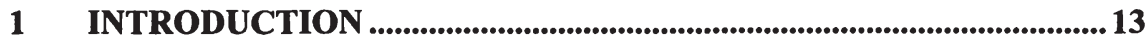

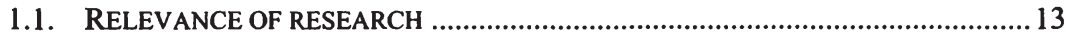

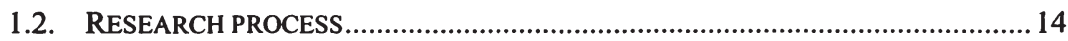

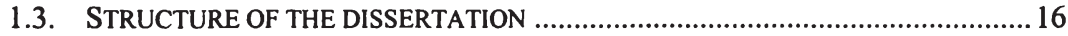

2 AN INTEGRATIVE MODEL OF MULTINATIONAL TEAM PERFORMANCE -REVIEW OF THE LITERATURE ......................... 18

2.1. A BRIEF REVIEW OF THE LITERATURE ON INTERCULTURAL MANAGEMENT .. 18

2.2. LITERATURE ON MULTINATIONAL TEAM PERFORMANCE ...............................21

2.2.1. Divergent variables to model multinational team performance ...........22

2.2.2. Control variables: Task, team size and learning processes...................36

2.2.3. Integrative model to study multinational team performance ..................38

3 METHOD.

3.1. METHODOLOGIES IN EMPIRICAL SOCIAL RESEARCH: A COMPARISON FOR SELECTING THE APPROPRIATE METHOD TO STUDY MULTINATIONAL TEAMS 40

3.2. TECHNIQUES USED TO DEVELOP HYPOTHESES ….........................................43

3.2.1. Narrative Interview........................................................................43

3.2.2. Transcription and Content Analysis ..................................................45

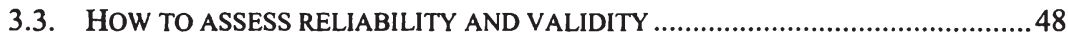

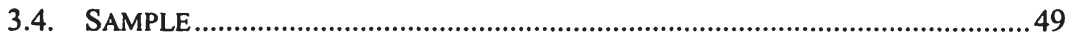

3.4.1. Sample in the European Commission ..............................................49

3.4.2. Sample in the European Parliament ...................................................51

4 EMPIRICAL FINDINGS IN THE EUROPEAN COMMISSION.........53

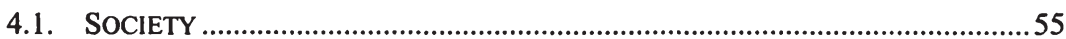

4.1.1. General cultural differences versus personality ................................56

4.1.2. Cultural differences in norms of behavior: North versus South ...........57

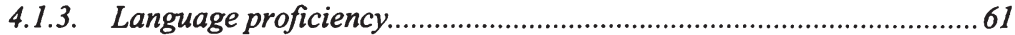

4.2. ORGANIZATION - ORGANIZATIONAL CULTURE .............................................62

4.2.1. Perceived kind of organizational culture..........................................65

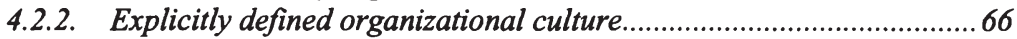

4.3. ORGANIZATION - ORGANIZATIONAL STRUCTURE .........................................67

4.3.1. Hierarchy: French versus Anglo-Saxon System ................................69

4.3.2. Performance appraisal ................................................................. 70

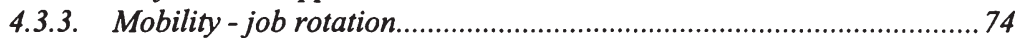

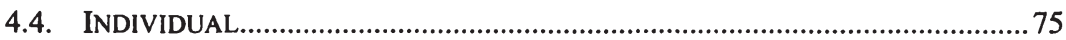

4.4.1. Personality traits......................................................................... 76

4.4.2. Personal Experiences...................................................................76

4.4.3. Personal Interests/Motivation......................................................... 77

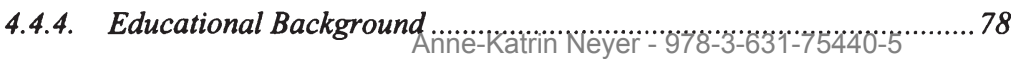




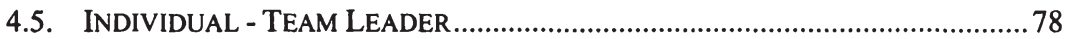

4.5.1. Leadership style and power ..................................................... 79

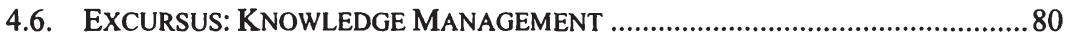

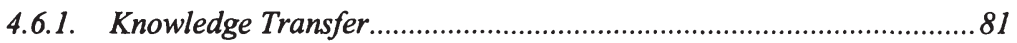

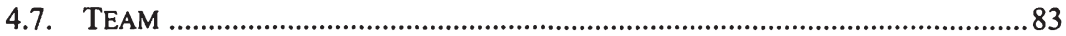

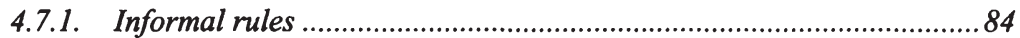

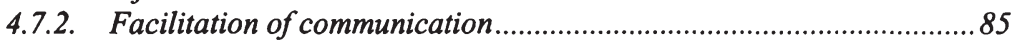

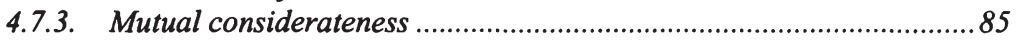

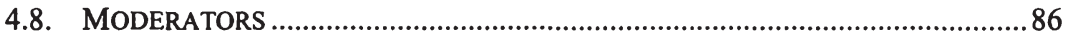

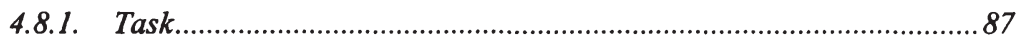

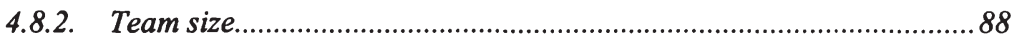

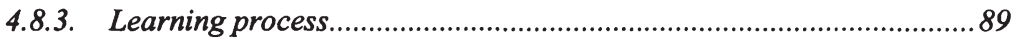

4.9. RECOMMENDATIONS FOR MANAGERS AND RESEARCHERS............................90

5 EMPIRICAL FINDINGS IN THE EUROPEAN PARLIAMENT...... 101

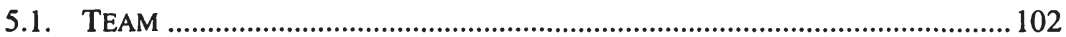

5.1.1. Informal working and networking ................................................ 102

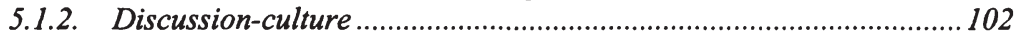

5.1.3. Culture of compromise .................................................................. 103

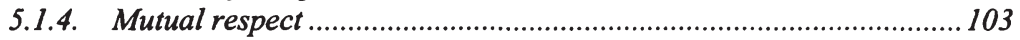

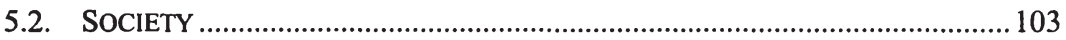

5.2.1. Cultural differences in communication styles...................................103

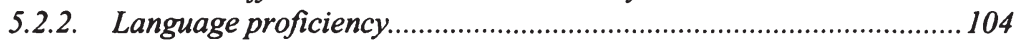

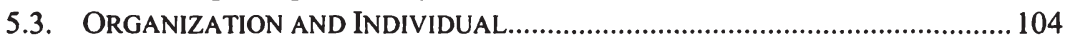

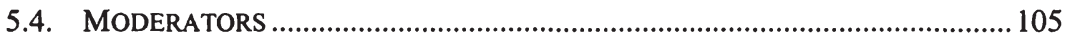

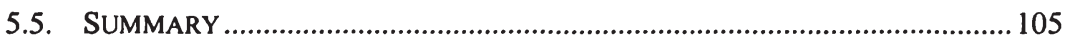

6 GENERAL CONCLUSIONS ..........................................................................112

6.1. MANAGERIAL IMPLICATIONS.................................................................112

6.2. IMPLICATIONS FOR FUTURE RESEARCH ................................................116

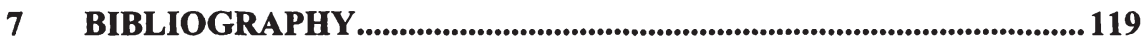

APPENDIX A: A SHORT DESCRIPTION OF THE EUROPEAN COMMISSION ..................................................................................................... 135

APPENDIX B: A SHORT DESCRIPTION OF THE EUROPEAN

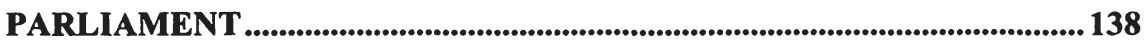

APPENDIX C: OVERVIEW OF THE FINDINGS IN THE EUROPEAN COMMISSION .............................................................................................................................. 140 


\section{List of figures}

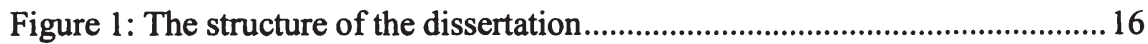

Figure 2: Model of interaction between two cultures based on Parsons (1962).... 19

Figure 3: Variables used to study multinational team performance........................23

Figure 4: An integrative diversity approach to study multinational interactions .. 38

Figure 5: Method-Decision Tree .43

Figure 6: Research approach somewhere between the inductive and deductive approaches ....................................................................................................4 4

Figure 7: Criticism continuum............................................................................58

Figure 8: Benefits and Problems of the Career Development Review................... 73

Figure 9: Five categories determining team performance: The complexity model of multinational team performance ........................................................................91 
Anne-Katrin Neyer - 978-3-631-75440-5

Downloaded from PubFactory at 01/11/2019 04:49:55AM

via free access 


\section{Introduction}

\subsection{Relevance of research}

"For every complex problem there is a simple solution. And it is always wrong" (H.L. Menken, American journalist, as quoted by Lane, Maznevski, \& Mendenhall, 2004: 23)

Going back in history shows that teamwork has existed since the dawn of time. Teams composed of many members with complementary skills in order to be most effective were already implemented by primitive man for hunting and gathering (Erny, 1987; Desjeux, 1987; Guigo, 1994 as quoted by Mutabazi \& Derr, 2003: 2).

Today, due to globalization and European integration multinational teams are increasingly gaining in importance and are becoming widespread. In international public organizations like the European Commission and the European Parliament people from 25 European nations are working together. In multinational companies people from all over the world are mixed to fulfil a task.

Regarding the different cultural and individual backgrounds of individuals in multinational teams, it is no longer a secret that cultural as well as organizational features are important factors which drive multinational teams. However, the understanding of the complexity inherent in multinational teams is not always easy to handle, and a false understanding and interpretation of the multiple categories (e.g. cultural values and norms, organizational context, interests, perceptions, personality) influencing multinational team performance reduces the success of those teams.

Although there is a substantial body of literature addressing selected issues of multinational teams previous research reports divergent results on the effects of cultural diversity on team outputs. While some researchers found positive effects of diversity and, therefore, dwell on the 'value in diversity' hypothesis (Richard, 2000: 165) others mainly found negative effects. Researchers from numerous disciplines, most importantly psychologists, culture specialists and management scholars, pull in several directions to analyze multinational teams. Across the field a broad range of categories was identified, which have an influence on specific aspects of team performance. Results differ widely depending on the selection of those explanatory variables and on the perception of 'team performance' or 'team output'. Particularly, recent research focuses on selected categories of influence on team performance, more or less ignoring the complex relations that might exist between the categories.

Consequently, the purpose of this dissertation is first to attempt to clarify the influence of the various categories on multinational team performance and their 
interrelations. Additionally, it aims to convey a new understanding of the relevance of the complexity inherent in multinational teams.

Regarding the history of the European Union and its institutions the number of employees with different cultural backgrounds has increased with each enlargement process of the European Union. The ongoing increase in employees from different cultural backgrounds allows the European Commission and the European Parliament to be an interesting research object to investigate the research question "What does really matter in multinational teams?" Due to the high degree of multinationality it was decided to analyse the complexity inherent in working in a multinational team (particularly in contrast to working in a domestic team) in the context of these both institutions from an Austrian perspective.

Additionally, this decision was supported by the interest of studying the basic question of how multinational teams work in a bureaucratic organization. This contribution is highly valuable, as so far only rudimentary empirical research was undertaken in the field of multinational teams in international public organisations.

The result of this dissertation is an intensive analysis of the requirements of multinational teams concerning the influence of the complex relations of societal (i.e. culture), organizational and individual categories on team work. Linking these categories allows us to identify how individuals in multinational teams in a specific context deal with the inherent complexity in order to improve their performance.

\subsection{Research process}

To deal with the complexity inherent in this research topic the research process was organized as follows.

\section{Desk research - Theory Building}

The first research objective was to gain understanding of the various categories influencing team performance in the literature. In order to integrate this dissertation into the international field of multinational team research an intensive literature analysis of leading (international) academic journals was undertaken.

Desk research has allowed to develop a research concept and theoretical framework to study the complexity of multinational team performance. Literature of various academic streams (e.g. international management, psychology, sociology, organizational behavior) was reviewed.

\section{Field research - Empirical Analysis}

The empirical analysis of the data was based on the theoretical framework. The second research objective was to show what categories are to be seen as important for team performance by multinational team members. The final goal is to present the complex relations among these categories. Empirical analysis will show how 
multinational team members cope with the complexity inherent in multinational team work. In the context of the European Commission and the European Parliament multinational teams are defined as groups of individuals from different nations that seek to make sense of various work-related events (Smith \& Peterson, 1988). 'Event' can be defined as "a partially abstracted bit of social reality that serves as a unit of information processing, interpretation, or meaning constructed by a social actor in interaction with other social actors" (Peterson, 1993: 7). 'Work related' implies that there is pressure for achievement. A work team has to perform within a limited time span, i.e. to deliver results which are important to the team itself and/or the organization.

The aim of this study is to study social patterns of behaviour of multinational team members to figure out how they are influenced by e.g. organizational settings and how in turn they influence multinational team performance. This study highlights the development of theory in close context to "multinational team reality". In his presentation at the Academy of Management meeting 2004 (New Orleans, Louisiana, Session 476: The great applied theorists, Monday, 10:40am12:00am), Jay Lorsch, one of the most famous researchers in organizational behaviour, pointed out: "If you want to learn about the organization, you have to learn from real people". Thus, if you want to learn about multinational teams you have to ask real team members.

This approach goes beyond quantitative research methodology. Consequently, qualitative research was found to be the appropriate research methodology. Qualitative data were analyzed in a way that allows for the generation of propositions. Empirical data were collected with in-depth narrative interviews. 25 interviews were conducted with Austrian employees in the European Commission. 15 interviews were conducted with Austrian members of the European Parliament. The experiences and knowledge of the interview partners in multinational team work are an important source to figure out what influences multinational team performance. Therefore, the findings based on their experiences can be used to close gaps in the literature and to study in detail the complex relations of various categories of influence on team performance.

Narrative interviews are biased by individual attributes and personal perspectives of the interview partners as well as of the interviewer. However, the appropriate use of research methodology (i.e. a professional, well prepared interview process and an accurate data analysis) helps to overcome disadvantages of the qualitative research approach.

\section{Results - Managerial implications and implications for future research}

The findings of desk and field research help to develop an integrated model of team performance which considers the complexity of the research topic. Both, the theoretical foundation and the empirical analysis of data, which reflect the reality

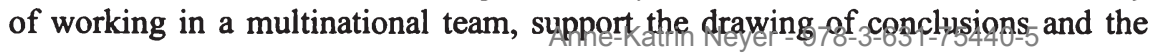


development of propositions. It suggests topics for future multinational team research and gives managerial implications for the efficient use of multinational teams.

\subsection{Structure of the dissertation}

This study is structured as follows (for illustration see Figure 1).

FIGURE 1: THE STRUCTURE OF THE DISSERTATION

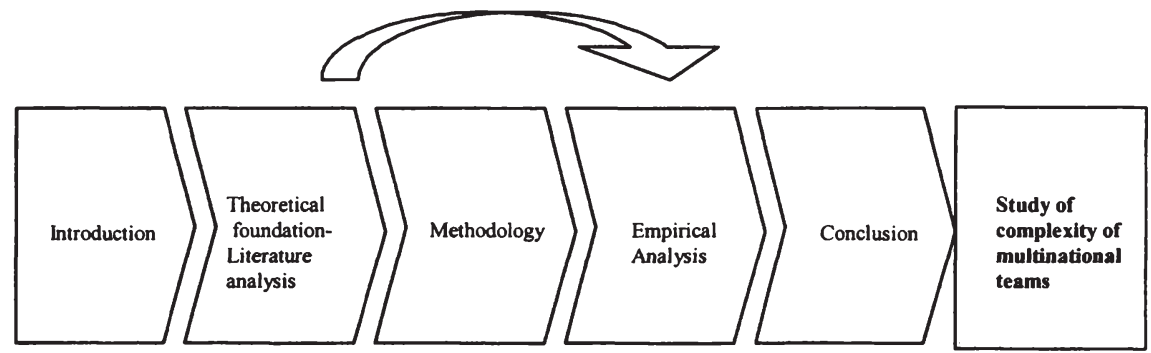

Source: The author

After this brief introduction, the theoretical framework for this study will be developed based on an intensive literature analysis. It begins with a brief overview of existing studies on intercultural management. Three major strands in cross-cultural literature can be identified: general cultural values, culture shock/cultural adjustment concepts based on personality traits and cultural standard methods. These major strands in literature can be loosely related to the Parsons \& Shils (1962) concept of interrelated values, personality and action.

In a next step, literature focusing on multinational team performance was analyzed, including all of the three strands of literature mentioned above. According to the literature analysis, the following variables can be selected which explain influences of multinationality on team work: society, organization, individual, team and moderators. In a last step, these categories that affect multinational team performance are arranged into an integrated model. The analysis of the literature leads to the following three research aspects:

- Which categories influence the performance of multinational teams?

- Are these categories related? If yes, how are they related?

- How do individuals cope with the complexity of working in multinational teams? 
Chapter 3 deals with the methodology used in this study. In a first step, methodologies in empirical social research (quantitative versus qualitative) were compared in order to identify the appropriate research tool. Then the techniques used to develop propositions are explained in detail: The narrative interview was used to collect empirical data. The collected data were analyzed according to the qualitative content analysis (Mayring, 2003). Finally, this chapter discusses how reliability and validity of data can be ensured in qualitative research in contrast to quantitative research.

Chapters 4 and 5 present the results of the empirical analysis for the European Commission and the European Parliament. Each identified category of influence on team performance is presented in detail. The summary of the chapter allows the developing of propositions and presents the complex relations of the identified categories.

The study concludes with summarizing the results of the empirical parts. It offers managerial implications of how to deal with the inherent complexity in multinational teams as well as implications for future research. 


\section{An integrative model of multinational team performance - Review of the literature}

The analysis of literature is based on two steps. First a literature screen of the (intercultural) literature covering "intercultural performance" as the dependent variable (1996 to 2002) was undertaken. In a next step the findings of literature analysis on "intercultural performance" were complemented with a more recent literature screen of 18 leading journals (1996-2004) covering "multinational team performance" as the dependent variable.

In the following, a brief overview of the existent literature on intercultural management will be given. Then the focus will be on the second literature review as the source for the development of an integrative model to study multinational team performance.

\subsection{A brief review of the literature on intercultural management}

Understanding the dynamics of international business encounters requires a fundamental shift from comparative studies of cultural differences to the study of intercultural interactions. The decisive issue in international management is not the existence of differences per se, but the way behavioral differences are perceived, interpreted and managed by members of different national cultures in the context of their business.

There are three major strands in cross-cultural research literature:

a) The general culture descriptions along a few culture dimensions (Hall \& Hall, 1990, 2000; Hofstede, 1980, 1993, 2001; House et al., 2004; House et al., 2002; House et al., 2001; Kluckhohn \& Strodtbeck, 1961; Rokeach, 1973; Schwartz, 1992; Trompenaars \& Hampden-Turner, 1997).

b) The culture shock/cultural adjustment concepts based on personality traits (Black et al., 1991; Caligiuri, 2000, 2000a; Gudykunst et al., 1978; Oguri et al., 2002; Parker \& McEvoy, 1993; Ward et al., 2001).

c) The critical incidents/cultural standard method that deals with differences in the types of perceiving, norms of sensing, thinking, judging, and acting (Thomas, 1996, 2003; Fink \& Meierewert, 2001).

These major strands in literature can be loosely related to the Parsons \& Shils (1962) concept of interrelated values, personality and action. Parsons (1951) describes action as process to achieve satisfaction of needs or to reach a goal in a situation. Action is organized in three systems: personality, social system and cultural system. These systems are interdependent and interpenetrating, but still remain self-contained. The social system is made up of the action of individuals. Role and role expectation can be defined as the most important elements of this system. Interaction of individuals in the social system makes the development of 
culture on a human level possible. The need dispositions in the personality system emerge from the interrelation with the social and cultural system. We enlarged Parsons subsystems of action from the monocultural to the intercultural context (see Figure 2).

FIGURE 2: MODEL OF INTERACTION BETWEEN TWO CULTURES BASED ON PARSONS (1962)

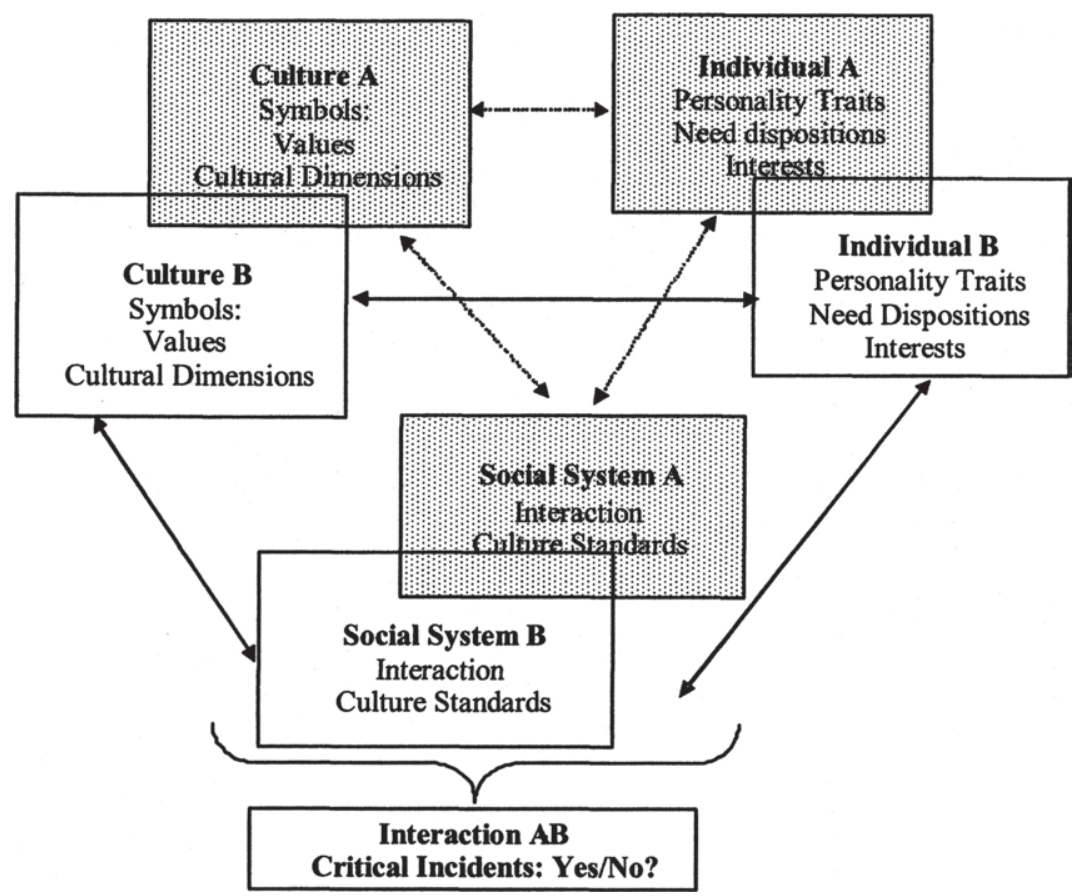

Source: Neyer \& Kölling (2003)

The three major strands in research related to intercultural management can be loosely linked to this intercultural action model:

- Value system: cultural dimensions

- Personality system: personality traits

- Action system: cultural standard method

However, general culture concepts with 4 to 11 dimensions from Hofstede (2001) to Schwartz (1992) have limited predictive value for the coping capabilities of individuals with difficulties in cross-cultural encounters (Ward et al., 2001; Caligiuri, 2000) and also for critical incidents emerging in cross-cultural encoun- 
ters (Fink \& Meierewert, 2001; Thomas, 1996, 2003). In a first literature screen, all articles out of 15 leading academic journals from 1996 to 2002 were examined for "intercultural performance" content. Out of 4,847 articles in 15 leading academic journals (Table 1 ) only 57 or $1.2 \%$ dealt with intercultural effectiveness and/or personality traits/values. Not one deals with critical incidents or intercultural performance.

\section{Table 1: Intercultural effectiveness, personality traits/values in top academic journals}

Literature screening: 15 journals, 1996-2002 (except: International Journal of Cross-Cultural Management (until 2001)), 4,847 articles

\begin{tabular}{|l|c|}
\hline \multicolumn{1}{|c}{ Journals } & $\begin{array}{c}\text { Number } \\
\text { of relevant studies }\end{array}$ \\
\hline Academy of Management Journal (AMJ) & 4 \\
\hline Academy of Management Review (AMR) & 2 \\
\hline Administrative Science Quarterly & 2 \\
\hline Human Relations & 1 \\
\hline Educational Psychology Review & 0 \\
\hline International Journal of Cross-Cultural Management & 2 \\
\hline International Journal of Intercultural Relations & 30 \\
\hline Journal of Applied Behavioural Sciences & 1 \\
\hline Journal of Applied Psychology & 1 \\
\hline Journal of Cross-Cultural Psychology & 3 \\
\hline Journal of International Business Studies & 2 \\
\hline Journal of Occupational and Organizational Behaviour & 3 \\
\hline Journal of Personnel Psychology & 5 \\
\hline Management International Review & 1 \\
\hline Psychiatry Research & 0 \\
\hline Total & 57 \\
\hline
\end{tabular}

Following Parsons, it is assumed that values, norms and personality related factors determine the kind of action undertaken. When this action leads to interaction with agents from other cultures, critical incidents may emerge either due to conflicts of interest or to different behaviour. Action and critical incidents determine intercultural performance and have some influence on the intercultural competence of the acting individuals. Critical incidents induce the cultural adjustment process (the culture shock and learning processes). So far the research instruments to identify personality traits of individuals, cultural dimensions, and critical incidents are only loosely related to each other. Nevertheless each strand offers a number of categories to explain action-oriented differences in the intercultural contact. As cultural values, personality traits and culturally determined norms of 
behaviour are important parts of the integrated model to study multinational team performance, they will be explained in detail in chapter 2.2.

\subsection{Literature on multinational team performance}

This literature review was influenced by the vast array of cultural studies and studies in international management, notably on universal cultural values, identities, and cultural adjustment, and, on the other hand, by the Parsons/Shils (1962) model of action which consists of the three closely related subsystems: values, personality, and social system. If this model can provide a valid description of national systems of action, then transposing this model to a multinational system of action must necessarily embrace differences in values, personalities, and social systems that can be attributed to differences in nationality.

Most of the variables that are employed in multinational team research and relate to multinationality can be grouped into categories that are major research fields by themselves: universal values; cultural standards: norms of behavior; perceptions: stereotypes and identities; and personality traits. Indeed, these sets of variables can be found in the literature on multinational and/or multicultural work teams. However, mostly only a limited number of variables is applied together. Several times when subsets of these variables were jointly used disturbing cross effects as estimated parameters changed signs emerged.

Thus, while noting substantial achievements in the literature, there is room for going beyond its present limitations by using broader and more recent/advanced sets of variables and by investigating the relations among different sets of variables. An increased awareness of the complex relations between these categories is needed.

In their extensive literature review, Jackson et al. (2003) analyzed recent research on diversity and its impact on teams and organization. They define diversity as the "distribution of personal attributes among independent team members of a work unit". Personal attributes refer to (a) the "visible" attributes of a person (e.g. age, sex, racio-ethnicity), (b) to those attributes which are only becoming evident when knowing a person well (e.g. personality, knowledge, values) and (c) to attributes which are between these two sides (e.g. education, tenure) (Jackson et al., 2003: 802).

In contrast to their research this review does not only focus on distribution of personal attributes but aims to identify the influences of macro (e.g. society and organization)- and micro (e.g. individual and team) categories on team performance, focusing particularly on the complexity of their relations.

This part of the literature analysis is structured along these lines: Next an overview about those groups of variables which were identified in the literature review is given: in addition to 'context', four categories of variables were identified, which explain multinational team performance (universal values; cultural stan- 
dards: norms of behavior; perceptions: stereotypes and identities; personality traits), and three control variables: team size and task as having an influence on the strength of the effect of certain variables and learning processes, which are influenced by power and interests. An integrative approach was developed as a framework for the empirical analysis.

\subsubsection{Divergent variables to model multinational team performance}

Diversity across nations can be attributed to differences in national identities of people engaged in multinational teams. Jiménez et al. (2004) identified three lines of thought that explain national identities: a cultural theory, an instrumental theory, and a civic theory. Smith $(1992,1995,1999)$ and Østerud $(1999)$ found that cultural heritage, language, myths, symbols, and emotional bonds form the foundations of national identities, and that cultural diversity and structural differences are deeply rooted in European cultures. With their instrumental theory Brass (1979) and Cinnirella 1997 argue that "the perception of the potential gains or losses that might result from membership of a given social group may influence people's identification with it" (Jiménez et al., 2004: 3). Finally, the civic theory "stresses the development of identities around agreement over rules ... shared cultural norms and common beliefs" (Mancini, 1998: 8; Weiler, 1999: 346; Kersbergen, 1997, as quoted by Jiménez et al., 2004: 4).

From these theories follows that a specific set of variables can largely embrace diversity that emerges out of national difference: Cultural values; cultural standards (rules and norms); perceptions and beliefs, interests (task), and personality traits. In reference to the cultural, civic and instrumental theories 18 leading academic journals during 1996-2004 were screened and 51 articles were identified with the keywords (multi-cultural) team performance, cultural diversity, values, personality traits, and contextual factors (Table 2). Based on this literature screen it is intended to offer a comprehensive concept that can serve as a frame of reference for further research.

Table 2: Research on team and organizational diversity in top academic journals

(1996-2004, 18 journals)

\begin{tabular}{|l|c|}
\hline Selected Journals & $\begin{array}{l}\text { Number of relevant } \\
\text { studies (1996-2(0)4) }\end{array}$ \\
\hline Academy of Management Executive & 1 \\
\hline Academy of Management Journal & 8 \\
\hline Academy of Management Review & 4 \\
\hline Administrative Science Quarterly & 6 \\
\hline Applied Psychology (1998-2003) & 2 \\
\hline Group and Organization Management & 7 \\
\hline Human Relations & 2 \\
\hline \multicolumn{2}{|c|}{ Anne-Katrin Neyer-978-3-631Trobecentinued } \\
\hline
\end{tabular}




\begin{tabular}{|l|c|}
\hline Selected Journals & $\begin{array}{l}\text { Number of relevant } \\
\text { studies (1996-2004) }\end{array}$ \\
\hline $\begin{array}{l}\text { International Journal of Cross Cultural Management } \\
(1998-2003)\end{array}$ & 2 \\
\hline International Journal of Intercultural Relations & 2 \\
\hline International Journal of Human Resource Management & 3 \\
\hline Journal of Cross Cultural Psychology (1998-2003) & 2 \\
\hline Journal of Organizational Behaviour & 4 \\
\hline Journal of World Business (1997-2003 online) & 1 \\
\hline Leadership Quarterly & 2 \\
\hline Management International Review & 0 \\
\hline Organization Science & 1 \\
\hline Organizational Behavior and Human Decision Process & 2 \\
\hline Organizational Dynamics & 2 \\
\hline Total & 51 \\
\hline
\end{tabular}

When trying to make sense of the divergent variables used in these 51 articles, variables were grouped into organizational context, four categories of explanatory variables, and three sets of control variables, which together explain team performance:

Team Performance $=f$ [organizational context $]+$ [universal values + norms of behavior + perception of others and self + personality traits $]+[$ task + team size + learning process (influenced by power/interest)] (Figure 3 ).

\section{FIGURE 3: VARIABLES USED TO STUDY MULTINATIONAL TEAM PERTORMANCE}

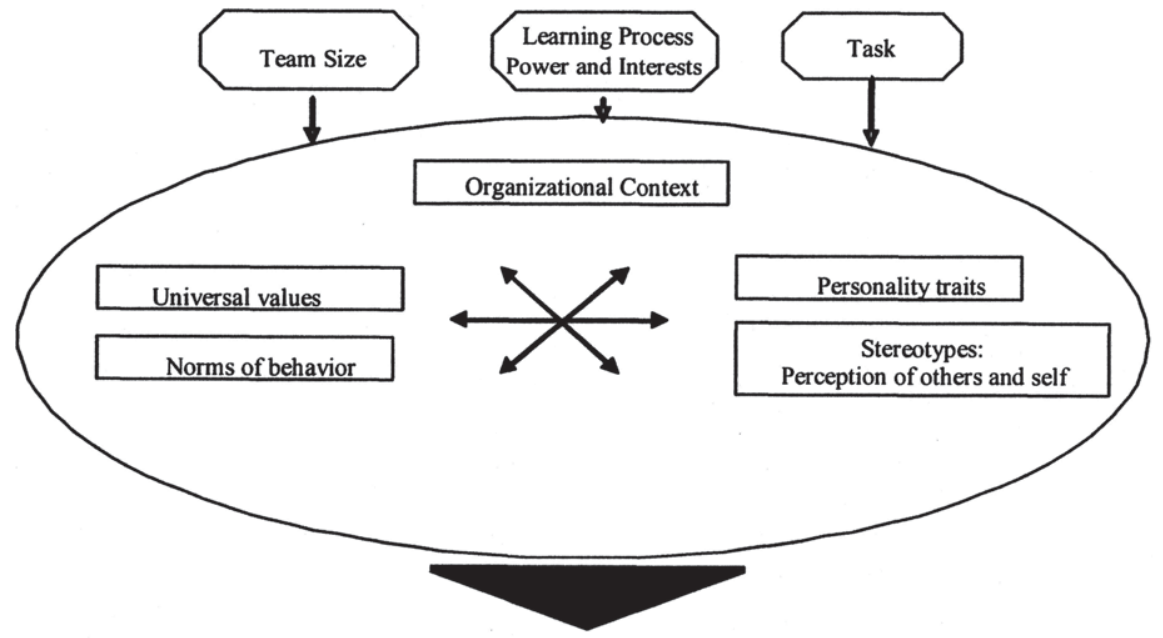

TEAM PERFORMANCE 
Next, those 25 articles with significant empirical content were selected and it was not further dealt with more theoretical papers. These papers illustrate the sparse and selective use of variables in the existing literature. In three papers only a maximum of 3 predictors is used while the whole body of 25 articles embraces a broad range of variables (Table 3). In the following, the different sets of variables which were identified will be described in more detail.

Table 3: Frequencies of predictors of team performance in (multinational) team research (hased on literature analvsis)

\begin{tabular}{|c|c|c|c|c|c|c|}
\hline Study & $\begin{array}{l}\text { Lniversal } \\
\text { Vialues }\end{array}$ & $\begin{array}{l}\text { Norms of } \\
\text { behatior }\end{array}$ & $\begin{array}{l}\text { Stereotypes } \\
\text { Perception of } \\
\text { others and } \\
\text { self }\end{array}$ & $\begin{array}{l}\text { Personality } \\
\text { Traits }\end{array}$ & $\begin{array}{l}\text { Power } \\
\text { and } \\
\text { Interest }\end{array}$ & Category \\
\hline $\begin{array}{l}\text { Neumann et al. } \\
\text { (1999) }\end{array}$ & & & & $\mathrm{x}$ & & 1 \\
\hline $\begin{array}{l}\text { Ely \& Thomas } \\
\text { (2001) }\end{array}$ & & & $\mathrm{X}$ & & & 1 \\
\hline Jehn et al. (1999) & & & $\mathrm{X}$ & & $\mathrm{X}$ & 2 \\
\hline $\begin{array}{l}\text { Watson et al. } \\
\text { (1998) }\end{array}$ & & & $\mathrm{x}$ & $\mathrm{x}$ & & 2 \\
\hline Elron (1997) & $\mathrm{X}$ & & $\mathrm{X}$ & & $\mathrm{X}$ & 3 \\
\hline $\begin{array}{l}\text { Joshi et al. } \\
\text { (2002) }\end{array}$ & & & $\mathrm{x}$ & & $\mathrm{X}$ & 2 \\
\hline $\begin{array}{l}\text { Hofner Saphiere } \\
\text { (1996) }\end{array}$ & & $\mathrm{x}$ & & & & 1 \\
\hline Randel (2003) & & & $\mathrm{X}$ & & & 1 \\
\hline $\begin{array}{l}\text { Flynn et al. } \\
(2001)\end{array}$ & & & $\mathrm{x}$ & $\mathrm{x}$ & & 2 \\
\hline $\begin{array}{l}\text { Kirkman et al. } \\
(2001)\end{array}$ & $\mathrm{X}$ & & & & & 1 \\
\hline $\begin{array}{l}\text { Salk \& Brannen } \\
(2000)\end{array}$ & & $\mathrm{X}$ & $\mathrm{X}$ & & $\mathrm{X}$ & 3 \\
\hline $\begin{array}{l}\text { Watson et al. } \\
\text { (1998a) }\end{array}$ & & & $\mathrm{X}$ & $\mathrm{x}$ & & 2 \\
\hline $\begin{array}{l}\text { Earley \& Mosa- } \\
\text { kowski (2000) }\end{array}$ & & $\mathrm{x}$ & $\mathrm{x}$ & & & 2 \\
\hline $\begin{array}{l}\text { Probst et al. } \\
\text { (1999) }\end{array}$ & $\mathrm{x}$ & & & & & 1 \\
\hline $\begin{array}{l}\text { Thomas, D. } \\
\text { (1999) }\end{array}$ & $\mathrm{X}$ & & $\mathrm{x}$ & & & 2 \\
\hline $\begin{array}{l}\text { Kirkman \& } \\
\text { Shapiro (2001) }\end{array}$ & $\mathrm{X}$ & & & & $\mathrm{X}$ & 2 \\
\hline $\begin{array}{l}\text { Kirkman \& } \\
\text { Shapiro (2001a) }\end{array}$ & $\mathrm{X}$ & & & & $\mathrm{x}$ & 2 \\
\hline
\end{tabular}




\begin{tabular}{|c|c|c|c|c|c|c|}
\hline Study & $\begin{array}{l}\text { Universal } \\
\text { Values }\end{array}$ & $\begin{array}{l}\text { Norms of } \\
\text { behavior }\end{array}$ & $\begin{array}{l}\text { Stereotypes } \\
\text { Perception of } \\
\text { others and } \\
\text { self }\end{array}$ & $\begin{array}{l}\text { Personality } \\
\text { Traits }\end{array}$ & $\begin{array}{l}\text { Power } \\
\text { and } \\
\text { Interest }\end{array}$ & Category \\
\hline $\begin{array}{l}\text { Barsade et al. } \\
(2000)\end{array}$ & & & $\mathrm{X}$ & $\mathrm{X}$ & $\mathrm{X}$ & 3 \\
\hline $\begin{array}{l}\text { Beersma et al. } \\
\text { (2003) }\end{array}$ & & & & $\mathrm{X}$ & & 1 \\
\hline $\begin{array}{l}\text { Chattopadhyay } \\
\text { (1999) }\end{array}$ & & & $\mathrm{X}$ & & & 1 \\
\hline $\begin{array}{l}\text { Gomèz et al. } \\
(2000)\end{array}$ & $X$ & & $\mathrm{X}$ & & & 2 \\
\hline $\begin{array}{l}\text { Baugh \& Graen } \\
\text { (1997) }\end{array}$ & & & $\mathrm{x}$ & & & 1 \\
\hline $\begin{array}{l}\text { Richard et al. } \\
(2003)\end{array}$ & & & $\mathrm{X}$ & & & 1 \\
\hline $\begin{array}{l}\text { Kiffin-Petersen } \\
\& \text { Cordery } \\
\text { (2003) }\end{array}$ & $\mathrm{X}$ & & & $\mathrm{x}$ & & 2 \\
\hline $\begin{array}{l}\text { Tjosvold et al. } \\
(2003)\end{array}$ & & $\mathrm{X}$ & & $\mathrm{X}$ & & 2 \\
\hline Total & 8 & 4 & 16 & 8 & 7 & \\
\hline
\end{tabular}

\subsubsection{Context}

'Organizational context' is the framework within which teams are established and act (organizational culture, strategic context, temporal context). 'Team context' gives the framework within which team members act and interact. Binding (obligatory) norms of the embedding organization have a strong impact on team norms, while other team norms can deviate from less binding norms of the organization if at the level of the organization some norms are considered as a rule that 'should' or 'could' be met.

One of the major limitations in previous research of 'cultural diversity' and its impact on team performance is the neglect of 'context'. "For work teams, departments and even whole organizations, context provides the purpose, resources, social cues, norms and meanings that shape behavior" (Jackson et al., 2003: 813). Earley \& Gibson (2002) underline the importance of context-dependent information about the research focus (team, organizational, or societal context) and offer a series of qualitative descriptions (see also Earley \& Erez, 1997). Additionally, Gibson et al. (2003) evaluated team effectiveness in multinational organizations across contexts.

The context may have an effect on whether differences are noticed and how single team members react (Milliken \& Martins, 1996: 420). This conclusion is consistent with the findings in a bi- and tricultural context. Austrian students or Austrian managers perceive 'diversity" in a different context (studying abroad 
versus doing international business) and consequently their reactions, perceptions, and adjustments are different (Fink \& Meierewert, 2001). Therefore, in research on multinational team performance we have to consider the institutional context, i.e. the kind of organization and the contextual factors given within the particular organization. However, in the literature research on teams in multinational companies is predominant and only a few researchers (e.g. Elron et al., 2003) are already analyzing teams in international organizations and non-profit organizations.

Jackson et al. (2003: 814) found that organizational culture, strategic context, and temporal context (but also task characteristics) are those contextual influences which received some attention. Garcia-Prieto et al. (2003: 431) argue that understanding the inconsistency of the effects of diversity on team performance might be easier if team members are seen as individuals with multiple social identities which are a) subjective, dynamic and context dependent and b) influencing the assessment of issues and events. They emphasize the importance to study more methodically how contextual and situational factors in work teams influence team members' identity salience (Garcia-Prieto et al., 2003: 432).

\subsubsection{Universal values}

Universal values are the characteristics of national cultures which are most widely used in international management research when cultural differences matter. The study of universal values has a long tradition and is a research field by itself. It delivers important inputs to the study of international management and related fields. Notably in multinational team research universal values are also considered as important.

Clyde Kluckhohn (1951) assumed that there are universal aspects that all societies have to address. Values give guidance to individuals or groups within a society how to solve problems. He defined values as: "A conception, explicit or implicit, distinctive of an individual or characteristic of a group, of the desirable which influences the selection from available modes, means and ends of action" (Kluckhohn, 1951: 395).

Schwartz \& Bilsky $(1987,1990)$ generated a conceptual definition of values that incorporates five formal features of the values recurrently mentioned in the literature: "Values (1) are concepts or beliefs, (2) pertain to desirable end states or behaviors, (3) transcend specific situations, (4) guide selection or evaluation of behavior and events, and (5) are ordered by relative importance" (Schwartz, 1992: 3-4).

It is important to note that values do not determine, but influence the selection from available modes, means and ends of action, i.e. the general norms that prevail in a given society or specific norms that prevail in a given organization (Popitz, 1980). Thus, norms of behavior cannot be equated with values! Value orientations are complex, but patterned (rank ordered) principles, resulting from the transactional interplay of three analytically distinguishable elements of the 
evaluative process - the cognitive, the affective and the directive elements. These principles vary from culture to culture, but only in the ranking patterns of culture elements, which are cultural universals by themselves. Variation of another kind is variation in degrees of conscious awareness individuals have of the value orientations, which influences their behavior (Kluckhohn \& Strodtbeck, 1961: 4).

Most studies refer to Hofstede's (2001) four dimensions (individualism/collectivism, masculinity/feminity, power distance, uncertainty avoidance) or Kluckhohn \& Strodtbeck's (1961) dimensions (human nature orientation, man nature orientation, time orientation, activity orientation, relational orientation). Probst et al. (1999) make use of the earlier research by Triandis (1995) and refer to horizontal collectivism (the self-concept is seen as closely tied to and interdependent with others of the in-group, who are seen as similar to the self), horizontal individualism (is a cultural pattern characterized by a self-concept that is autonomous, yet the individual is seen as equal in status to others), vertical collectivism (the self-concept is closely tied to and interdependent with others of the in-group, but the members of the in-group differ from one another, in particular with regard to social status), and vertical individualism (is a cultural pattern in which the individual views the self as autonomous and expects inequality. Doing well in competition is an important aspect of this pattern).

The influence of these value measures on different dependent variables was analyzed: team performance (Kirkman \& Shapiro, 2001; Probst et al., 1999), process outcomes (Thomas, 1999), issue-based conflict and social cohesion (Elron, 1997), work attitudes, i.e. job satisfaction and organizational commitment (Kirkman \& Shapiro, 2001a), evaluation generosity, i.e. the generosity of positive team performance evaluations (Gomèz et al., 2000), and trust (Kiffin-Peterson \& Cordery, 2003). Probst et al. (1999), Kirkman \& Shapiro (2001) and Thomas (1999) found a positive correlation between collectivism and team performance. When additional independent variables were used, e.g. 'resistance to teams', then the originally assumed positive influence of collectivism on different dependent variables became negative or insignificant (Probst et al., 1999; Kirkman \& Shapiro, 2001; Kirkman \& Shapiro, 2001a). It can be assumed that the variables 'resistance to teams' and 'collectivism' are inversely related and were measured in a similar (inverse) way. Resistance to teams explains most of the variance that could be also explained by collectivism, but with a negative sign (Kirkman \& Shapiro, 2001).

As seen, so far most of multinational team research is based on Hofstede's value scales. However, beyond the seminal work of Hofstede, more recently the GLOBE project offers new insights, as it offers information about the distributions of values and information about the current (as is) societal practices and the desired (should be) perceptions of values. Although the insights of e.g. Hofstede's work and the GLOBE project prove helpful in sensitizing management scholars and managers to the need to be culturally sensitive when inferring what "effec- 
tive" management practice is, for several reasons it is assumed that their conclusions do not inform management scholars or managers in detail about how to effectively manage teams that are multinational in nature. Overall it can be concluded that the results achieved with cultural value dimensions are not conclusive. Several reasons could explain why these results diverge:

Cultural value dimensions quantitatively describe cultures to which team members belong and can be used to approximate presumed cultural distance. There are, however, two caveats: 1) While the dimensions offer "objective" and quantitative measures of cultural distance, the perceptions of those distances may vary among team members and have an effect on cooperation of the team. Value scales serve as a proxy for expected value perceptions of multinational team members, but the perceptions of individual team members may deviate from the mean or median of the distribution of national values. 2) Stereotypes, which team members have about people from other nations, can exert a disturbing influence on team members' behavior.

'Practices' as identified by the GLOBE project are not a description of the prevailing norms of behavior which a team member would chose, as indicated in the definition of values of Kluckhohn (1951) where a clear distinction is made between values and the culturally influenced/determined norms of behavior (i.e. modes of action). In a multinational team it is of importance to be aware of culturally determined norms of behavior of team members.

Cultural value distances are often taken as an approximation for differences in norms of behavior. However, the GLOBE project itself does not take a step towards the detailed analysis of norms of behavior, which are relevant in the interactions of multinational team members. Value dimensions cannot directly predict the actual problems emerging in business and management encounters. Value scales may turn out to be of limited value to serve as a proxy for cultural standards (e.g. since values can be the same, but norms of behavior or institutional rules are different). They cannot explain how business encounters are perceived and how and why managers and staff react in a specific way. Guided by values these reactions are chosen by the individuals from the available repertoire of behaviors. Illchosen modes of behavior may produce undesired conflict and counterproductive results, if the valid norms of behavior of counterpart cultures are not adequately considered.

Another important feature in previous research is that in many studies norms of behavior are used to illustrate differences in observed or perceived behavior of people from other nations. Nevertheless, in the technical analyses only selected universal values are used as independent variables. While this sometimes works, it may not necessarily be a valid method. This can be illustrated with a non-business example: In all societies there is a general value that guides us not to kill other people. To prevent people from being killed, certain rules (norms of behavior) are set up how to drive a car. In many countries the norm is to drive on the right hand 
side of the road, but in numerous others it is to drive on the left hand side. Thus, the value is the same, norms are different!

All researchers on cultural value dimensions (Table 4) maintain that their system of value dimensions explain a large part of the observable variances across cultures (Hall \& Hall, 1990, 2000; Hofstede, 1980, 1993, 2001; House et al., 2001; House et al., 2002; Kluckhohn \& Strodtbeck, 1961; Rokeach, 1973; Schwartz, 1992; Trompenaars \& Hampden-Turner, 1997).

In studies of multicultural teams there has hardly ever been any discussion whether it is appropriate to combine value dimensions from different concepts.

There is a broad range of studies on universal values available (see Table 3), but in multicultural team studies most authors who use value dimensions as independent variables rely on only few dimensions from the studies of Hofstede, Kluckhohn and Triandis. Nevertheless, there are limits and open questions. So far, no meta-analysis has been undertaken to find out whether different dimensions from different concepts are substitutes or complements. The fundamental approach of Kluckhohn \& Strodtbeck (1961) provided the basic principles for all further research in the field of cross cultural research aiming at quantitative measures of cultural values (see Table 4).

Table 4: Cultural dimensions in mainstream literature

\begin{tabular}{|c|c|c|c|c|c|}
\hline GLOBE: (2002) & $\begin{array}{l}\text { Ilofistede } \\
(2001)\end{array}$ & $\begin{array}{l}\text { Ilall/IIall } \\
(2000)\end{array}$ & $\begin{array}{l}\text { Trompenaars } \\
(1993)\end{array}$ & $\begin{array}{l}\text { Schwart/ } \\
\text { (1992) }\end{array}$ & $\begin{array}{l}\text { Kluckhohı/ } \\
\text { Strodtbeck } \\
(1961)\end{array}$ \\
\hline $\begin{array}{l}\text { Performance } \\
\text { Orientation }\end{array}$ & $\begin{array}{l}\text { Long and } \\
\text { ShortTerm } \\
\text { Orientation } \\
\end{array}$ & & & & $\begin{array}{l}\text { Activity Orien- } \\
\text { tation }\end{array}$ \\
\hline $\begin{array}{l}\text { Future Orienta- } \\
\text { tion }\end{array}$ & & Time & Time & Tradition & $\begin{array}{l}\text { Time Orienta- } \\
\text { tion }\end{array}$ \\
\hline Assertiveness & $\begin{array}{l}\text { Masculinity } \\
\text { Femininity }\end{array}$ & & & & \\
\hline $\begin{array}{l}\text { Humane Orienta- } \\
\text { tion }\end{array}$ & & & & Benevolence & Human Nature \\
\hline \multicolumn{6}{|l|}{$\begin{array}{l}\text { Gender Egali- } \\
\text { tarianism }\end{array}$} \\
\hline Power Distance & $\begin{array}{l}\text { Power Dis- } \\
\text { tance }\end{array}$ & & $\begin{array}{l}\text { Status } \\
\text { Achievement } \\
\text { Status Ascrip- } \\
\text { tion } \\
\end{array}$ & $\begin{array}{l}\text { Power } \\
\text { Achievement }\end{array}$ & \\
\hline $\begin{array}{l}\text { Institutional } \\
\text { Collectivism } \\
\end{array}$ & $\begin{array}{l}\text { Individualism } \\
\text { Collectivism }\end{array}$ & & $\begin{array}{l}\text { Individualism } \\
\text { Collectivism } \\
\end{array}$ & Self-Direction & $\begin{array}{l}\text { Relational Ori- } \\
\text { entation }\end{array}$ \\
\hline $\begin{array}{l}\text { In-Group Collec- } \\
\text { tivism }\end{array}$ & & & $\begin{array}{l}\text { Universalism } \\
\text { Particularism }\end{array}$ & $\begin{array}{l}\text { Conformity } \\
\text { Universalism }\end{array}$ & \\
\hline $\begin{array}{l}\text { Uncertainty } \\
\text { Avoidance }\end{array}$ & $\begin{array}{l}\text { Uncertainty } \\
\text { Avoidance }\end{array}$ & & & Security & \\
\hline
\end{tabular}




\begin{tabular}{|c|c|c|c|c|c|}
\hline GL.OBE: (2002) & $\begin{array}{l}\text { Ilofstede } \\
(2001)\end{array}$ & $\begin{array}{l}\text { Ilall/Ilall } \\
(2000)\end{array}$ & $\begin{array}{l}\text { Trompenaars } \\
\text { (1993) }\end{array}$ & $\begin{array}{l}\text { Schwart/. } \\
\text { (1992) }\end{array}$ & $\begin{array}{l}\text { Kluckhohn/ } \\
\text { Strodtbeçk } \\
\text { (1961) }\end{array}$ \\
\hline & & $\begin{array}{l}\text { Information } \\
\text { Flow }\end{array}$ & & & \\
\hline & & $\begin{array}{l}\text { Low/ High } \\
\text { Context }\end{array}$ & & & \\
\hline & & Space & & & \\
\hline & & & $\begin{array}{l}\text { Emotional } \\
\text { Neutral }\end{array}$ & & \\
\hline & & & $\begin{array}{l}\text { Specific } \\
\text { Diffuse }\end{array}$ & & \\
\hline & & & $\begin{array}{l}\text { Man Nature } \\
\text { Relationship }\end{array}$ & & $\begin{array}{l}\text { Man Nature } \\
\text { Orientation }\end{array}$ \\
\hline & & & & Stimulation & \\
\hline & & & & Hedonism & \\
\hline & & & & Spirituality & \\
\hline
\end{tabular}

The questions are open, whether the different concepts could be transferred to other contexts or rather not, and whether replications of the methods in other contexts and over time would deliver the same, similar or different results. So far, no one considered e.g. that Schwartz's dimensions give general information about a society, but that they lack specific information based on experiences in the business environment, as the sample consists of teachers and students.

\subsubsection{Cultural standards and norms of behavior}

It is apparently difficult to emphasize the importance of universal values without referring to norms of behavior in specific national cultures. Since the notion 'norm of behavior' is too narrow to characterize the available repertoire of modes of behavior (see the definitions by Kluckhohn, 1951 and Schwartz, 1992), the term 'cultural standards' as it is widely used in the German and Austrian literature (Thomas, 1999, 2003, 2003a; Fink \& Meierewert, 2001) is introduced.

"By cultural standards we understand all kinds of perceiving, thinking, judging, and acting that in a given culture by the vast majority of individuals are considered for themselves and others as normal, self-evident, typical and obligatory. Cultural standards regulate behavior and guide individuals to assess observed behavior" (Thomas, 1993: 381, translation by the author). Cultural standards, in turn, are based on the values in a given culture, but also on traditional modes and rules of behavior that comply with these values.

While values influence creation and use of cultural standards, the latter influence the way how people act, react and interact. Thus, in many instances it is the unexpected encounter with different modes of behavior which is difficult to inter- 
pret, that could cause irritation or even conflict, because of misinterpretation, and could have a negative effect on multinational team performance.

The cultural standard method delivers a more differentiated picture of the impact of culture on observed, experienced and perceived behavior than the culture dimension studies. In about 50 publications/dissertations/master theses more than 50 cultural standards were found which caused cross-cultural encounters in management and business. For the sake of brevity these master theses and doctoral theses written in German, which were undertaken to collect data by 30 interviewers in narrative interviews with 750 Austrian managers during 1996-2003, were not reviewed.

For illustration, cultural standards that relate to four deliberately chosen value dimensions are selectively provided: power distance, collectivism, performance orientation, and time-related behavior. Power distance can find its expression among other things in: hierarchy, status orientation, respect of the achieved positions, formal distance, title emphasis, avoiding being criticized by a supervisor, avoiding deviating opinions from that of supervisor, and authority by knowledge. As different forms of collectivism we identified: national pride, elite thinking, familiarism, paternalism, clientelism, amigo business, reciprocity expectations, and professional-private versus relationship orientation. Performance orientation finds its expression in the following cultural standards: quest for efficiency, economic thinking, rule orientation, quality orientation, goal orientation, and learning orientation. Time behavior can lead to different norms as to timing of interactions (related to it is punctuality); time requirements (time needed to perform a task); time planning; permanent time pressure; more efficient use of time; time available should be used only for economically efficient purposes; accelerated pace of time; scarce and more valuable time; value of our time and their time; and qualitative dimensions of working time: combinations of duration, sequence and meaning of time; and feeling of singularity of time (Fink \& Meierewert, 2004; Hassard, 1996).

Knowledge about different cultural standards as they prevail in different cultures greatly enhances the available repertoires of modes of behavior from which individuals or teams may choose. In that sense awareness of different cultural standards and related modes of behavior may greatly enhance team effectiveness, as it also offers more problem solutions.

In articles identified in the review the constructs 'use of local norms' and 'norms of (intra) team communication' were used among other independent variables. Hofner Saphiere (1996: 227-259) studied 56 business people from 12 global business teams (9 nationalities: Canadian, Chinese, Czech, English, French, Indian, Japanese, Nicaraguan, U.S., who resided in 7 countries and worked for 11 companies within 3 U.S.-based corporations) to identify patterns of behavior which correlate with team productivity. Highly productive teams were strongly task oriented and showed a high degree of process awareness. Many of the highly produc- 
tive teams had developed an informal format for written correspondence within the team, opening and closing with a personal or relational message and dealing with the task issue in the 'meat' of the correspondence. This seems to indicate awareness of the importance of interpersonal trust and rapport to effective business functioning, and conscious attention to communication behavior. Salk \& Brannen (2000) found that reference to local norms of consensus and decision making had a positive effect on the influence of individual team members on team work.

Many other cultural standards that could have an influence on team performance, such as punctuality, meeting deadlines, negotiation styles, etc., were not considered in previous literature. In general, outside Germany and Austria cultural standards are an understudied field. Since the differences in values are not decisive per se, but rather the experienced and perceived differences in behavior, more intensive exploration in cultural standards would be worthwhile. In addition, since variations in cultural standards and norms of behavior need not necessarily be in conflict with underlying values, the procedures how to establish norms of behavior for work teams or to adapt existing norms of behavior to new needs in multinational work teams would deserve more thorough analysis. If together with the implementation of work teams appropriate norms of work team behavior would be established or if teams would apply norms that proved successful in previous experiences, team effectiveness could be better secured.

\subsubsection{Perceptions: Stereotypes and identities}

From a few studies, which were undertaken in a multicultural setting or simulated a multicultural setting, we can draw a few conclusions which also should apply to multinational teams: Measures taken by management will enhance team performance, if they increase social cohesion (Elron, 1997 and Hofner Saphiere, 1996) and identity salience (Randel, 2003), and make team members perceive differences as a valuable source (Ely \& Thomas, 2001, Richard et al., 2003).

In an experimental setting simulating different team compositions by gender and race with 392 female and 282 male white undergraduate students, Bakir et al. (2004) found a strong influence of perceptions on behavior of team members and team performance. To elaborate on this we try to transpose these findings to a multinational setting (Fink et al., 2004b). Therefore, we have to discuss perceptions as they emerge in multinational settings and influence multinational team performance.

In multinational teams, not the differences per se, but the perceptions of differences seemingly have a strong impact on actual behavior in a given context. For example, as a result of the GLOBE project, Germany (former East and former West), Austria, Switzerland and the Netherlands can be grouped into the Germanic cluster (Gupta et al. 2002). Within the Germanic cluster practices of assertiveness are largely in common for all countries. Thus, one could expect little con- 
flict to emerge because of similar levels of assertiveness. In contrast to these expectations, cross cultural interaction analysis between East and West Germany shows that East Germans often feel offended by the assertiveness of West Germans (Kölling, 2004). Austrians feel similarly offended (Brück, 1999). Seen from a distance, e.g. from Spain, the attribution of these countries to a Germanic cluster seems to be perfectly appropriate. Spanish business people can hardly distinguish Austrians from Germans and usually note their assertiveness (Dunkel, 2001). But relative closeness does not imply that difference would not matter when Austrians interact with highly assertive West Germans. If Austrians perceive Germans as extremely assertive, if not arrogant, then cooperation within a multinational team is seriously affected.

Perceptions are strongly influenced by stereotypes and people's own experience. In that sense 'nationality is not completely deterministic', since several factors might determine whether an individual is close to or far away from national tendencies: international experience of the individual; personal experiences, which may be dissimilar to those of others within the same nationality; or if the individual has been socialized by an organization's culture in ways that are different or similar to the individual's national culture (Hambrick et al., 1998: 183184). Social processes as team work and their outcomes are strongly influenced by the way of how individual team members a) define themselves in different situations and b) identify the situation (Garcia-Prieto et al., 2003: 417). This in turn depends on the identities (diversity categories) that team members hold. Earley \& Erez (1997: 16) introduce the term "self-knowledge" referring to the way people define and perceive themselves. The concept of self-knowledge includes the many roles one plays within his/her life (such as manager, partner, golf partner) and the specific characteristics that mark one's specific traits.

A stereotype is "a simplified and standardized conception or image invested with special meaning and held in common by members of a group" (Flexner \& Hauk, 1987: 1867). Stereotyping is a constitutional element of human culture. The desire and need of human beings to understand the world can be considered to be a major reason why human beings create culture. Culture serves to make knowledge explicit as it helps to structure thought. By the manipulation and reduction of complexity knowledge becomes more consistent, less variable and better distinguishable, which helps to combine new knowledge with previous experience and known structures of thought. Thus, human beings are strongly motivated to manipulate their knowledge, which helps them to widen applicable experience and to enhance the importance of that knowledge for themselves as individuals. Human beings react positively when they can widen their knowledge and feel unpleasantly surprised when they receive contradicting or conflicting information which may force them to reduce their available stock of knowledge (Dermath, 1993: 136, 2002: 208). Stereotyping is a means to manipulate knowledge and to reduce complexity. 
In addition to many other important factors (Holden, 2002), actionable knowledge of human beings is also dependent on capabilities of human beings to stereotype, i.e. to reduce complexity and to react quickly when required. Problems arise when stereotypes that guide actions are wrong and therefore misleading in a new situation. If stereotypes are right then human beings can react faster in a given situation (Adler, 1997: 75-76).

It is important to note that people coming from different social groups may carry different stereotypes of their own group and of the same groups of others. Since perceptions influence the perceived cultural differences and, consequently, attitudes and team members' behavior in communication and collaboration with the others, it is important to regulate these perceptions (stereotypes) with the implementation of multinational work teams.

\subsubsection{Personality traits}

Although people are socialized within a society that promotes levels of conformity in the ways of thinking and acting of people being a part of a society, the extent of this socialization process is influenced by the individuals themselves (Brannen et al., 2004: 46). The concept of personality traits helps to a certain degree to explain perceived differences in the general (cultural) values within a society. In the context of management, where the enhancement of performance is of major interest, the following definitions of personality traits are appropriate:

"Personality characteristics are [...] understood as dispositional motives utilized during goal attainment" (Buss, 1991). That is, "personality characteristics predispose humans to behave in certain ways, given particular situations, to accomplish goals and so forth." (Caligiuri, 2000: 71; see also Buss, 1989; Costa \& McCrae, 1992).

The most commonly known and studied personality traits are the so-called "Big Five" personality traits: extroversion, agreeableness, conscientiousness, neuroticism, and openness to experience (for a short description: e.g. Brannen et al., 2004: 46). In the context of multinational teams we are particularly interested in those personality traits explaining multinational effectiveness. Therefore, we would like to go beyond the concept of "Big Five" and offer additional personality dimensions influencing effectiveness (Table 5).

Table 5: Personality traits in cultural adjustment and expatriate success literature

\begin{tabular}{|l|l|}
\hline Personality Traits & Publications \\
\hline Agreeableness & Caligiuri (2000a); Schmit, Kihm, Robie (2000) \\
\hline Allocentrism & Chen et al. (2001) \\
\hline $\begin{array}{l}\text { Collectivism } \\
\text { (Cultural Dimension) }\end{array}$ & $\begin{array}{l}\text { Chen, Chen, Meindl (1998); Bochner (1994); } \\
\text { Bhawuk, Brislin (1992) }\end{array}$ \\
\hline
\end{tabular}

To be continued

Anne-Katrin Neyer - 978-3-631-75440-5 


\begin{tabular}{|l|l|}
\hline Personality Traits & Publications \\
\hline Contact & $\begin{array}{l}\text { Caligiuri (2000) } \\
\text { Baron, Gibbons, Mchmer, Kyhm, Robie (2000); } \\
\text { Higgins, Thoresen, Barrick (1999) }\end{array}$ \\
\hline Conscientiousness & $\begin{array}{l}\text { Oudenhoven, Van der Zee (2002); Harrison, } \\
\text { Chadwick, Scales (1996); Cui, Awa (1992) }\end{array}$ \\
\hline Cultural Empathy & $\begin{array}{l}\text { Caligiuri (2000a); Oudenhoven, Van der Zee (2002); } \\
\text { Oudenhoven, Van der Zee, Kooten (2001) }\end{array}$ \\
\hline Emotional Stability & Ruben, Kealey (1979); Cui, Awa (1992) \\
\hline Empathy & $\begin{array}{l}\text { Caligiuri (2000a); Schmit, Kihm, Robie (2000); } \\
\text { Oudenhoven, Van der Zee, Kooten (2001), Judge, } \\
\text { Higgins, Thoresen, Barrick (1999) }\end{array}$ \\
\hline Extroversion & $\begin{array}{l}\text { Oudenhoven, Van der Zee (2002); Oudenhoven, Van } \\
\text { der Zee, Kooten (2001); Harrison, Chadwick, Scales } \\
\text { (1996); Cui, Awa (1992); Arthur, Bennett (1995) }\end{array}$ \\
\hline Flexibility & Chen et al. (2001); \\
\hline Idiocentrism & $\begin{array}{l}\text { Chen, Chen, Meindl (1998); Bochner (1994); } \\
\text { Bhawuk, Brislin (1992) }\end{array}$ \\
\hline $\begin{array}{l}\text { Individualism } \\
\text { (Cultural Dimension) }\end{array}$ & $\begin{array}{l}\text { Oudenhoven, Van der Zee (2002); Oudenhoven, Van } \\
\text { der Zee, Kooten (2001) }\end{array}$ \\
\hline Open-Mindedness & $\begin{array}{l}\text { Caliguri (2000a); Caligiuri (2000); Oguri, } \\
\text { Gudykunst (2002); Caligiuri, Jacobs, Farr (2000); } \\
\text { Arthur, Bennett (1995) }\end{array}$ \\
\hline Openness & Harrison, Chadwick, Scales (1996); Cui, Awa (1992) \\
\hline Caligiuri (2000) \\
\hline Patience & Ruben, Kealey (1979) \\
\hline Sociability &
\end{tabular}

Source: Literature analysis

In 1978, Gudykunst et al. identified 24 personality traits of importance for 'intercultural effectiveness'. They proposed to group these into three dimensions: the ability to deal with psychological stress, the ability to effectively communicate, and the ability to establish interpersonal relationships. Cui \& Berg (1991) added 'cultural empathy', and Cui \& Awa (1992) further extended the model with the constructs 'managerial ability' and 'interpersonal skills'.

Arthur \& Bennett (1995) developed five dimensions which influence 'effectiveness/success of an international assignment'. In their research the constructs 'flexibility/adaptability' and 'extra-cultural openness' were used for the first time in addition to 'job knowledge and motivation', 'relational skills', and 'family situation'. Recently, Oudenhoven \& van der Zee (2002) suggested five dimensions (emotional stability, cultural empathy, flexibility, open mindedness and social initiative) to predict the multinational effectiveness of international students.

Altogether, a broad range of personality traits was identified in the context of research on 'cultural effectiveness', 'cultural adjustment', 'acculturation' and 'ex- 
patriate success', which after some adaptation may also prove helpful in research on multinational teams (Black et al. 1991; Caligiuri, 2000, 2000a; Gudykunst et al., 1978; Oguri et al., 2002; Parker \& McEvoy, 1993; Ward et al., 2001).

Among other things, some findings of this field and the related psychological research already served as an input to multinational team research: Neumann et al. (1999); Flynn et al. (2001); Beersma et al. (2003) use the 'Big Five' (extroversion, agreeableness, conscientiousness, emotional stability, intellect/openness); Watson et al. (1998) use 'team orientation vs. individual orientation'; Barsade et al. (2000) use 'trait positive effect', i.e. the degree to which a person is high in enthusiasm, energy, mental alertness, and determination; Kiffin-Petersen \& Cordery (2003) use trust and Tjosvold et al. (2003) use 'positive attitudes towards conflict', i.e. evaluations of the positive and negative utility of conflicts.

The statistical significance of some personality traits seems to be sensitive to other variables. For example, in a study by Beersma et al. (2003) viewed independently, 'agreeableness' and 'extroversion' had no direct positive effect on team performance. However, in combination with cooperative reward structures a positive influence of both variables on performance was found. Neumann et al. (1999: 28-45) investigated the effectiveness of different strategies for using personality tests (Big Five) to select members for work teams. Their research question was whether 'team personality elevation' (= the average level of a given trait within a team) and 'team personality diversity' (= the variability or differences in personality traits found within a team) predict performance of teams. They found that high levels of agreeableness, conscientiousness and openness to experience, but also 'team personality diversity' of extroversion and emotional stability were valid predictors of team performance. Therefore, according to their findings, the appropriate team selection strategy would be to select candidates who are highly agreeable and open to new experience, but differ with respect to extroversion and emotional stability.

\subsubsection{Control variables: Task, team size and learning processes}

Hackman (1987: 324) defines the task of a group as a "whole and meaningful piece of work, with a visible outcome". The task may determine performance pressure, since a goal has to be met. Rewards for achieving and sanctions for not achieving determine the influence of performance pressure on the behavior of team members and on possible outcomes. The nature of a task determines the needs for resources and skills. An optimal qualification mix (diversity) of team members by educational and cultural background, experience, physical requirements, etc. has to be identified. Consequently, work on the task shows how efficient the team selection and implementation process was and how well the team is performing (Hackman, 1987: 324-327). 
Team size has to be large enough to fulfill the task, meaning that sufficient resources (manpower, time), sufficient capabilities and knowledge must be available. In consensus driven teams it seems to be easier to reach consensus among a smaller than a larger group. Therefore, large multinational teams might not be as efficient as smaller teams (Hackman, 1987: 327). At least, this is a proposition also often raised in the context of the enlargement of the European Union. On the other hand, it can be assumed that the larger the team and the more culturally different the members in the team, are the more easily the occurrence of bilateral conflicts might be reduced.

Learning processes within teams help to overcome insufficiencies in the action repertoires of individuals and the organization itself (e.g. organizational culture, organizational structure) (Stern, 1997: 70). Experienced team members are possibly aware of some specific issues and can contribute to re-define rules and procedures (new team norms) to prevent a possible future re-appearance of problems (Stern, 1997). Thus, new knowledge might be created through the transformation of experience (Kolb, 1984). Reflection on team processes increases awareness of team members and fosters learning processes, which in turn (in analogy to Argyris \& Schön, 1974) could help to make things right, but also to make the right things.

The learning process of individual team members and the team itself is directly influenced by power and interests of the individual team members and the contextual organization(s). Conflicts of interest, the desire to gain or maintain power, or the wish not to subordinate oneself have an influence on team learning and consequently on team performance. Interests of individuals are influenced by the social system into which they are embedded (the contextual organization), by their personal needs, income, experience and stock of knowledge. Interests have an influence on the will to gain or to maintain a certain power status. That also can depend on past experiences in a specific social system: relatively speaking, West Germans have a stronger desire to 'make a career' and gain powerful positions than East Germans (Koelling, 2004). Openly discussed conflicts of interest can also contribute to success. In research on several decision making areas of top management teams of eight multinational corporations with at least five overseas subsidiaries, Elron (1997) identified a positive relation between team performance and issue-based conflicts about goal priorities of the subsidiary, functional policies, organizational structure and process, day-to-day decision making, needs of subsidiaries in contrast to headquarter demands.

In a comparative static analysis Watson et al. (1998: 425) highlighted the relevance of time for the learning process. They found that "individual orientation was negatively related to team performance, and team orientation was positively related to team performance across all time periods", for both, culturally nondiverse and culturally diverse groups. But, at time point 4 of measurement the diverse groups' individual orientation rose while the non-diverse groups contin- 
ued to decline. So, they hypothesize that "perhaps by time point 4 the diverse groups were able to maintain their high team orientation and allow individual orientation to a reasonable extent. That is, the diverse groups now were utilizing their cultural differences to their advantage" (Watson et al., 1998: 424).

\subsubsection{Integrative model to study multinational team performance}

To illustrate the integrative concept the interaction of three team members with different national background (values and norms of behavior), interests, perceptions, and personality traits is illustrated. The team interacts within the context of an organization and under the influence of team size, learning processes, and task. The integrative model clarifies the relations among the various variables that influence the performance of multinational teams. This model assumes that the establishment of multinational team norms helps to deal with the complexity of multinational teams. Managers aware of these dimensions and their relations are well equipped to secure team performance and benefit from the advantages of multinational teams (Figure 4).

\section{FIGURE 4: AN INTEGRATIVE DIVERSITY APPROACH TO STUDY MULTINATIONAL INTERACTIONS}
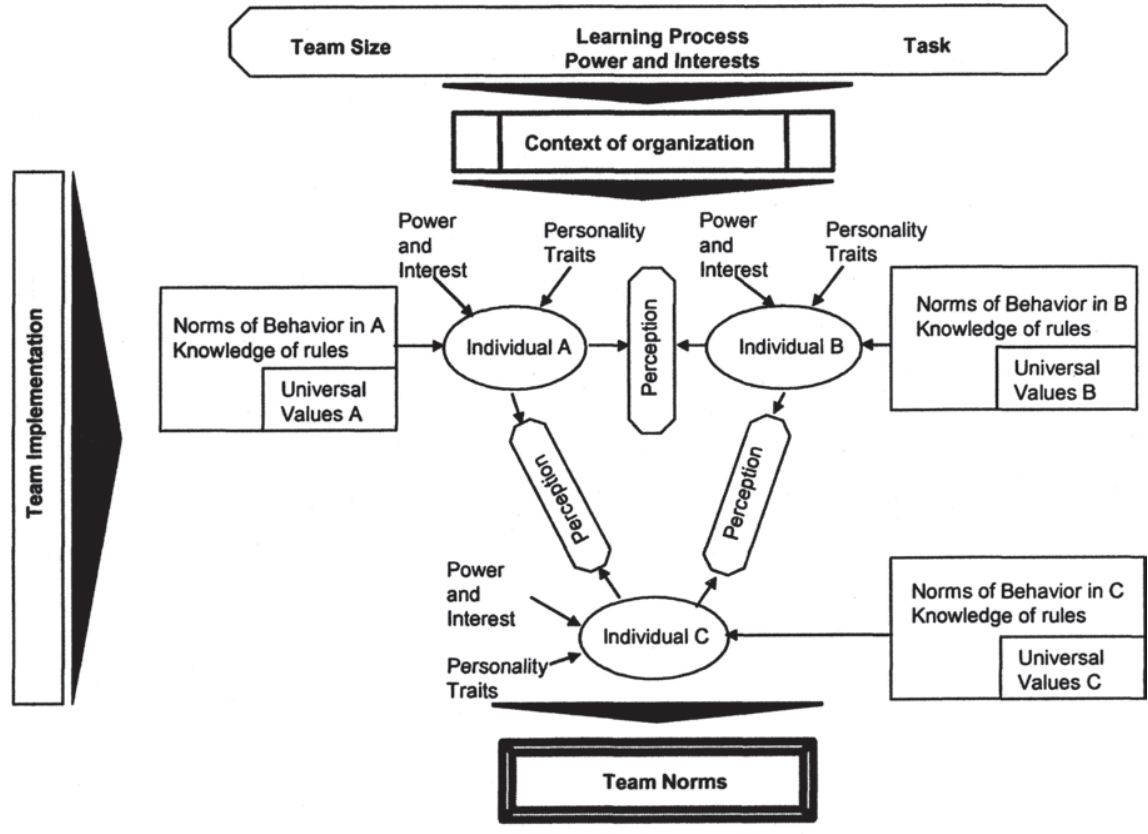
The complex relations of the categories identified in the literature lead to the following research aspects:

- Which categories influence the performance of multinational teams in the European Commission and the European Parliament?

- Are these categories related? If yes, how are they related?

- How do individuals cope with the complexity of working in multinational teams? 


\section{Method}

\subsection{Methodologies in empirical social research: A comparison for selecting the appropriate method to study multinational teams}

The analysis of relevant factors for the performance of multinational teams in the European Commission and the European Parliament was the setting for this study. The research method used (qualitative or quantitative) should help to reach the proposed research aim (Lamnek, 2000: 26).

Quantitative research methodology has a long tradition and is widely spread in empirical social research. In recent years these approaches have reached their limits and consequently an increase of the impact of qualitative research methods can be recognized (Bewley, 2002; Hermanowicz, 2002; Kölbl, 2001: 1). In research practice these methodological approaches are predominantly separately used. In the literature particular characteristics can be found which differentiate qualitative and quantitative methods (e.g. Bortz \& Döring, 2002; Brüsemeister, 2000; Flick et al., 2000; Lamnek, 2000). Sample size is one of these characteristics: In general, quantitative research is characterized by large sample size whereas in qualitative research sample size is limited to a smaller number (Brüsemeister, 2000: 21). In quantitative research existing theoretical propositions are tested with precise hypotheses (Bucher, 1994: 23). Quantitative techniques focus on measuring things that can be counted "using predetermined categories that can be treated as interval or ordinal data and subjected to statistical analysis" (Patton, 1997: 273).

Qualitative research, however, concentrates on the detection of theoretical propositions on the basis of the empirical data (Kölbl, 2001: 2). The intention of empirical-qualitative exploratory studies is to generate new hypotheses and theories (Bewley, 2002). The particular presentation and use of qualitative data help to identify causal relationship and phenomena in a specific field which has not been studied in detail until now (Bortz \& Döring, 2002: 386). Qualitative research aims to explain social reality by describing the complexity of the social setting under study from the people's experiences (Flick et al., 2000: 14) and "the meanings they place on the events, processes and structures of their normal social setting" (Skinner et al., 2000: 165). In contrast to quantitative research the subjective elements of the interviewed individual are the main research focus in qualitative research (Mruck \& Mey, 2000: 3). The main difference between these two methodological approaches can be explained with the terms "discovery" and "testing". Whereas a discovery can already be made with the help of one interview, the testing in the quantitative research needs significantly measurable quantities in order to verify or disprove the underling hypotheses (Brüsemeister, 2000: 22).

In order to define the appropriate type of research study for the abovedescribed research aspects an analysis of the differences and similarities in bothquantitative and qualitative - approaches was conducted. 
- Qualitative research gathers and analyzes „pure” qualitative data (with the exception of socio-demographic data).

- It is assumed that there are two different methodological approaches in quantitative research:

- Collection and analysis of "real" quantitative data, i.e. the analysis of measured statistical values/data (e.g. economic statistics).

- Collection and analysis of "quasi-quantitative" data: The term "quasiquantitative" was introduced as in the framework of a questionnaire a "qualitative" interpretation by the interviewed person is needed, which will be converted in a quasi-quantitative interpretation along a Likert-Scale. The data won't be measured, but the interviewed persons are asked to identify a (subjective) value for a particular question. This value is given by the developer of the questionnaire and is consequently biased by his/her subjective estimations or by his/her subjective interests. As an example a question concerning selfdescription can be given: "How do you describe yourself?" The values for the self-description of the interviewed person are predetermined by the developer of the questionnaire. They are a list of pre-defined values, which are mostly based on the subjective value-estimation ("Which values are important for me as the developer of the questionnaire?") of the developer of the questionnaire. In a next step these data are analyzed in the same manner as "measured" quantitative data, i.e. using statistical analysis tools.

The ignorance of the differences between quantitative and quasi-quantitative data and the possible bias inherent in the particular measurement can lead to a loss of information which might be of relevance for the particular research question. Table 6 compares quasi-quantitative data with qualitative data and shows their impact on data collection and analysis. It is refrained from considering quantitative data in the overview as they are not particularly important in the field of multinational team research. According to these findings, a clear separation between quasi-quantitative and qualitative research cannot easily be made. It becomes obvious that in order to find the "right" data collection method for the particular research question one has to be aware of the differences between the three possible interview methods: standardized interview, semi-standardized interview, and nonstandardized (open) interview. Other qualitative methods like observation are excluded from the analysis.

The impact on and the gathering of social situations in the interview depend on whether the interview concept is open i.e. less structured or if a structured questionnaire is used. The degree of structure is defined by the aim of research: The less structured the interview is the more qualitative-oriented it is. In contrast, the higher the degree of structure of the interview is, the more it allows for the collection of quantitative aspects (Atteslander, 2000: 156). 
Table 6: Social data and its impact on data collection and data analysis in the quasi- quantitative and the qualitative research

\begin{tabular}{|c|c|c|c|c|}
\hline 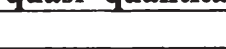 & \multicolumn{2}{|c|}{ Quasi-quantitative Research } & \multicolumn{2}{|c|}{ Qualitative Research } \\
\hline \multirow[t]{3}{*}{ Data } & \multicolumn{2}{|c|}{$\begin{array}{l}\text { Apparently measured quantita- } \\
\text { tive data }\end{array}$} & \multicolumn{2}{|c|}{ Observed qualitative data } \\
\hline & \multicolumn{4}{|c|}{ Openly asked for qualitative data } \\
\hline & \multicolumn{4}{|c|}{ Structured asked for quantitative/qualitative data } \\
\hline Questions & Closed & Open & Open & \begin{tabular}{|l|} 
Closed (to test \\
already collected \\
information, to col- \\
lect socio- \\
demographic data)
\end{tabular} \\
\hline \multirow[t]{2}{*}{ Data Collection } & $\begin{array}{l}\text { Standardized } \\
\text { Interview }\end{array}$ & & \multicolumn{2}{|c|}{ Non-standardized (open) interview } \\
\hline & \multicolumn{4}{|c|}{\begin{tabular}{|l|} 
Semi-standardized interview \\
\end{tabular}} \\
\hline $\begin{array}{l}\text { Data Interpre- } \\
\text { tation }\end{array}$ & $\begin{array}{l}\text { Quasi- } \\
\text { Quantitative }\end{array}$ & Qualitative & & $\begin{array}{l}\text { Quasi- } \\
\text { Quantitative }\end{array}$ \\
\hline
\end{tabular}

Source: The author

The standardized interview is characterized by a structured order of questions and the wording of questions is binding on the interviewer. The questions have to be defined precisely and have to be quickly answerable by the person interviewed. It is recommended to use this form of interview if there exists already knowledge about a clearly defined research topic like in the end phase of a study. A special form of the standardized interview is that including open questions. An open question is characterized by non-fixed response categories. Therefore, the person interviewed is able to define his/her answer on his/her own. The interviewer has to minute the statements of the interviewee in detail. In the course of the data analysis these statements are connected to determined categories (Atteslander, 2000: 158).

In the semi-standardized interview the interviewer uses a so-called interviewerguide. This guide is based on an in-depth analysis of the research issue. Thus, the interview is concentrated on a certain issue and the interviewed person is encouraged to have one's say preferably free, i.e. the interviewer should use a nondirective interview form. This kind of interview should also be used when there exists already knowledge about the issue under research (Mayring, 2002: 67; Bortz \& Döring, 2002: 315-317).

In contrast to the (semi)-standardized interview, the non-standardized interview is characterized by providing only a thematically framework for the interview. The interview form is open, i.e. the interviewer has to stimulate a conversation. This kind of interview is most notably used in explorative studies to get a first impression of information and opinions about a certain topic and about com- 
plex patterns of behaviours and motives. Selected types of non-standardized interviews are the problem-centred and the narrative interview as well as group discussions. In the narrative interview the interviewed person is encouraged to openly tell about his/her experiences (Mayring, 1999: 55). This enables the collection of subjective meanings of the interviewee. Consequently, new and pervasive cognitions about the research topic can be gathered, which might be limited in the framework of a systematic standardized questioning (based on predefined assumptions).

Based on this analysis, qualitative social research was identified as the appropriate method in this study. Therefore, the following method-decision tree is developed (Figure 5).

\section{Figure 5: Method-DeCision Tree}

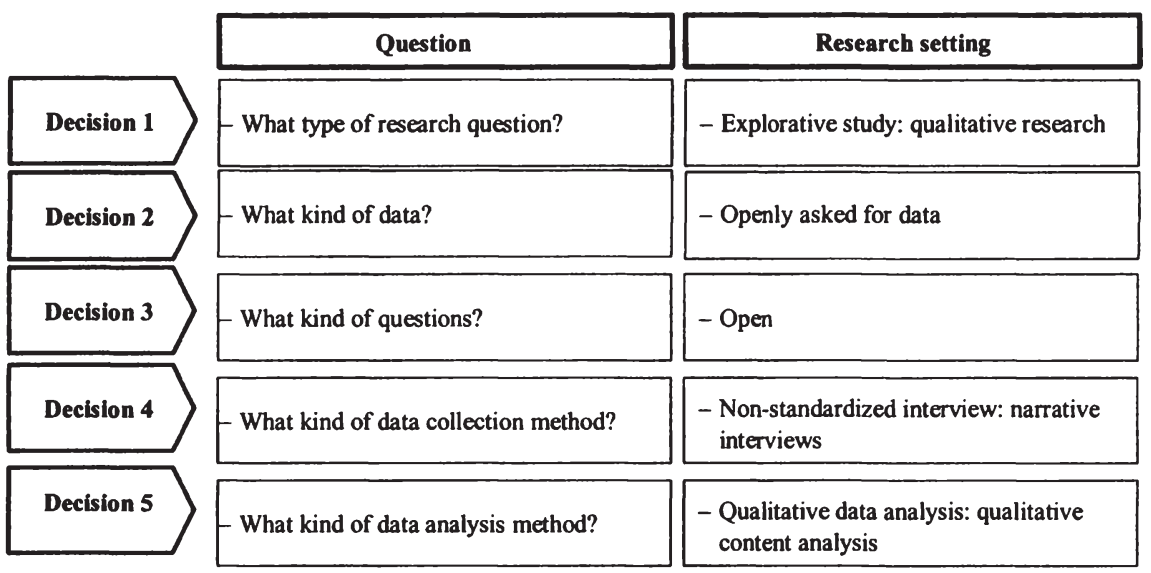

Source: The author

According to this decision tree, narrative interviews and in consequence qualitative content analysis will be used to gather and analyse the data.

\subsection{Techniques used to develop hypotheses}

The techniques used to develop hypotheses are based on the narrative interview and on the qualitative content analysis according to Mayring (2003).

\subsubsection{Narrative Interview}

The technique of narrative interviews allows to collect information/data without restricting data collection by presuppositions (prejudices, previous 
restrictive assumptions). It is a hermeneutic method to be applied whenever we have inadequately detailed information insufficient for theory building or when there are doubts about the assumptions made in already existing theories (Bewley, 2002). With narrative interviews we collect short stories about situations experienced in multinational team work. Short stories about real incidents permit us (the experts) to analyze the reported events and to convert collected experience of managers into knowledge. Otherwise we would collect only information about the reflections, prejudices and stereotypes of the interviewed persons (Fink, 2002).

\section{Procedure}

Mostly in convenience samples interview partners are identified with the help of a range of informed people like accessible managers, trade representatives, but also by directly approaching top and middle managers of international firms. To be a worthwhile interview partner the interviewee must a) have experienced something, b) still remember the incident, c) find it to be a worthwhile story, and d) be willing to tell the interviewer (Fink, 2002).

The interviewed person is willing to tell little stories, if she/he finds the interviewer likeable or if she/he can help the interviewer to solve a difficult task. Interviewed persons mostly find interviewers who belong to their own culture more likeable and trustworthy. Interviewed persons do not want to look bad or lose their face during the interview (Bewley, 2002). Van de Vijver \& Tanzer (1997: 268) raise the issue: "Construct bias can occur if there is only partial overlap in the definitions of the construct across cultures." If interviews are led by interviewers who are not from the same culture as the interviewed person, there is a higher risk that interviewer and interviewed person consider different factors as important, because of different cultural standards. They both would attribute different meanings and interpretations to the events/behaviour described by the interviewed person. When Alexander Thomas tried to undertake narrative interviews in China with Chinese managers he encountered numerous problems due to the differences between direct and indirect communication styles and between fact and harmony orientation (Thomas, 1996). These forms of construct bias mostly can be avoided when interviewers and interviewed persons belong to the same culture.

The interviewer bias is quite often linked with interviews in foreign languages and can have a strong impact on trust building, the current flow of the interview and on the content of the interview (e.g. number of critical incidents told, stereotypes, generalisations). Age, gender, personality, appearance, and expectations of interviewers and interviewed persons can easily lead to unnoticed problems during the interview. Not only the interviewer himself/herself, his/her behaviour and his/her relationship with the interviewee, but also the context of the interview could influence research results. Some people become embarrassed when openly asked about critical incidents, e.g. when male interviewers interview females, or females interview males, when interviews do not take place in a purely bilateral 
setting, but a secretary or the wife/husband of the interviewed manager is listening, etc.

To deal with interviewer bias and construct bias it is strongly recommended that interviews are undertaken by members from the same culture as the interviewed persons. We recently tested this effect. An Austrian student who interviewed American managers could not collect critical incidents. He was only told generalizations and various repetitions of auto- and hetero-stereotypes (Fink et al., 2004a: 12).

Originally Alexander Thomas followed the recommendations by Witzel (1982) and Lamnek (1995) to confront the interview partners only at the beginning of the interview with the aim of the interviews (Thomas, 1993, 1996). After jointly discussing our experiences we decided to modify the original approach (Fink et al., 2004a: 12). Since interviewees should tell short stories about incidents they need time to mobilize their memory (Hermanowicz, 2002). Therefore, information about the research topic should be given in advance. When establishing the first contact we inform the persons to be interviewed that we want to collect short stories about encounters/ situations experienced within the multinational team (Fink et al., 2004a: 12). During the interview, after an opening remark the interviewed persons are asked to tell significant or remarkable task-related critical incidents. We again explain what critical incidents are. After the interviewed person has told a little story, he/she is asked in a first feedback-loop: "How do you explain that?", next: "How did you cope with that problem?", and finally: "What was your reaction? Did you adjust your behaviour later on?" (Fink \& Meierewert, 2001). These questions are posed in order to collect information about value perceptions, stereotypes and learning behaviour of the interviewed person (Latein, 1996: 13; Ward et al., 2001). The collected information about the personal assessment of critical incidents, of stereotypes, value judgments, and coping strategies should help at this and later stages to deal with possible bias in data collection and interpretation of the data.

After each interview the interviewer has to reflect on her/his experience: What went well, what went wrong, and how to improve the interview technique? The interviewers are also asked to participate in interview trainings and group discussions at regular intervals.

\subsubsection{Transcription and Content Analysis}

To move towards identifying relevant categories determining multinational team work it is necessary to undertake a qualitative content analysis of the interviews (Mayring, 2000a, b). All narrative interviews must be taped. A transcript of all narrative interviews has to be produced. The results of the transcription of the interviews are so-called "primary documents" which have to be analyzed and coded. Kuckartz (1999: 25) defines the coding of the data as the selection of relevant text passages and the assignment of significant codes. The interpretative ap- 
proach to data analysis is supported by Atlas.ti@, a computer assisted qualitative data analysis software package. This software package aids users in handling non-numerical and unstructured qualitative data. However, it does not substitute the "human interpretation-work" (Kuckartz, 1999: 75).

\section{Procedure}

The transcripts are analyzed with structured qualitative content analysis developed by Mayring $(1999,2000 \mathrm{a}, 2000 \mathrm{~b})$ to identify social reality by deducing from characteristics of a transcript (an existing text) to characteristics of a non coded context (Merten, 1983: 16). Content analysis according to Mayring is based on 3 steps: summarizing, explication, structuring (Lamnek, 1995: 208). By selection, bundling, omission, integration and generalization the text will be reduced to the important content (summarizing). Additional material (e.g. relevant literature) is used to get an understanding for those parts of the text which are not easily interpreted because of the chosen wording, terminology or incomplete formulation of sentences (explication). In a last step it has to be defined what characteristics a piece of text or a phrase has to meet in order to be of use for a specific category. Categories are characteristics of the text which were developed by the researcher during reading and rereading the interview protocols and the transcripts (structuring) (Lamnek, 1995: 208). The development of categories is at the centre of qualitative content analysis as huge data material can be reduced to the most relevant contents (Mayring, 2000b: 74). Besides explication, analysis and interpretation of text passages, the qualitative content analysis aims at identifying similar parts of analysis in diverse text passages. There are two different ways of developing a manageable amount of categories: inductive category development and deductive category application. With inductive category development it is "of central interest to develop the aspects of interpretation, the categories, as near as possible to the material and to formulate them in terms of the material. ... Deductive category application works with prior formulated, theoretically derived aspects of analysis, bringing them in connection with the text" (Mayring, 2000a: 3-4). In research practice a mix of those two approaches seems to be appropriate as also qualitative researchers have mostly vaguely defined hypothesis about the research topic and knowledge of research findings in the particular literature. Therefore, it was decided to use an approach somewhere between the inductive and deductive approaches (Figure 6).

According to this scheme, thematic main categories (derived from research aspects and theoretical background) are created which are described by subcategories. If a text passage is assigned to a category, it has to be tested - in comparative analysis loops - if the next text passage can also be assigned to this category or if a new category has to be developed. If a code-word is represented by a text passage in particular, then this text passage is used as a "significant code" for the ongoing analysis. 


\section{FIGURE 6: RESEARCH APPROACH SOMEWHERE BETWEEN THE INDUCTIVE AND DEDUCTIVE APPROACHES}

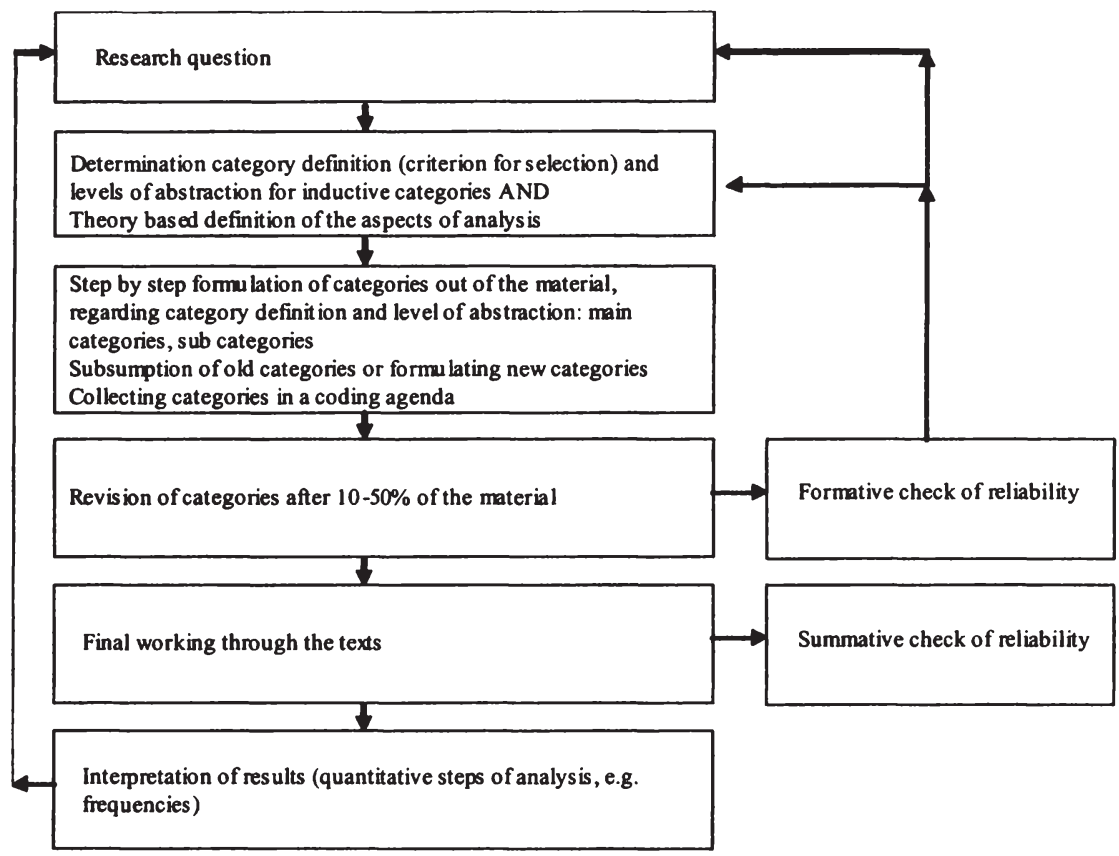

Source: amended from Mayring (2000a: Paragraph 11, 14); Mayring (2003: 75)

Together with the identified relevant codes those variables of each interview that may have had an impact on the interview like context, age, gender, experience of the interviewed person, etc. should be coded (Kuckartz, 1999: 157).

Remarks which were made at earlier stages of the interview have to be compared with remarks reported at later stages of the interview (Boeije, 2002). After checking individual interviews for consistency, the researcher starts with the interpretation of results to finally achieve a summary presentation of typical cases ordered by categories (Lamnek, 1995: 208). Further comparative steps are recommended. 1) Pair-wise comparisons: compare the first interview with the second; the second with the third interview etc. 2) Compare short series of interviews: Do the results of the first 6 interviews differ from the results of the second 6 interviews, etc.? Why do these results differ? What conclusion can be drawn from the sub series in comparison with the whole interview series? 
A summary analysis of the first 4-6 interviews was found to be helpful to improve interview techniques. After that interviews usually become more effective. One may consider the first few interviews as biased by the interviewer. Usually after 12 interviews an experienced interviewer will have a record that covers all important types of incidents. However, only after 25 interviews one will be able to identify the most important types of incidents. It is helpful to establish a rank order by how many respondents mentioned a similar type of incident (Fink, 2002). The result of the content analysis is grouped by different preliminary categories that should be sufficiently homogenous and distinct from other categories.

The main problem at this stage of the analysis is the so-called cultural interpretation bias. The culture, experiences, prejudices and stereotypes of the analyzing researcher can have an impact on content analysis.

\subsection{How to assess reliability and validity}

Quantitative research is characterized by providing accepted criteria defining whether or not a particular measurement may be regarded as objective, reliable, and valid (Mruck \& Mey, 2000: Paragraph 29). In contrast, qualitative research has to define its own quality factors as those of quantitative research are not implicitly target-oriented for measurement in the qualitative field of social research (Mayring, 1996: 115):

Usually qualitative researchers regard the research evaluation criterion "objectivity" as inadequate. In qualitative research subjectivity should not be eliminated as an interference variable, but has to be used for communicative and understanding processes (Mruck \& Mey, 2000: Paragraph 30). Bernart \& Krapp (1998: 33) underline that the aim of the narrative interview is not the identification of the objectively detectable truth but the explication and reconstruction of the subjective perception of the interviewed person.

Demands towards reliability, i.e. the accuracy and precision in the process of measurement (Mayring, 1999: 116), are also rejected by few researchers (Mruck \& Mey, 2000: Paragraph 31). In contrast to quantitative methods a re-test of qualititative findings is difficult, as social reality is not constant but ever evolving. Mayring (1993: 107) states that "people (also test persons) are continually developing and situational conditions are changing, parallel to social change". Especially in the case of narrative interviews the interviewed person might reconsider and adjust her behaviour in a particular situation. Consequently, they might tell other stories when they are re-questioned about their experiences.

As in quantitative research, the validity of a measurement is the most important quality factor in qualitative research (Bortz \& Döring, 2002: 327). Mayring (2002: 144-148) identified 6 general quality factors in qualitative research: 
- Documentation of the method: making the pre-assumptions, the decision for a particular qualitative analysis tool and the collection and analysis of data as comprehensible and transparent as possible.

- Argumentative coverage of the interpretation: the interpretation has to be coherent -if there are argumentative breaks they have to be explained.

- Observation of method rules: it is important to be aware of every single analysis step in the analysis model (see figure) in order to gain highly qualitative "qualitative data".

- Closeness to the subject: as qualitative research focuses on the analysis of concrete social problems the researcher has to be close to the every day life of the participant persons to collect the data.

- Triangulation: triangulation is concerned with diverse solution strategies for a given problem. However, the aim is not to achieve exactly the same results with the diverse method approaches but to compare the diverse perspectives and to make a kind of SWOT analysis of the diverse approaches.

- Communicative validity: in order to ensure the validity of interpretations and generalizations the consent development and intersubjective agreements are very important (Mruck \& Mey, 2000: Paragraph 32). The so-called "communicative validity, i.e. the discussion and interpretation of the results with/by the research participants) is one possibility to ensure validity in the qualitative research process. This validation tool is already used during the narrative interview where the participants are asked how they explain a particular situation (feedback loops within the interview). Their responses are included as a part of the analysis process (Mruck \& Mey, 2000: Paragraph: 32).

With the exception of triangulation the present study considers the quality factors mentioned by Mayring (2002) and consequently ensures validity of the measurement tool.

\subsection{Sample}

\subsubsection{Sample in the European Commission}

In February 2004, 25 narrative interviews with Austrian employees in the European Commission were conducted in Brussels. Appendix A describes the European Commission's aim and tasks. In table 7 sex, age, number of years in the European Commission, foreign languages, educational background and position of each interview partner are presented. If there is an "X" the interviewed person was not willing to reveal this sensible information in order to guarantee anonymity.

To allow to identify the corresponding demographic questionnaire and interview pairs and yet to ensure anonymity, interviews were tagged with pseudo ran- 
dom numbers generated using the rand function of PERL, version 5.6.1 using a time dependent random seed.

Table 8 presents the number of interviews in various directorates-general. In the European Commission there are four separate grades: A-, B-, C- and Dgrades. The so called A-officials are employees with a university degree. The Agrade is the policy-making and policy management grade. It is divided into eight points. The responsibilities in each point are as follows: Al - director general or equivalent; A2 - deputy director general, director or principal adviser; A3-head of unit; A4-A5 -principal administrator, or in some cases head of unit; A6-A8 - assistant administrator (Nugent, 2001: 169).

The interviews were undertaken with Austrians in A-positions as multinational team work especially takes place at this level. The outcomes of this study cannot claim to yield an overall model of multinational team performance. However, data provided by the interview partners were comprehensive and tight enough to end interviewing after 25 interviews. Additionally, it has to be underlined that in January 2004, 178 Austrian permanent employees were in A-level positions (see Bulletin Statistique: Le Personnel de la Commission, January 2004: 20). Consequently, $14 \%$ of the population could be interviewed.

Table 7: Demographic and statistical information of the interview partners in the European Commission

\begin{tabular}{|c|c|c|c|c|c|c|}
\hline Interview & Sex & Age & $\begin{array}{l}\text { Years } \\
\text { in the EC }\end{array}$ & $\begin{array}{l}\text { Foreign } \\
\text { Languages }\end{array}$ & $\begin{array}{l}\text { Educational } \\
\text { Background } \\
\text { (Master/ } \\
\text { Doctorate) }\end{array}$ & Position \\
\hline EK 461 & Male & 36 & 9 & French, English & Business & $\mathrm{X}$ \\
\hline EK_543 & Male & 53 & 8 & English & Physics & $\begin{array}{l}\text { Head of } \\
\text { department }\end{array}$ \\
\hline EK_191 & Female & 43 & 7 & English, French & Business & $\begin{array}{l}\text { Head of } \\
\text { department }\end{array}$ \\
\hline EK_751 & Male & 52 & 4 & English, French & Engineer & $\begin{array}{l}\text { Head of } \\
\text { department }\end{array}$ \\
\hline EK_43 & Male & $\mathrm{X}$ & 8 & $\begin{array}{l}\text { English, French, } \\
\text { Italian }\end{array}$ & $\mathrm{X}$ & Coordination \\
\hline EK_156 & Male & 41 & 5 & English, French & $\begin{array}{l}\text { Degree in } \\
\text { Law }\end{array}$ & $\mathrm{X}$ \\
\hline EK 586 & Male & 35 & 7 & English, French & $\mathrm{X}$ & Coordination \\
\hline EK_312 & Male & 41 & 13 & $\begin{array}{l}\text { English, French, } \\
\text { Spanish }\end{array}$ & $\mathrm{X}$ & $\begin{array}{l}\text { Head of } \\
\text { Department }\end{array}$ \\
\hline EK_579 & Male & 40 & 8 & $\begin{array}{l}\text { English, French, } \\
\text { Spanish }\end{array}$ & $\mathrm{X}$ & Officer \\
\hline EK_910 & Male & 57 & 8 & $\begin{array}{l}\text { English, French, } \\
\text { Russian, Dutch, } \\
\text { Italian }\end{array}$ & $\mathrm{X}$ & $\mathrm{X}$ \\
\hline EK_716 & Male & 51 & 6 & English, French & Business & $\begin{array}{l}\text { Head of } \\
\text { Department }\end{array}$ \\
\hline EK_489 & Male & 50 & 7 & $\begin{array}{l}\text { English, French, } \\
\text { Dutch, Italian }\end{array}$ & $\begin{array}{l}\text { Degree in } \\
\text { Law }\end{array}$ & $\begin{array}{l}\text { Hauptverwaltungs- } \\
\text { rat }\end{array}$ \\
\hline
\end{tabular}




\begin{tabular}{|c|c|c|c|c|c|c|}
\hline Interview & Sex & $\operatorname{lge}$ & $\begin{array}{l}\text { Years } \\
\text { in the EC }\end{array}$ & $\begin{array}{l}\text { Foreign } \\
\text { Languages }\end{array}$ & $\begin{array}{l}\text { Educational } \\
\text { Background } \\
\text { (Naster/ } \\
\text { Doctorate) }\end{array}$ & Position \\
\hline EK 424 & Male & 41 & 6 & English, French & Engineer & Coordination \\
\hline EK_693 & Female & 38 & 6 & $\begin{array}{l}\text { English, French, } \\
\text { Spanish }\end{array}$ & $\mathrm{X}$ & $\begin{array}{l}\text { Member of } \\
\text { Cabinet }\end{array}$ \\
\hline EK_357 & Female & 41 & 10 & English, French & $\begin{array}{l}\text { Degree in } \\
\text { Law }\end{array}$ & Desk officer \\
\hline EK_261 & Female & 43 & 7 & English, French & $\begin{array}{l}\text { Degree in } \\
\text { Law }\end{array}$ & Judge \\
\hline EK_654 & Male & 37 & 1 & English, French & $\mathrm{X}$ & $\begin{array}{l}\text { Head of } \\
\text { Information and } \\
\text { Communication }\end{array}$ \\
\hline EK_899 & Male & 42 & 10 & English, French & $\begin{array}{l}\text { Degree in } \\
\text { Law }\end{array}$ & $\begin{array}{l}\text { Hauptverwaltungs- } \\
\text { rat }\end{array}$ \\
\hline EK_955 & \begin{tabular}{|l|} 
Female \\
\end{tabular} & $\mathrm{X}$ & $\mathrm{X}$ & $\mathrm{X}$ & $\mathrm{X}$ & $\mathrm{X}$ \\
\hline EK 857 & \begin{tabular}{|l|} 
Female \\
\end{tabular} & 38 & 8 & English, French & $\mathrm{X}$ & $\mathrm{X}$ \\
\hline EK_699 & \begin{tabular}{|l|} 
Female \\
\end{tabular} & 48 & 8 & English, French & $\mathrm{X}$ & Senior official \\
\hline EK_493 & Male & 44 & 9 & English, French & $\mathrm{X}$ & $\begin{array}{l}\text { Head of } \\
\text { Department }\end{array}$ \\
\hline EK_44 & Male & & 8 & $\begin{array}{l}\text { English, French, } \\
\text { Dutch, Italian }\end{array}$ & $\begin{array}{l}\text { Political } \\
\text { Science } \\
\end{array}$ & $\mathrm{X}$ \\
\hline
\end{tabular}

Table 8: Overview of interviews in diverse directorates-general

\begin{tabular}{l|l|l|l|}
\hline Directorate - General & $\begin{array}{l}\text { Number of } \\
\text { Interviews }\end{array}$ \\
\hline ELARG (Enlargement) & 1 & $\begin{array}{l}\text { TAXUD (Tax and Customs } \\
\text { Union) }\end{array}$ & 1 \\
\hline AGRI (Agriculture) & 3 & BUDG (Budget) & 1 \\
\hline ENV (Environment) & 4 & RTD (Research) & 1 \\
\hline EAC (Education and Culture) & 2 & RELEX (External Relations) & 1 \\
\hline INFSO (Information Society) & 1 & Counsellor & 1 \\
\hline ENTR (Enterprise) & 4 & Member of Cabinet & 2 \\
\hline MARKT (Internal Market) & 1 & $\begin{array}{l}\text { ADMIN (Personnel and } \\
\text { administration) }\end{array}$ & 1 \\
\hline TREN (Transport and Energy) & 1 & Total & 25 \\
\hline
\end{tabular}

\subsubsection{Sample in the European Parliament}

In February 2004, 15 interviews (including interviews with 8 members and 7 employees of the European Parliament) with Austrians working at the European Parliament were conducted (Table 9). Appendix B describes the European Parliament's aim and tasks. In February 2004, (when the interviews were conducted) 21 Austrians were European parliamentarians. Consequently, 38\% of the population of Austrian members of the European Parliament could be interviewed, supplemented by 7 interviews with Austrians working for the members of the European Parliament.

In order to guarantee anonymity the political party of the interviewed persons is not listed. 
Table 9: Demographic and statistical information of the interview partners in the European Parliament

\begin{tabular}{|l|l|l|l|l|l|l|}
\hline Interview Sex & \multicolumn{7}{|c|}{$\begin{array}{l}\text { Iears in } \\
\text { the EP }\end{array}$ Loreign } \\
Languiges & $\begin{array}{l}\text { Educational } \\
\text { Background }\end{array}$ & Position \\
\hline EP_819 & Female & 43 & 8 & French, English & University Degree & $\begin{array}{l}\text { MEP (Member of } \\
\text { European Parliament) }\end{array}$ \\
\hline EP_122 & Male & 25 & 2 & $\begin{array}{l}\text { English, } \\
\text { French, Italian }\end{array}$ & X & Secretary \\
\hline EP_817 & Male & 52 & 7 & English & $\begin{array}{l}\text { Doctoral Degree in } \\
\text { Philosophy }\end{array}$ & MEP \\
\hline EP_708 & Male & 59 & 10 & $\begin{array}{l}\text { English, } \\
\text { French, } \\
\text { Spanish }\end{array}$ & Doctoral Degree & MEP \\
\hline EP_404 & Female & 57 & 9 & English & Vocational School & MEP \\
\hline EP_188 & Male & 56 & 8 & English & University Degree & MEP \\
\hline EP_416 & Male & 31 & 3 & English, French & Doctoral Degree & Research Assistant \\
\hline EP_745 & Female & 23 & 2 & English, French & Degree in Law & Assistant \\
\hline EP_129 & Male & 57 & 8 & $\begin{array}{l}\text { English, French } \\
\text { Doctoral Degree in } \\
\text { Law }\end{array}$ & MEP \\
\hline EP_430 & Male & 48 & 9 & English & University Degree & MEP \\
\hline EP_384 & Female & 27 & 1,5 & $\begin{array}{l}\text { English, } \\
\text { Spanish, } \\
\text { French }\end{array}$ & $\begin{array}{l}\text { College of Higher } \\
\text { Education }\end{array}$ & Political Assistant \\
\hline EP_847 & Female & 56 & 5 & English, French & University Degree & MEP \\
\hline EP_287 & Male & 28 & 6 months & English, French & Doctoral Degree & Assistant \\
\hline EP 967 & Female & 27 & 6 months & English, French & Degree in Law & Assistant \\
\hline & & & & & & \\
\hline
\end{tabular}




\section{Empirical Findings in the European Commission}

Based on the qualitative content analysis according to Mayring (2003), several categories were identified as factors influencing teamwork in the European Commission. This general analysis implies the following:

- Successful multinational teamwork consists of five categories: society, organization, individual, team and moderators.

- Relevant relations exist between these categories.

- Each category consists of sub-categories which are described by codes and sub-codes.

- The interrelations of the several codes in each sub-category have to be considered in the analysis.

- A combined analysis of the categories is crucial for understanding of what really matters in the multinational team work.

In the following, the empirical results of the study of multinational teams in the European Commission will be presented. Data analysis and interpretation are based on the findings of the literature analysis and interview transcripts reflecting the behavior and experiences of the interview partners. Analyzing some 200 pages of interview protocol (textual data), makes presenting all quotations in detail impossible. Consequently, those quotations are chosen which represent typical as well as particular arguments and are translated into English by the author. The empirical analysis is organized as follows:

- Description of the category

- Detailed analysis of codes

Table 10 shows the five categories of influence on team performance in the European Commission, focusing on the relevant sub-categories and its codes with sub-codes.

After the empirical analysis, this chapter is concluded by a summary and propositions derived from the empirical data.

For the presentation of the categories I start with macro-level influences on team performance (society and organization), next I analyze the micro-level (individual and team) and conclude the empirical analysis with a presentation of the relevant moderators. 
Table 10: Five categories of influence on multinational team performance in the European Commission

\begin{tabular}{|c|c|c|c|}
\hline Category & Sub-category & $\begin{array}{l}\text { Defined as } \\
\text { (Codes) }\end{array}$ & $\begin{array}{l}\text { Defined as } \\
\text { (Sub-Codes) }\end{array}$ \\
\hline \multirow[t]{3}{*}{ Society } & \multirow[t]{2}{*}{ Culture } & $\begin{array}{l}\text { General cultural } \\
\text { differences versus } \\
\text { personality }\end{array}$ & \\
\hline & & $\begin{array}{l}\text { Cultural differences in } \\
\text { norms of behavior: } \\
\text { North versus South }\end{array}$ & $\begin{array}{l}\text { Style of criticizing } \\
\text { Goal- versus process- } \\
\text { orientation }\end{array}$ \\
\hline & $\begin{array}{l}\text { Language } \\
\text { Proficiency }\end{array}$ & & \\
\hline \multirow[t]{5}{*}{ Organization } & \multirow[t]{2}{*}{$\begin{array}{l}\text { Organizational } \\
\text { Culture }\end{array}$} & $\begin{array}{l}\text { Perceived } \\
\text { organizational culture }\end{array}$ & $\begin{array}{l}\text { "Being a human machine in } \\
\text { the system" (main } \\
\text { organization) } \\
\text { Culture of tolerance (team) }\end{array}$ \\
\hline & & $\begin{array}{l}\text { Explicitly defined } \\
\text { organizational culture }\end{array}$ & Eurospeak \\
\hline & \multirow[t]{3}{*}{$\begin{array}{l}\text { Organizational } \\
\text { Structure }\end{array}$} & Hierarchy & $\begin{array}{l}\text { French- versus Anglo- } \\
\text { Saxon system }\end{array}$ \\
\hline & & Performance appraisal & \\
\hline & & Mobility - job rotation & \\
\hline \multirow[t]{5}{*}{ Individual } & \multirow{4}{*}{$\begin{array}{l}\text { Individual } \\
\text { Team Member }\end{array}$} & Personality traits & \\
\hline & & Personal experiences & \\
\hline & & $\begin{array}{l}\text { Personal } \\
\text { interests/motivation }\end{array}$ & \\
\hline & & $\begin{array}{l}\text { Educational } \\
\text { background }\end{array}$ & \\
\hline & Team Leader & $\begin{array}{l}\text { Leadership-style and } \\
\text { power }\end{array}$ & \\
\hline \multirow[t]{3}{*}{ Team } & \multirow[t]{3}{*}{ Team Norms } & Informal rules & \\
\hline & & $\begin{array}{l}\text { Facilitation of } \\
\text { communication }\end{array}$ & \\
\hline & & Mutual considerateness & \\
\hline \multirow[t]{3}{*}{ Moderators } & \multirow{3}{*}{$\begin{array}{l}\text { Moderating } \\
\text { Variables }\end{array}$} & Task & Responsibility assignment \\
\hline & & Team size & Number of cultures in team \\
\hline & & Learning process & \\
\hline
\end{tabular}

Source: Analysis of interviews 


\subsection{Society}

\section{Major findings}

The influence of cultural value dimensions on multinational team performance is superimposed by personality traits of the individual team members. The personal characteristics are more important in the multinational team interactions than the measured cultural characteristics within a society.

Two major cultural differences in norms of behaviour can be identified: different styles of criticizing and different approaches to work (goal- versus process orientation).

The different styles of criticizing (direct, diplomatic, indirect criticism, or more specific: allusive, oblique) have consequences for successful multinational team interactions: The same message should be presented in different ways depending on the cultural background of the other team members, who receive the same message.

Consequently, to perform efficiently, teams have to be made aware of the different styles of criticizing they use and have to develop a common style that suits all members in a multinational team.

$40 \%$ of the interviewed persons pointed out that they recognize cultural differences in working styles. The north-countries (e.g. Germany, Finland, Sweden, Denmark) including Austria are seen as being more goal-orientated and therefore prefer to come straight to the point e.g. in presentations or during the preparation of a paper. In contrast, south-countries (e.g. France, Spain, and Portugal) are more process-orientated. They prefer extended explanations in e.g. presentations and rely on personal relationship in the communication.

A mediator of this code is "time pressure". If there is enough time to fulfil a task then the different working approaches might not significantly influence the teamwork. However, if the team is under time pressure, the different approaches might lead to dissatisfaction of team members.

With EU enlargement 2004 there are now 20 official languages in the European Union. However, in the European Commission the daily working languages are more or less limited to English and French. The inherent problem is that nonnative speakers might feel under pressure and feel themselves more vulnerable than it is the case when working in their mother language.

Most of the culture description/cultural dimension literature (GLOBE, Hall \& Hall, Hofstede, Kluckhohn \& Strodtbeck, Schwartz, Trompenaars) is implicitly based on sociological and anthropological backgrounds. Based on Parsons' model of the interdependence of the social, personality, and cultural systems, the underlying assumption is that personality traits and values characterize individuals and somehow relate to their behaviour (Parsons \& Shils, 1962: $47-234$ ). The values shared within a group allow the group to distinguish itself from other groups (dif- 
ferent cultures). Therefore, there are at least two reasons why culture is of relevance to understand the performance of multinational teams: (i) given little or no other information about an individual's values and behaviour, culture provides a good first impression of that person, (ii) cultural assumptions and values describe the nature of relationships between people and their environment and among people themselves (Maznevski \& Peterson, 1997: 66). In multinational team literature, studies using the cultural value dimensions to investigate the relation between cultural differences in a multinational team and its impact on multinational team performance are widespread (e.g. Probst et al., 1999; Kirkman \& Shapiro, 2001; Thomas, 1999). However, the empirical analysis of the interviews in the European Commission shows that the influence of diverse cultural value dimensions on multinational team performance is highly influenced/moderated by the personality traits of the team members.

The category "society" is divided into two levels: First, an analysis of the role of general cultural differences and its relation to the personality of the individual will be conducted. Secondly, a description of the perceived North-Southdifferences in norms of behavior and its consequences on teamwork will be presented.

\subsubsection{General cultural differences versus personality}

According to the Parsons/Shils model (1962) the individual system is influenced by the cultural system and vice versa. This strong relation was also emphasized by the interview partners. Although the perceived general cultural differences (i.e. often stereotyping) play an important role in the first impression formation towards other team members, it seems that experienced multinational team members quite often rely more on the "personality-fit" than on the "culture-fit" to ensure the functioning of the team work. The personal characteristics are more important in the multinational team interactions than the measured cultural characteristics within a society. As also seen in the literature analysis, the statistical significance of some personality traits seems to be sensitive to other variables (e.g. Beersma et al., 2003). This has an important impact on management of as well as on the investigation into multinational teams: The role of general cultural differences within societies (expressed as values) should be linked to personality traits of the interacting individuals to get a more complete picture of the influencing forces on multinational team work.

Then, of course, it depends on the people there. These multicultural types - there really are two main elements in this respect. One maybe really is a person's origin, or that may be stereotypes you often find shown to be true, but also exceptions, and what is maybe even more important, personality. How can I say, a person can come from a Southern European area, who does not fit this southern stereotype at all, because he has a strong personality and this ability to interact with other people. (P15: EK_586; 03:03) 
However, there are two main cultural differences in norms of behavior influencing the multinational team work from an Austrian perspective.

\subsubsection{Cultural differences in norms of behavior: North versus South}

When talking about the influence of cultural differences in norms of behavior on the performance of multinational teams, the interviewed persons were mainly concentrating on a more general kind of "North versus South" category thinking. They use this classification to describe problems occurring as a result of different working and communication styles of various cultures. Nevertheless, the findings of culturally determined differences in norms of behavior in multinational teams are supported by the findings of the cultural standard research in a bi-cultural setting (Fink et al., 2004c).

In the analysis of the interviews two main work- and communication-related norms of behavior were found: the way of "how to criticize other team members" and the "goal- versus process orientation".

\subsubsection{Style of criticizing}

The aim of the analysis is to highlight the importance of the perceived differences in norms of behavior in a general way. This is valid as the interviewed persons are using this kind of generalized thinking in their daily work. The northcountries mentioned in particular are Denmark, Sweden, Finland, and Netherlands whereas the south-countries are Spain and Italy.

$36 \%$ of the interviewed persons referred to different types of criticism in the interaction with other team members (Table 11).

Table 11: Types of criticism

\begin{tabular}{|l|l|l|}
\hline \multicolumn{3}{|c|}{ As seen by the Austrian interview partners } \\
\hline $\begin{array}{l}\text { Indirect criticism (e.g. it is } \\
\text { important to highlight that } \\
\text { the criticism has nothing to } \\
\text { do with the person itself). }\end{array}$ & $\begin{array}{l}\text { Diplomatic criticism (e.g. } \\
\text {,that is an important point, } \\
\text { but maybe we should also } \\
\text { concentrate on this fact"). }\end{array}$ & $\begin{array}{l}\text { Straight to the point (e.g. } \\
\text {,the way you are carrying } \\
\text { out the evaluation is } \\
\text { completely } \\
\text { unsatisfactory"). }\end{array}$ \\
$\begin{array}{l}\text { The importance of } \\
\text { "question of honour" has } \\
\text { to be considered when } \\
\text { criticising }\end{array}$ & "Bauchpinseln" & \\
\hline
\end{tabular}

Source: Analysis of interviews

[...] Many people including me think that we Austrians do this for quite tactical reasons, not because we're nice, but for tactical and rhetorical reasons, to flatter people $a$ bit, and we say, yes that's a very interesting aspect and I can really go along with 
this, but I would really think and so on and so forth. And you somehow manoeuvre through the meeting, until you state quite clearly where you want to go. The Finn, Whack - Statement-End of Story, doesn't care on the effect this has on the other [...]. Now, we often have meetings where we discuss problems with the DGs (note: Directorates General). Well, I know, he arrives at the meeting and is already a little bit tense and thinks, what is it we get from the budget DG today, and then this Mr.X arrives (note: above-mentioned Finn) and says, erm, the way you are carrying out the evaluation is completely unsatisfactory. That's the introductory statement and that was it, he is not trying to be nasty or aggressive, but that's simply his assessment. And then there are people who ... either they get aggressive and quarrel or what have you [...]. The meeting stalls from the beginning and there's practically nothing you can do. There's some antagonism and right to the last minute of the meeting, there is no mutual improvement or so or we're looking for a solution, but there are opposing positions and that's crystal clear. (P10: EK_461; 10:10)

The following assumptions can be made and are presented in the "criticismcontinuum" (Figure 7). One issue that might emerge from the different styles of criticizing is that the point of critique is not catched by the counterpart.

- Direct criticism meets diplomatic criticism = clash (depends on the degree of the direct criticism (e.g. impoliteness))

- Indirect criticism meets diplomatic criticism = clash

- Indirect criticism meets direct criticism $=$ clash

\section{FigURE 7: CRITICISM CONTINUUM}

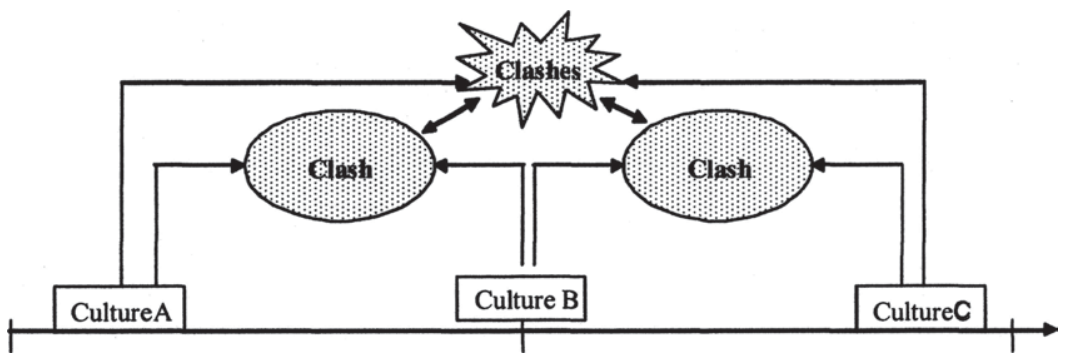

Source: Analysis of interviews

In analogy to this general presentation of styles of criticizing the following more specific/detailed styles of criticizing could be identified: The Austrians perceive themselves as being oblique in their criticizing style. Austrians perceive e.g. Italians and Spaniards as allusive in their criticizing style. This is consistent with 
findings in a bi-cultural context (Fink et al., 2004c). The Finish and Danish style of criticizing is perceived as straight to the point by the Austrian interview partners.

The way of criticizing (direct, diplomatic, indirect criticism, or more specific: allusive, oblique) has consequences for successful multinational team interactions: The same message should be presented in different ways depending on the cultural background of the other team members. However, there is no easy way out since within teams communication is directed to all team members at once. It is not possible to communicate simultaneously in an allusive style to e.g. Spaniards and in a straightforward style to e.g. Finns. Consequently, teams have to be made aware of the different styles of criticizing they use and have to develop a common style that suits all members in a multinational team (Fink et al., 2004c).

\subsubsection{Goal-versus process-orientation}

$40 \%$ of the interviewed persons pointed out that they recognize cultural differences in working styles. The north-countries (e.g. Germany, Finland, Sweden, Denmark) including Austria are seen as being more goal-orientated and therefore prefer to come straight to the point e.g. in presentations or during the preparation of a paper. In contrast, south-countries (e.g. France, Spain, and Portugal) are more process-orientated. They prefer extended explanations in e.g. presentations and rely on personal relationship in the communication. These findings are consistent with the code "criticism" (Table 12).

The different work approaches directly influence team work. Consequently, strategies have to be developed of how to deal with these different approaches in order to ensure efficient team processes. This is closely linked to the creation and establishment of a team culture, meaning the use of team norms.

A mediator of this code is "time pressure". If there is enough time to fulfil a task then the different working approaches might not significantly influence the teamwork. However, if the team is under time pressure, the different approaches might lead to dissatisfaction of team members.

Table 12: Goal- versus process-orientation

\begin{tabular}{|l|l|l|}
\hline \multicolumn{2}{|c|}{ Austria } \\
\hline \multicolumn{2}{|c|}{ As seen by the Austrian interview partners } \\
\hline $\begin{array}{l}\text { Process orientation: } \\
\text { Extended Explanations (see } \\
\text { interviews 1,2) }\end{array}$ & Goal orientation: & Straight to the point \\
$\begin{array}{l}\text { Personal relationship } \\
\text { oriented (see interviews 2, }\end{array}$ & & Straight to the point (see \\
3) & & \\
\hline
\end{tabular}

Source: Analysis of interviews 


\section{Interview 1:}

With Scandinavians, English, the Benelux, they are more reticent, less self-portrayal. With the French, Spanish, they talk more, verbose [...]. When I work in a team with 6 Frenchmen, 4 Italians and 3 Spaniards, I need some restraint. They are so much more extrovert. For example, an awful lot has to be explained. The Finns are silent, a reticent people. Another Example: a meeting on Friday, 4 p.m. with Dutchmen and Norwegian, much more relaxed than a bunch of Italians/Frenchmen and Spaniards. Furthermore it depends on the situation. (Note: responding to the interviewer's question: How do you react?). If, for instance, there is a Directory Meeting on Monday, 9.30, you are calm, patient, haven't read any mails yet (Note: But) on Friday afternoon, pointless blather, endless talk. (P9: EK_44; 41:42)

\section{Interview 2:}

Well, it can get interesting, for example, when you are, I have experienced this myself, when you are under time pressure, when people approach a problem differently. Then, people from several countries, rather Northern Europeans, when there's not much time and you ask them, quite simple, is there something about this, do we have a problem or don't we? And then the answer is no, there's no problem, that's enough for an answer. I you ask a Frenchmen, in particular, he thinks it intellectually unsound to give you a straight answer without a prior explanation. Following the French education method you have to provide at least three pros and three cons before you can arrive at an acceptable conclusion and this takes time and, particularly with people not used to this, listening to this beforehand, this results in impatience and can effectively lead to communication problems, because you simply say, this person is inefficient, instead of saying yes or no it always takes him 5 minutes to explain why. I'll gladly spend the 5 minutes if I have the time or if I want to know more but a yes or no would be a sufficient answer. Why should I listen to the rest? I've e.g. specifically encountered this problem even with highly qualified personnel, where the counterpart, in particular under time pressure or when you want to work efficiently and fast, where you have no sympathy, that people, I've particularly seen this with my French colleagues, that they think it's intellectually unsound to come out with the result straight away, but simply think it's important to also provide the reasoning that led them to arrive at a particular conclusion. (P6: EK_321; 07:07)

\section{Interview 3:}

[...] When you go into a meeting, the feel good factor so to say, basically as opposed to the Finns, Dutch or Swedes, but from the Italians or Portuguese you learn very little when you go straight to the point. Or it's not ideal for the atmosphere and you realise, he's stalling a bit, he wasn't very open or some such. You really have to take your time to take social preferences into consideration. That's sometimes extremely difficult, if you're under a lot of stress yourself [...]. For years, rather $21 / 2$ years, $I$ 
had a Portuguese boss, with whom I got along awfully well. There were absolutely no problems of hierarchy and we worked together a lot on important dossiers. Calls me to his office, hey, call from the Cabinet, a crisis, they need a briefing on such and such topic for the commissioner within an hour, because a press guy or someone from Parliament is on his way, or something like that. Quite a tricky subject, where you knew that's not just cut and paste, but you're thinking, I'll have to think about that, how do we do that, how do we approach this and where we get that from. And there's hardly any time and you have to put this on paper and it has to look good and so on. What does the Portuguese say? Let's have a coffee first, I'm not exaggerating, I've had this a couple of times with this guy and also with others, the old Italian with whom I worked. You have one hour for something you'd like to have a whole afternoon for and then you're not sure whether it can be done, and he says, let's go for a coffee first. That does not mean you spend half an hour in the cafeteria, but you go two floors up, have a coffee from the machine and lose ten minutes. Without that you couldn't work with him. He wouldn't have accepted me saying, forget your bloody coffee, we can have that later once it's done, that's how I would have done it, sit down for a coffee and a fag and relax a little, wouldn't have worked. We already discussed the topic over the coffee and so on. And then he was ready and we went to the computer and that's how we handled it. (P10: EK_461; 42:42)

\subsubsection{Language proficiency}

The aspect of working in a foreign language was found to be crucial for the efficiency of multinational teams. Marschan et al. (1997) argue that language is an important element in multinationals as is pervades every aspect of the business activities. Language barriers cause a huge number of negative consequences: breeding of uncertainty and suspicion, accentuation of group dividing, deterioration in trust building and leading to polarisation of perspectives, perceptions and cognitions (Feely \& Harzing, 2003: 41).

With EU enlargement 2004 there are now 20 official languages in the European Union. However, in the European Commission the daily working languages are more or less limited to French and English. The inherent problem that nonnative speakers might feel under pressure and feel themselves more vulnerable as it is the case when working in the mother language was mentioned by the Austrian interview partners.

First, and I'm looking at the facts here, there's a difference whether you work in your mother tongue or not. They simply have, depending on how good their command of the language is, an output that's lower than with someone working in his mother tongue. I think that's not appreciated enough in our work, because those working in their mother tongue more or less assume that the others have no difficulties with that 
either and can do it in the same way. On the other hand, it works very well. (P12: EK_493; 03:03)

A Frenchman is a Frenchman and will always be a Frenchman and will have no problems in French. An Englishman is and will always be English and will have no problems in English. You have to work in English and French here and everybody who is no Anglophone or Francophone from birth is required to operate in a foreign language and this has an influence on team work. E.g. in a meeting, English has been agreed upon, but now there is one person who's not very good at it, he as well as the others will now have a problem. Okay, everybody talks in his favourite language, in meetings languages are mixed. DG X, for example, which works a lot with South America, there are departments with Spain as a lingua franca. (P22: EK_857; 11:11)

\subsection{Organization - Organizational Culture}

\section{Najor findings}

Organizational context is the framework within which teams are established and act. This study identified a strong impact of organizational context (i.e. organizational culture and organizational structure) on multinational team performance.

The perceived organizational culture in the European Commission (main organization) can be described as 'being a human machine in the organization'. The team culture (team organization) within the main organization is perceived as 'culture of tolerance'.

The feeling of 'being a human machine in the organization': The creation of tasks solely for the functioning of the bureaucratic system ("Parkinson's Law") has been recognized by several interview partners as an important aspect of the organizational culture of the European Commission. It is examined as being inefficient for the function of multinational teams. The analysis of the interviews suggests that under the existing organizational culture the establishment of efficient and goal-oriented teams is difficult.

While the organizational culture of the main organization is described with the feeling 'being a human machine in the organization' the culture within teams is perceived as a 'culture of tolerance'. As the regulations of the main organization are often felt to be too rigid, multinational teams (i.e. team organization) in the European Commission develop their own 'culture of tolerance'. However, this specific 'culture of tolerance' of a particular team is itself defined by e.g. team norms affecting the team work.

One characteristic of the explicitly defined organizational culture is the 'eurospeak': In the European Commission a kind of "euro-speak" (i.e. a special language) has been developed as a result of the mixed use of different working languages, especially French and English. 
'Organizational context' (e.g. organizational culture) is the framework within which teams are established and act. According to Milliken \& Martins (1996: 420) the context may effect whether differences between the individual team members are noticed and how the single team members react. However, the question of how contextual and situational factors in multinational teams influence team members' behavior and team members' identity salience is an understudied field of research (Garcia-Prieto et al., 2003: 432). The analysis of the interviews shows the strong impact of organizational context (in particular 'organizational culture' and 'organizational structure') on multinational team performance in the European Commission.

Cartwright \& Cooper (1992: 56) define organizational culture as "the way in which things get done in an organization". In multinational teams the following three characteristics of organizational culture are of particular importance:

- "The way in which people interact, their terms of address and the language and technical jargon they use,

- the norms which govern the way in which work is organized and conducted, e.g. preference for written or verbal communication, and

- the rules for playing the organizational game, e.g. what is considered to be a good employee or effective manager" (Cartwright \& Cooper, 1992: 57).

The relation between organizational culture and teamwork is characterized by the influence of the organizational culture on the socialization process of the individual team member in the organization. In order to stabilize the organizational culture the optimal person-organization fit (meaning the congruence between organizational values and individual values) should be investigated by the organization (Chatman, 1991).

Cartwright \& Cooper (1992) elaborate upon Harrison's (1972) four typologies of organizational cultures "power, role, task/achievement and person/support" to develop their model of organizational cultures. This model can be used as a frame of reference to identify the optimal organization-person fit in a given organizational culture. In analogy to their typology, the European Commission can be described as a "role culture". Role cultures represent the Weberian concept of bureaucracy. The organization defines itself as a collection of roles to be undertaken rather than a collection of people/personalities. In such cultures things get done according to a 'corporate bible', meaning that role requirements, boundaries of authority and reporting arrangements are clearly defined. Therefore, a central characteristic of this type of culture are formal procedures and regulations defining the way in which work is to be conducted (Cartwright \& Cooper, 1992: 62).

According to the cultural immersion theory, people develop "shared schemas" and consequently, "if people from a given society share schemas, then the organizations within that society are likely to have structures and cultures that reflect those schemas" (House et al., 2004: 77). The fundament of the organizational cul- 
ture is set by the founders and their core group affected by cultural values of the larger society (Kirchler et al., 2004: 155; House et al., 2004: 78).

The creation of the High Authority of the European Coal and Steel Community (1952-1967) was characterized by Jean Monnet's thinking that the creation of a commonly administered common market for coal and steel could provide the foundations for Franco-German, and more broadly Western European, reconciliation. Drawing on the model of the French Planning Commission, which he himself had largely created, Monnet wanted the High Authority to be an innovative organization, leaving the routine and detailed work as far as possible, to national authorities. Therefore, the High Authority was to be small, non-hierarchical, and informal. However, the increasing workload and size, overlapping competencies and delays in decision-making caused by the non-hierarchical structure, lead to a movement towards a more bureaucratic structure and a hierarchical approach of procedure (Nugent 2001: 19-22). According to Mazey (1992: 43), between 1952 and 1956 "the administrative services of the High Authority [...] were transformed from an informal grouping of sympathetic individuals into a professional bureaucracy which, in terms of its structure and "technocratic" character, resembled the French administration". In 1967, the High Authority of the European Coal and Steel Community (ECSC), the Commission of the European Atomic Energy Community (Euratom), and the Commission of the European Economic Community (EEC) were merged into one Commission of the European Communities. Nugent (2001: 27) showed that French practices strongly influenced the construction and development of the EEC Commission (e.g. the Commission's structure was designed along the lines of the High Authority and systems established for staff recruitment and grading were similar to those long used in France). This historically explains that the organizational culture in the European Commission is (at least at the moment) French dominated. Therefore, one can assume that team members who have been socialized in the French administration system, might more easily adapt to the organizational culture than members from other countries:

I think we have a cultural entry barrier here, because we are in this French system, which I do not want to discredit, on the contrary, I'm being completely neutral here, I'm just saying there is this tradition and you have to bow to that or you don't survive, or you have to adapt, let's put it like that. (P20: EK 716; 31:31)

Thus, the first context-dependent characteristic in the European Commission is that individuals working there might have different approaches to the organizational culture caused by their different socialization processes and educational background (e.g. French team members who are familiar with the French administration system as they were educated in the "école nationale d'administration").

Nevertheless, the reform of the Commission (Reforming the Commission: A White Paper - Part 1, 2000) might lead to a change in the relevant aspects of the 
existing organizational culture. Especially in bureaucratic systems the need for a development towards a performance oriented organizational culture is recognized. Conducting an analysis of the existing organizational culture helps to identify ineffective basic assumptions. Therefore, practical interventions can be undertaken in order to change the organizational culture towards the defined direction (Kirchler et al., 2004: 157).

The sub-category „organizational culture” is subdivided into:

- "Perceived kind of organizational culture": "being a human machine in the organization" and culture of tolerance

- "Explicitly defined organizational culture": Eurospeak

\subsubsection{Perceived kind of organizational culture}

\subsubsection{1. "Being a human machine in the organization"}

As Kirchler (2004: 155) states it is difficult to make the organizational culture of an organization obvious. According to current organization theories, especially in the New Public Management theory (e.g. Budäus, 2002; Hughes, 2003; Schedler \& Proeller, 2003), the organization should focus on the improvement of its efficiency. However, Parker \& Bradley (2000) analyzed the organizational change towards the development of a post-bureaucratic organizational culture in six public sector organizations, concluding that these organizations continue to emphasize the values of a bureaucratic organizational culture.

The creation of tasks solely for the functioning of the bureaucratic system has been recognized by several interview partners as an important aspect of the organizational culture and is examined as being inefficient. These findings can be explained with "Parkinson's Law". It identifies two causal driving powers which can be summarized as follows: (1) Every civil servant or employee seeks to maximize the number of his subordinates but not the number of his rivals, (2) civil servants or employees create tasks to keep each other busy (Parkinson, 1992: 18-21, translation by the author).

The analysis of the interviews suggests that under the existing organizational culture the establishment of efficient and goal-oriented teams is difficult.

Regarding administrative structure I can give you an example: a department is overworked, asks for new staff, which is approved, a sort of sub-department develops, with the result, as nobody's to be discriminated against, that the same letter, which up to now had been answered by just one person, will now be replied to by three. The organisation has thus created work for itself. (PI: EK_424; 32:32) 


\subsubsection{Culture of tolerance}

There seems to be a discrepancy between the organizational culture of the main organization, perceived as very rigid and a perceived culture of tolerance within teams. There are theories that help to understand the dialectic relationship between personal freedom and individualism at the level of society on the one hand and strong corporate cultures and rule dominance at the firm level (Lehmann, 2003a, 2003b). In the European Commission 25 cultures work together. The organization tries to handle these 25 culturally based degrees of freedom by implementing rigid structures. One consequence is that the organizational culture of the main organization (i.e. the European Commission as a whole) is perceived as supporting the feeling of "being a human machine in the organization". As the regulations are often felt to be too rigid, multinational teams (i.e. team organization) in the European Commission develop their own 'culture of tolerance'. However, this specific 'culture of tolerance' of a particular team is itself defined by e.g. team norms affecting the team work.

Although we are talking about perceptions of the organizational culture it appears that the perceived culture results in the creation of team (inter)action strategies. Thus, the analysis of the perceived organizational culture is the starting point to develop guides for action, meaning the creation of efficient team norms as optimal solutions, i.e. how to work efficiently together within the given organizational culture and organizational structure.

A lot of pragmatism, a lot of tolerance - and tolerance is seen positively now. Often also the realisation that it cannot be done any other way. And if you as the head of unit, the department head, have had to struggle with Portuguese and other nations for three years, who often work a little differently, you try to accept or you have to accept they do it differently and try to take them as they are. That means an anything goes culture, you could say, in a homogeneous culture you can work with mutual values, common sense and so on, and you don't do that and there are certain standards and so on. Naturally, you don't get that anymore from Finland to Greece, you can forget all that, if you somehow have to find a common standard, it will be very low, which basically means laissez faire, you leave a lot of leeway, you accept a lot. There's a tendency towards - tolerance, a positive term, opportunism, a more negative word, pragmatism, that can't changed, that's just the way it is. (P10: EK_461; 6:6)

\subsubsection{Explicitly defined organizational culture}

\subsubsection{Eurospeak}

According to Schein (1992: 8) culture is made up by the observed behavioral regularities in the interaction of people. One of these regularities is the language that members of an organization use. In the European Commission a kind of 
"euro-speak" has been developed as a result of the mixed use of different working languages, especially French and English.

It is also an important factor in comprehending people, as in administrative practice and in work practice some type of separate language has developed. This is administrative French or English, that's quite interesting. With their own idioms, and how notes will be written. But also if you take a look at the language of these notes, that's not French anymore, I'm quite sure if a Frenchman reads this, who hasn't been outside France in his life, he would find that quite weird as regards the language. The same goes for English native speakers [...]. (P18: EK_693; 1:1)

\subsection{Organization - Organizational Structure}

Major findings

In the European Commission there is a discrepancy between the promoted 'tools' of the new public management approach and the existing structures of the bureaucratic, hierarchical organization, which are perceived as rigid. The role of hierarchy in the European Commission is explained as the sub-category "hierarchy: French versus Anglo-Saxon system".

Another important aspect of the organizational structure is the performance appraisal system, i.e. the system an organization uses to reward its employees. In the European Commission a Career Development Review has been implemented. As seen in the interviews an inadequate performance appraisal system might have negative impacts on (a) the establishment of a team culture and (b) on an already existing team culture. This emphasizes the role of "organizational context" when implementing and developing teams: the characteristics of a bureaucratic system have to be considered.

With job rotation employees should gain a better knowledge of the work of other organizational units. However, the analysis of the interviews shows that job rotation does not automatically lead to knowledge transfer. The interviewed persons emphasized the issue of trust building within a team in an organizational climate of high mobility.

The theoretical foundations of public administrations essentially originate from Woodrow Wilson and Frederick Taylor (United States), Max Weber (Germany), and the Northcote-Trevelyan Report of 1854 (United Kingdom) (Hughes, 2003: 17). As Weber's theory of bureaucracy is one of the most important theoretical principles in the traditional model of public administration it will be briefly explained in the following. Weber set out 6 principles for modern systems of bureaucracy (as quoted by Shafritz \& Ott, 1987: 81-82):

- There is the principle of fixed and official jurisdictional areas, which are generally ordered by rules, that is, by laws or administrative regulations. 
- The principles of office hierarchy and of levels of graded authority mean a firmly ordered system of super- and sub-ordination in which there is a supervision of the lower offices by the higher ones. [...]

- The management of the modern office is based upon written documents ("the files"), which are preserved in their original or draught form. [...]

- Office management, at least all specialized office management - and such management is distinctly modern - usually presupposes thorough and expert training. [...]

- When the office is fully developed, official activity demands the full working capacity of the official, irrespective of the fact that his obligatory time in the bureau may be firmly delimited. [...]

- The management of the office follows general rules, which are more or less stable, more or less exhaustive, and which can be learned. [...]

Hughes (2003) characterizes the traditional model of public administration as "an administration under the formal control of the political leadership, based on a strictly hierarchical model of bureaucracy, staffed by permanent, neutral and anonymous officially, motivated only by the public interest, serving any governing party equally, and not contributing to the policy but merely administrating those policies decided by the politicians" (Hughes, 2003: 17). Nowadays the characteristics of the public administration according to the six principles of Weber have reached their limits: A highly dynamic environment requires increased flexibility of the public administration (Schedler \& Proeller, 2003: 17). The limitations of the traditional models of public administration demonstrated by the model of Weber lead to the emergence of a new managerial approach in the public sector (new public management). Since the 1970s, public sector organizations across the world have been undergoing a series of progressive reforms. The aim of these reforms was to open up the public sector by increasing effectiveness, and reinforcing the concept of merit in recruitment and promotion (Dann, 1996: 28). However, in the analysis of the interviews it became apparent that there is a discrepancy in the European Commission between the 'tools' of the new public management approach and the still existing rigid structures of the bureaucratic, hierarchical organization. The role of hierarchy in the European Commission is explained in the following as the sub-category "hierarchy: French versus Anglo-Saxon system".

Following Hughes (2003: 44-45) three elements describing the new public management approach influence the work of multinational teams in the European Commission:

- Pay greater attention to the achievement of results and the personal responsibilities of managers.

- Set organizational and personal objectives. This enables the measurement of their achievement through performance indicator. 
- These two elements are strongly linked to the code "performance appraisal" identified in the interviews. As also seen in the interviews, critics of the New Public Management approach consider it as simply an "unquestioned adoption of the worst features of private management which pays no regard to the fundamental differences to the public sector environment" (Hughes, 2003: 45). Therefore, one has to be aware that dedicated public management practices have to be developed which take into consideration the differences between the sectors (Hughes, 2003: 45).

- Make organizations, personnel, and employment terms and conditions more flexible. This element is linked to the code "mobility: job rotation" identified in the interviews.

To sum up the sub-category „organizational structure” is sub divided into:

- Hierarchy: French versus Anglo-Saxon system

- Performance appraisal

- Mobility: job rotation

\subsubsection{Hierarchy: French versus Anglo-Saxon System}

In single Directorates-General the hierarchical structure is different. The historical background of the structure in the Directorate-General influences the organizational structure today and consequently the organisation of the daily work. Thus, e.g. the Directorate-General Agriculture is historically anchored in the French system.

The interview partners gave a good example of the influence of the hierarchical system on the daily work.

In order to be really integrated here, you have to follow a certain model and this model is still strongly influenced by the French system. We live here under French administration and even the general directorates in which e.g. English is the main language, can't escape from this. A least that's what I say. It was also quite interesting when I realised how far that went. Even the Spaniards, Italians and Dutch adapt to the system. It's incredibly strong, this French organisation, merely from the point of view how the work is done, ending with the question how good the contact is with political bodies; something that's handled completely differently in Germany or Austria than here in the Commission. Here there really is a strict separation between the political level, i.e. the Commissioner, and the General Directorate, i.e. the ministry if you want. So all informal contact with a Cabinet is practically reduced to old boy networks, but in normal life, for work they do not come in at all. Let me give you an example: When Commissioner $X$ arrived, it was customary, whatever he did in city $X Y$, he does not follow the hierarchy, for said reasons, because for political reasons country $Y$ has always been critical towards the other, but also because of knowledge. $I$ know from mister $X$, he simply called the civil servant directly, wants to know ex-

Anne-Katrin Neyer - 978-3-631-75440-5 
actly who is responsible, he was given the name, calls him and the guy freaks out, the Commissioner is calling me, how is that possible? Well, that's one thing, I'd say the system here is well established. It is likely to remain like this for some time. The question is, whether the new member states, which are more English, will soften that. Well, the whole organisation here follows this system and so you have to adapt, or you can't survive. (P20: EK_716; 11:11)

Thus, the importance of differences in the French and the Anglo-Saxon system has to be considered in the analysis of the influence of the hierarchical structure on teamwork. One of the interview partners highlighted the relevance of being aware of this difference. He gave an example of problems after the merger of two Directorates Generals representing the two different bureaucratic structures:

There are different national domains/islets, some DGs (note: General Directorates) are more characterised by one culture. This was interesting when the DG traffic (Tram), which is very heterogeneous and the English language prevails, as well as the English administrative style, merged with $D G$ energy, which is very francophone and where there's a strong Greek influence. The French administrative culture has been in the Commission since the 1950s and is very hierarchical. DG X has a French Director General, who is seen as an "absolute emperor", a sun god. There is some interaction between an extremely rigid hierarchy, the highest person in the hierarchy breaks the hierarchy and shows it too, e.g. by passing over people in the hierarchy. Greek administration o the other hand is very southern, there are official rules, which will then be disregarded somehow. After the merger mentioned above, there was a double culture shock in DHG traffic: a) on a linguistic level, .e. all documents have to be in French and b) also regarding the administrative culture: Anglo-Saxon administrative culture is very informal, there are hierarchies, but you can simply enter the room of a hierarchically superior person [...]. (P1: EK_424; (8:10)

\subsubsection{Performance appraisal}

In "Reforming the Commission: A White Paper - Part 1" (2000: 15) the European Commission defines the performance appraisal as follows:

"Any staff appraisal system serves a number of purposes from providing feedback to staff and assessing performance against agreed objectives to judging their suitability for promotion. The starting point for staff appraisal in the Commission must be clearly defined mission statements for each department and job descriptions and task assignments for each member of staff. These are, in any event, key elements of the system of planning and programming of Commission activities. While a new system is needed, experience has shown that the key to a successful staff appraisal system lies in its fair and proper application by assessors. As a priority, management will receive special training in appraisal and there will be checks on their application of the 
system. Further thought will be given to ways to guarantee that appraisals are conducted equitably and efficiently. The heart of the new system of appraisal should be an annual dialogue between the assessed and their assessor to discuss how far clearly set objectives have been achieved. This is common in other European administrations and would provide staff with objective feedback on their performance, recognizing achievement and, if necessary, encouraging them to do better by identifying areas for improvement. Career development issues, such as training and mobility, should also be discussed. Appraisal should also help in assessing a person's suitability for promotion based on past performance and aptitude for new tasks and responsibilities. Merit is a relative concept requiring staff to be assessed for promotion by comparison with their peers. This means that the appraisal needs to include the attribution of a mark (or marks). At present, appraisals in the Commission are made every two years. The link between the new annual appraisal and promotion procedures will be examined carefully to avoid placing an undue burden on managers and staff. More investment of time and effort in the new appraisal system is, however, needed. This new staff appraisal system must clearly be fair, transparent and objective. Assessment should be carried out by the staff member's immediate superior, perhaps involving other colleagues, and the use of "two-way feedback". Finally, the appraisal of managers should include an element of assessment by their staff. Safeguards will be developed for those involved in assessing their managers. A separate appraisal system will be introduced for Directors-General and Directors, which will assist the Commission in judging Directors for promotion to Director-General."

The European Commission describes the benefits of the appraisal system as follows:

"One of the benefits of a better appraisal system will be meeting the explicit requirement in the Staff Regulations that promotions should be based on merit. Further improvements to the promotion system are needed to bolster the aim that good performance should be properly rewarded. This should include taking account of mobility and the development of specialist skills. Procedures to help under-performing staff. A clear definition of each official's tasks will give them and their managers an agreed basis on which to assess performance. The annual appraisal dialogue ought then to lead to an earlier detection of under-performance. The new career guidance function will include counselling for apparent under-performers and a skills review. There will be a guide to provide a clear definition of under-performance and guidelines for detecting it as well as procedures to be followed. Remedial measures may include additional training and reassignment to other posts [...]."

McHugh \& Bennett (1999: 191) argue that "the new agencies have experienced some difficulty with the implantation of their often disintegrated programs of strategic change. The root cause of these difficulties might lie in a rigid adherence to an outmoded set of cultural values, a bureaucratic structure and old reward systems coupled with a panic crazed obsession with efficiency, all of which may act 
as impediments to longer term organizational performance". They pointed out that one of the problems of implementing efficient teams in the public sector is that the reward system is geared toward the individual rather than the team (McHugh \& Bennett, 1999: 191).

The Career Development Review and its implications on teamwork were critically analyzed by the interviewed persons. In teams with an established team culture (e.g. trust, existence of team norms that support the team work) the benefits of this control mechanism out weighed the problems.

I could imagine this has effects on a team that's not so cohesive. In our team there has always been open discussion, also about evaluation matters. We have always told each other how many points they got, which is not that customary really, and which might lead to more competition, as in the end everyone is evaluated individually. When you work in a team, you will then be evaluated individually and not the team as a whole. The team as a whole may be evaluated or it is a part of the team leader's evaluation, but generally there is individual evaluation. However, thank god this has worked pretty well in our case. (P7: EK_357; 31:31)

The benefits of the performance appraisal are a clear goal definition for the coming year based on the job description and a (more or less) subjective evaluation of the achievement of these goals.

What we do, what many department heads and directors and such recommend, is that for example, and that's new in the system, that at the beginning of the year every employee gets a clear target for the year and is told how this target will be evaluated. And this target is then measured at the end of the year and this year, January and February is when we have the evaluation talks, we will do that for the first time on the basis of the 2003 targets. Then we will see how it works. And this is often included in the positive criteria, the willingness and ability to work in teams, i.e. we signal the people fairly clearly that soloists who aren't willing to be team players have to expect negative points. (P6: EK_312; 54:54)

The major problem is that the Career Development Review is based on a point system. The number of points is directly related to the promotion. Therefore, there is a fierce competition in the team, although "being a team-player" is awarded with points in the performance appraisal. Individuals have to deliberate about individual interests or team interests. This might influence the efficiency of the whole team.

No system can offer an evaluation, it is always subjective, i.e. personal evaluation, and if someone doesn't fit... The employee evaluation system has effects on all the team. Everyone's equally good, but three get more points than the others. That's linked to promotion. In addition, it is difficult to define a civil servant's performance. I think that customer satisfaction and enforcing the law, that's a contradiction. I believe you'd have to use different methods: Advancement based on seniority and pro- 
motion when I'm ready to face new challenges. When applying for a job, if you want to change, there is an independent commission you talk to and then there will be a selection. Only so will teambuilding be possible. At the moment: everybody puts in as much as possible for himself [...]. The System (note: employee evaluation system) is suitable for performance-oriented industrial companies and not for the European civil service. I'm trying to minimise the damage. Now it has to be proven that employees don't get better. This system, however, expects employees to improve through trainings or depart. (P13: EK_543; 47:49)

Consequently, it could be difficult to reach one of the important goals of the reform, i.e. making the bureaucratic organisation more efficient. This emphasises the role of "context" when implementing and developing teams: the characteristics of a bureaucratic system have to be considered. A control mechanism like the Career Development Review can be useful in the specific context for which it has been developed (here: multinational companies) but can fail in another context.

In summary, it can be assumed that the creation of a team culture (of trust) might help to make use of the benefits of the Career Development Review and on the other hand might facilitate coping with the inherent problems (Figure 8).

\section{Figure 8: Benefits and Problems of the Career Development Review}
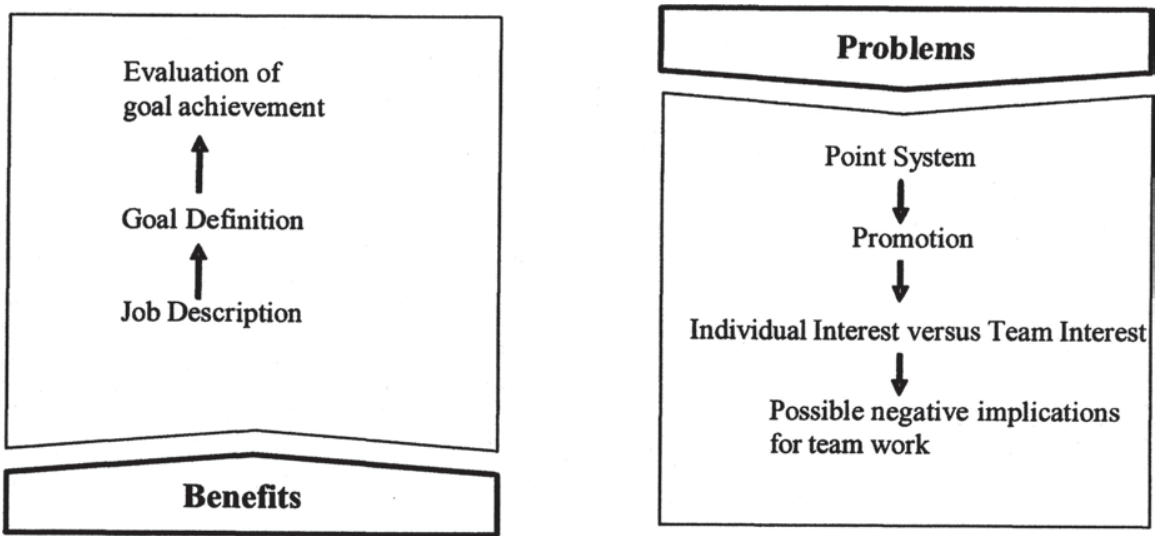

\section{Benefits}
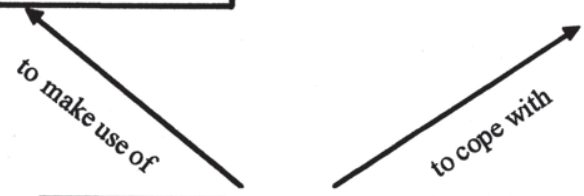

Creation of a team culture/team norms

Source: Analysis of interviews 


\subsubsection{Mobility - job rotation}

The movement of employees between jobs over a period of time and for different purposes can be described as job rotation (Bennett, 2003). With job rotation employees should gain a better knowledge of the work of other organizational units. Weerd-Nederhof et al. (2002: 327) suggest that a high degree of job rotation supports the consensus creation of individuals and therefore the interpretation of information. Thus, job rotation is often used as an organizational learning strategy. It is identified as a mechanism to reduce people's boredom and to keep them interested in their jobs (Ortega, 2001: 1361). Often job rotation is used to encourage the transfer of knowledge e.g. within a parent company and its subsidiaries. Kölling (2004) found out that in the knowledge management process between West- and East German companies the transfer of knowledge primarily takes place with the help of job rotation. However, the analysis of the interviews shows that job rotation does not automatically lead to knowledge transfer. The interviewed persons underlined the problematic of trust building within a team in an organizational climate of high mobility.

In "Reforming the Commission: A White Paper - Part 1" (2000: 13-14) the European Commission encourages mobility:

"Internal mobility will be encouraged by removing barriers such as those caused by the existing promotion system. The mobility rules specific to the External Service will be maintained and improved when necessary. The terms and conditions for mobility among European Institutions, and between them and Member State administrations and possibly public and private bodies, will be explored with a view to facilitating exchanges. More generally, to respond to limited mobility of certain people and to provide an incentive for mobility, it will be considered as an asset in staff appraisals and in appointing managers. The continuity of activities in the face of greater mobility will be ensured, notably, by better organization of the handover of responsibilities between officials."

The analysis of the interviews clearly demonstrates that there is a discrepancy between the "as it should be" situation defined by the organization and the "as it is" situation perceived by the team members.

The principle of rotation was formerly used in the diplomatic service, now universally for holders of so-called "sensitive jobs". This has led to enormous unrest amongst the staff. It has pros and cons: it provides relief for me as the boss, (note: the employee) will leave in a year's time anyway, don't make massive efforts to motivate him. The other person thinks the same, the German in question is 5 years older, knows he has to rotate away next year, thinks, I don't care what (note: the interviewed person) wants. This results in different behaviour. As a superior you invest more in new (note: employees), here I risk conflict, if you know someone leaves soon, what do I care. Rotation results in strange things. (P9: EK_44: 54:54) 
[...] In the unit people have struggled to an agreement, someone leaves and you have to start from zero to teach the new employee everything. Like at school, where you have to teach people the same things right from zero. In every system that believes it has to be so economical that there is no overlap when a person is replaced.(P22: EK_857; 26:26)

\subsection{Individual}

\section{Major findings}

This category comprises 'personality traits', 'personal experiences', 'personal interests/motivation' and 'educational background' of the individual team member as driving factors for efficient multinational team work.

$68 \%$ of the interviewed persons highlighted the importance of personality traits as a factor influencing multinational team interactions. According to the literature analysis (e.g. Ward et al., 2001) it can be assumed that specific personality traits are supportive for multinational team work.

Another decisive issue for a well-functioning team is the personal experience of individuals. Especially past international assignment turned out to be of particular importance for team performance. Team members, who are experienced in multinational team work, are able to enhance the performance of teams in the learning process of the team as they know how to use the diverse (cultural) knowledge of each individual team member (Stern, 1997).

The performance of an individual in the team work is based on personal interests and is motivation driven. The interviewed persons mentioned the stage of career development of the individual team member as a personal interestdriven factor (extrinsic motivation) of how to contribute to the team work. Additionally, personal interests/ motivation are strongly related to the performance appraisal (single versus team player). Hackman (1987: 325) pointed out that for efficient team work, rewards and objectives have to focus on group, rather than on individual behaviour. The conviction of doing something useful (intrinsic motivation) is a motivational factor which might lead to efficient contribution to the team work in the European Commission.

With team implementation the optimal level of diversity (qualifications, knowledge, personalities and cultural differences) has to be found to perform the task. A mix of educational backgrounds in a team (e.g. technicians and managers) might lead to a better problem solution as there are different approaches of how to deal with a problem. On the other hand the heterogeneity in the education of the team members might enhance the complexity of the team work. 
The sub-category "individual team member" comprises personality traits, personal experiences, personal interests/motivation and educational background of the individual team member.

\subsubsection{Personality traits}

The role of personality in multinational teams was already highlighted in the literature analysis. In analogy to the expatriate adjustment literature (Ward et al., 2001) it can be assumed that specific personality traits are supportive for multinational team work. Therefore, it is important to choose the 'right people'. Psychological tests, handpicking of experts and assessment centers are management tools right at hand. 17 of the interviewed persons mentioned the importance of personality as a relevant factor for the performance of their teams.

So, in preparation for the interview I thought, at the end of the day it's the person that counts, the human element, that is, what sort of human being a person is. Nationality maybe influences in a particular way, if you want you can certainly find national... Although I myself am a bit reluctant... I'm an open person, respect towards the other and then e.g. very personal factors play an important part, maybe also nationality, but in my experience it's more a person's personality. (P7: EK_357; 61:61)

It is tremendously important to create a feeling of trust, personal contact, personality. That is extremely personality-related and less related to nationality, well... in my area it is almost more important people have a certain attitude, a certain personality structure than that they come from a certain culture or are of a certain nationality. (P15: EK_586; 65:65)

\subsubsection{Personal Experiences}

One of the decisive issues of a well-functioning team is the personal experience of individuals. Especially past international assignment turned out to be of particular importance for team performance. It has an impact on the way people interact in a multinational team. One can assume that individuals with positive experiences towards living and working together with people from other cultural backgrounds will more easily integrate themselves in a multinational team. They are aware of problems multinational teams have to cope with and have the ability to understand implicit informal rules and norms in multinational teams much more easily than less experienced team members. Therefore, they are able to enhance the performance of teams in the learning process as they know how to use the diverse (cultural) knowledge of each individual team member (Stern, 1997).

What's more, nobody here comes unprepared from some godforsaken in-the-sticks backwater place and-whack- lands in a completely foreign environment. Everybody speaks foreign languages, two, three or mare. Almost pverybody joining the Commis- 
sion had worked somewhere else in an international context, far from home. Most have a postgraduate degree or at least completed some course abroad. That is, no one comes here really formed by his local environment and has to come to grips with a completely foreign environment, that's not the case. It may be very rarely the case that someone really speaks absolutely zilch French and starts showing nerves. That is the big exception. I don't think there is a cultural difference in this job and, let's say, the professional adaptation of the staff is so strong that we create significantly more mutuality. (P11: EK_489; 005:005)

\subsubsection{Personal Interests/Motivation}

The performance of an individual in the team work is based on personal interests and is motivation driven. This category deals with the question: What are the personal interests when contributing to team work? What is the motivation to add effectively to the team work? Power and interests of the individual team members on the one hand and the contextual organization on the other hand influence the learning process of individual team members and the team itself (Fink et al., 2004b).

The interviewed persons mentioned the stage of career development of the individual team member as a personal interest-driven factor of how to contribute to the team work: If the individual team member is e.g. in the middle of his or her career then she/he will perform in an outstanding manner in order to be promoted. If someone is already in the final stage of his/her professional career or sees no possibility to get promoted this might not be the case.

I addition, I'd say, there are several factors, cultural on the one hand and also from a development perspective, when the career perspectives are finished e.g. shortly before retirement, then they show a completely different behavioural pattern than people in the middle of their career. These probably try harder than those who are at the end. (P8: EK_43; 15:15)

However, it has to be considered that an outstanding performance of an individual may not automatically lead to efficient team work. The individual has to decide (based on personal interests) whether it is better to be a team player or a single player in order to get promoted. Additionally, personal interests/ motivation are strongly related to the performance appraisal (single versus team player). Hackman (1987: 325) pointed out that for efficient team work, rewards and objectives have to focus on group, rather than on individual behaviour.

The interviewed persons pointed out that people might work for the European Commission as they are convinced that they do something useful. This is one of the motivations which might lead to efficient contribution to the team work. 
To a satisfyingly large extent the Commission consists of people of conviction. If you don't believe in it, you despair. You will never find people so qualified who will accept personal problems and the glorious (note: ironic) career opportunities, unless they are motivated through doing something they think important. The day this factor disappears we might as well close down. (P22: EK_857; 35:35)

\subsubsection{Educational Background}

Well-composed teams are characterized inter alia by the high task-relevance expertise of their individual team members (Hackman, 1987: 326). The most visible kind of expertise is the educational background of a team member. The influence of a team member's educational background on team performance is strongly related to the task of the team. Depending on the type of organization, the task a team has to fulfill requires diverse skills. With team implementation the optimal level of diversity has to be defined to perform the task. A mix of educational backgrounds in a team (e.g. technicians and managers) might lead to a better problem solution as there are different approaches of how to deal with a problem. On the other hand the heterogeneity of the education of the team members might enhance the complexity of the team work. The code "educational background" does not only consider diverse fields of education but also diverse systems of education in the same field but in different cultures.

[...] In fact there is, I'm not aware of any example of communications problems due to different origins or of problems in getting their work done because two people having interpreted their tasks differently because of their different national backgrounds. The problems in perception and differences between lawyers, economists and sociologists are certainly greater in their daily work than the differences in opinion between, say, a Spanish and a German lawyer. And in this connection the educational background and the divided educational background really make things much easier. In my current team we have fairly uniform tasks, are very mixed as regards nationalities and very diverse as regards educational backgrounds. So lawyers, economists, translators, agriculture, what else is there, combinations from these areas. And there you see the main problem again, when addressing a subject, if you have to get the same type of work done as in the specifically nationality-related [...]. (P6: EK_312; 03:03)

\subsection{Individual - Team Leader}

\section{Major findings}

Team leader characteristics influence the performance of multinational teams. The types of leadership style and power were identified as relevant characteristics influencing the performance of a team. 
The task-oriented delegation of work and the transfer of relevant information to the team members were identified as crucial parts of a successful leadership style in the European Commission.

The type of leadership style, especially the way of delegation, is strongly related to personal interests and power of the leader. Consequently, for an efficient team work the leader has to walk a fine line in mixing personal interests, power and leadership style in a way that guarantees the optimal use of the potential of the individual team member.

With the new public management approach there is a move towards decentralization in administration. This is accompanied by the movement towards team working. Many managers perceive this as threatening, especially those individuals "who have been socialized within a culture where it is accepted that the manager is controller, rather than facilitator of team effort" (McHugh \& Bennett, 1999: 191).

Team leader characteristics affect the team work. They play a crucial role in the encouragement of framing and reframing knowledge within a team (Edmondson, 2003) and consequently influence directly the performance of a team. Besides other factors mentioned in the sub-category "individual team member", the type of leadership style and power were identified as relevant characteristics influencing the performance of a team.

\subsubsection{Leadership style and power}

The task-oriented delegation of work and the transfer of relevant information to the team members were identified as crucial parts of a successful leadership style in the European Commission. This is consistent with the findings of Sarin \& McDermott (2003). They investigated that the more team members are involved in the decision-making process by team leaders, the more efficient is the learning process within teams. If team leaders show this participatory behavior, team members take a broader view of their jobs, use a wider range of information and consider constraints in their decision-making process (Sarin \& McDermott, 2003: 725). A leadership style characterized by openness and information sharing supports the building of trust between team members (Costa, 2003: 119).

The type of leadership style, especially the way of delegation, is strongly related to personal interests and power of the leader. Consequently, for an efficient team work the leader has to walk a fine line in mixing personal interests, power and leadership style in a way that guarantees the optimal use of the potential of the individual team member.

[...] What apparently results in high motivation (note: in the team) is, when you really inform (note: the team members). I was shocked, because I had only said, I've

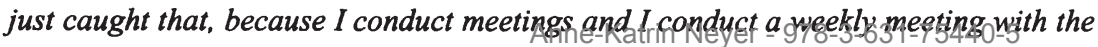


whole team, with all staff together, takes one hour, which is too long anyway, because I'm quite critical there, as it always turns into a monologue, because there's so much information. I inform them about it, apparently not everybody does that or not on a regular basis or not quite to such an extent, which surprises me, because I had thought everybody does it. And there they come up from the cafeteria and say they were in the cafeteria with a colleague from another department, they don't even know that and naturally this gives them the feeling of being included. That is, to be as transparent as possible and not to hold back information. Apparently this is an element [...]. (P20: EK_716; 61:61)

\subsection{Excursus: Knowledge Management}

\section{Major findings}

The knowledge transfer in multinational teams in the European Commission was seen as being influenced by the organisational structure within the given organizational setting. Job rotation and the "Carrier Development Review" were identified as barriers for efficient knowledge management as they enhance personal interests of the individual team member. Personal interests/motivation to share knowledge with the other team members is influenced by the value of the individual's knowledge and the motivational disposition of the individual team member: it is coupled with the individual's interest to acquire and retain relative power within the team and the organization.

The sharing/transfer of knowledge depends on trust. The trust building process between individual team members needs time. Consequently, the inherently useful element of job rotation might negatively influence the knowledge transfer in a team.

The transfer of information to the team members was identified as a characteristic of team leaders positively influencing multinational team work. Consequently, as knowledge management does not fit directly in one of the other categories it was introduced at this place.

Gupta \& Govindarajan's (2000: 475) concept of knowledge flows (into or out of a subsidiary) is based on the basic elements of a two-person communication: a message, a sender, a coding scheme, a channel, transmission through the channel, a decoding scheme, a receiver, and the assignment of meaning to the decoded message. It can be used as a frame of reference for the analysis of knowledge transfer within multinational teams in the European Commission. Gupta \& Govindarajan (2000) define the knowledge flow as a function of the following five factors: (a) value of the source unit's knowledge stock, (b) motivational disposition of the source unit, (c) existence and richness of transmission channels, (d) motivational disposition of target unit, and (e) absorptive capacity of the target unit (Gupta \& Govindarajan, 2000: 475). Applying these factors to individuals in 
multinational teams implies the following for knowledge transfer within such teams (Gupta \& Govindarajan, 2000: 475-476):

- Value of individual's knowledge: The greater the value of an individual's knowledge stock for the rest of the team, the greater its attractiveness for other team members. This is strongly related with the second factor influencing knowledge transfer within the team:

- Motivational disposition of the individual: An individual's uniquely valuable knowledge is likely to enjoy an "information monopoly" within the cooperation. This is strongly related with the codes "personal interests" and "motivation", meaning that it is coupled with the individual's interest to acquire and retain relative power within the team and the organization.

- Existence and richness of transmission channels: Knowledge flows within teams cannot occur without the existence of transmission channels.

- Motivational disposition of the other team members, which is characterized by the "Not-Invented-Here" syndrome. According to Gupta \& Govindarajan (2000: 476) this syndrome is driven by (a) an ego-defence mechanism against the other team members to block any information that might question one's own competence and by (b) power struggles within the team and/or the organization.

- Absorptive capacity of the other team members, which is characterized by their "ability to recognize the value of new information, assimilate it, and apply it to commercial ends" (Cohen \& Levinthal, 1990: 128 as quoted by Gupta \& Govindarajan, 2000: 476).

Holden (2002: 275-276) studies the role of 'atmosphere" in the cross-cultural transfer of knowledge. Atmosphere is a "pervasive feeling, which is derived from experience and serves as a determinant of expectations concerning future cooperation in a business relationship or group activity such as collaborative learning or knowledge sharing" (Holden, 2002: 315). In multinational teams individuals cannot know how to handle all situations. However, they can and should create and sustain a conductive and collaborative atmosphere to support knowledge flow within the team (Holden, 2002: 275). As seen in the analysis of the interviews the atmosphere within multinational teams is related to the establishment of multinational team norms.

\subsubsection{Knowledge Transfer}

In the empirical data the level of knowledge transfer was seen as being influenced by the organisational structure (i.e. the specific organizational context of the European Commission). Job rotation and the Career Development Review (which are themselves influenced by the codes "personal interests/motivation") were identified as barriers for efficient knowledge management: 
And as I said, this evaluation system, which is extraordinarily important for promotion, naturally is a very important evaluation for the individual him- or herself. Evaluation systems, where in the individual case there is of course the problem, do I keep my knowledge or abilities to myself and do I try as best as I can to get through with that vis-à-vis the director, department head or director general, or am I willing to share it beyond the borders of a department. And only very few, very good, people do that. Well, if someone really knows he is an authority in his area, really knows the subject inside out, then he is willing to share this. The, if he or she knows, if they do that, the other side also provides information he or she can make good use of. (P21: EK_751; 31:31)

The sharing/transfer of knowledge depends on trust. The trust building process between individual team members needs time. Consequently, the inherently useful element of job rotation might negatively influence the knowledge transfer in a team.

I don't know how often we reinvent the wheel within a year, but when a member of staff departs, at least half his knowledge is lost. Alright, there are the hand over notes and so on, but, no, a lot is lost. And often, no really as a rule, the successor of a departing civil servant, goes to another General Directorate, only arrives after he has left. That is, there is no overlap where you can pass things on. What is completely lost is contacts. If you have contacts to, say, professional organisations, stakeholders or whomever, or to other General Directorates, they are lost completely, they are not passed on. Reports and files are also not drawn up in a way to make them comprehensible, so that the next person cannot understand them. There is no uniform filing system, neither in the Commission itself nor in the departments, everybody does as he pleases. Well, that is an area where much is lost. (P23: EK_899; 83:83)

Earley \& Gibson (2002: 161) state that teams need to create repositories of team knowledge and information (e.g. email archives, electronic versions of reports, meeting notes) to enhance their effectiveness.

The lack of a common archiving-system (information technology) as a support for efficient knowledge management was mentioned by the interviewed persons. With the reform of the European Commission this is changing (Reforming the Commission: A White Paper-Part 1, 2000: 10).

Then, up to now, but this is about to change, there has partly been little culture of documentation in the sense of knowledge management with systematic archives and similar things, which in Austria is a matter of course. Filing plans, fort instance, still haven't been introduced in the Commission, which in Austria is standard procedure down to the army, but in fact very few people have problems adapting. (P6: EK_312; 23:23)

One interview partner gave an example of how to deal with job rotation and its influence on knowledge management. He highlighted the importance of core team Anne-Katrin Neyer - 978-3-631-75440-5 
members, meaning that there are some members who stay in the project for the whole duration as a kind of "knowledge manager".

There has certainly been a relatively strong continuity. Partly changed, but remained at the core, that is there were always memories, not just in paper and facts, but also in the form of informal communication, built-up trust, maybe also mistrust. Even this is possible. (P24: EK_910; 15:15)

\subsection{Team}

\section{Major findings}

The establishment of multinational team norms helps to deal with complexity inherent in multinational teams. Thus, team norms need to be established to ensure an efficient use of the particularities (diversity) of each individual team member.

Multinational teams have to establish both relational (mutual considerateness) and performance-oriented team norms (informal rules, facilitation of communication) to increase their performance.

Mutual considerateness is based on mutual dependency within the team. It is supported by the development of an 'embedded buffer', i.e. "don't feel offended when something does not work like you are used to". Thus, this team norm helps to overcome problems based on culturally determined different e.g. working and communication - styles.

The use of informal rules is an instrument to facilitate communication within a team. The establishment of informal rules within teams allows for the acceleration of the information flow. In times of intensive use of information technology, communication via e-mail is quite often used to overcome hierarchical barriers.

As seen in the integrative diversity approach to study multinational interactions (see Figure 4) based on the literature analysis, the establishment of team norms is crucial for dealing with the complexity inherent in multinational teams: Team norms are an important tool to manage members' behavior as they define the perception and interaction of a team's members, the decision making approach, and the way of how problems are solved (Chatman \& Flynn, 2001: 957). It has to be considered that norms are established and enforced not for every conceivable situation but with respect to behaviors that have some significance for the team (Feldman, 1984: 47).

An organization which delegates a team member, or an organization which establishes teams, could already have established a certain framework of norms for team work. Team members reconcile this framework and develop their own norms of communication and decision making within the given power and deci- 
sion room of the team. The establishment of efficient team norms is related to the 'atmosphere' (Holden, 2002) within a team: Although team members cannot be aware of all situations which might emerge in a multinational setting they can create a conductive and collaborative atmosphere supporting the establishment of efficient multinational team norms. These team norms notably base on repertoires of behavioral norms that are known by individual team members from different contexts, which are in turn influenced by team members' own perceptions, experiences and interests as well as cultural standards. Therefore, efficient multinational team norms are the mutual consensus of all team members of how to deal with their diverse perceptions and cultural standards within the given organizational context. Consequently, the existence of team norms does not mean that team members assimilate to a set of existing norms, which would imply a loss of the benefits of diversity within the team. Efficient team norms are a tool to facilitate interaction within a team, while at the same time making use of the particular knowledge of each team member based on his/her cultural background. Earley \& Mosakowski (2000) refer to these shared team norms as 'hybrid culture'. They define 'hybrid culture' as an "emergent and simplified set of rules and actions, work capabilities expectations, and member perceptions that individuals within a team develop, share, and enact after mutual interaction" (Earley \& Mosakowski, 2000 as quoted by Earley \& Gibson, 2002: 45). Duarte \& Synder (1999) point out that multinational teams have to develop organizational norms and values concentrating on collaboration, respecting and working with people from all cultures, keeping criticism constructive and sharing information.

\subsubsection{Informal rules}

The influence of the hierarchical system on the team work was already mentioned. Individuals in the teams develop their own informal structures to facilitate and accelerate the daily work within the hierarchical organization. It is important for an efficient team work that team members are aware of these rules. The identification of these informal rules is not easy. One of these rules that could be identified within the interviews is the informal way of communication in a team.

[...] and even when you're inside such a hierarchical system, you can still say, before I send a document on a trip, I'll call such and such person, try to clarify things in advance or I simply put it in the mail and wait how it turns out in the end [...]. (P4: EK_208; 16:16) 


\subsubsection{Facilitation of communication}

The use of informal rules is an instrument to facilitate the communication within a team. In particular, the interviewed persons see communication via email as a strategy to overcome hierarchical barriers.

Everything got much easier through e-mails. Because I must not send a director in another General Directorate a note, I am only allowed to officially communicate with directors general of my own level, that is with an official note. But I can send anyone an e-mail. Thus a lot is done informally. Well, I would say, e-mail has changed our working style significantly, quite for the better. (P23: EK_899; 107:207)

The question to whom to send a copy of the email is a question of power: If person A sends a mail to person B the question is whether to send the mail in copy to the team leader or not. The thought behind that is to ameliorate and accelerate the knowledge transfer as informing the team leader is used as a way of exerting pressure.

Much more influenced by e-mail than formal rules, that is by the opportunities e-mail provides, how many people you inform about everything you do. When I write an email to A, I add 5 people in copy or just one, or no one. There is yet little culture in the Commission to systematically include people in copy or generally to include no one. This is developing and much more depends on the individual than on fixed rules and I don't see any difference depending on a person's nationality. (P6: EK_312; 27:27)

\subsubsection{Mutual considerateness}

Based on the mutual dependency, i.e. the awareness that the particular knowledge of each team member is needed to fulfil the task, the interviewed persons identified the mutual considerateness as factor for the success of multinational team work. Webster Dictionary (online: 07.09.2004) defines considerateness as "kind and considerate regard for others, whereas 'considerate' is defined as showing concern for the rights and feelings of others".

Nevertheless, there are certain rules, you also have to think from a human and the political perspective. Like the bull in the china shop - with this mentality you probably won't get far, unless you're the boss, but not even then. You realise you need the people somewhere. What my first colleague told me, roughly, no matter which civil servant you meet, you'll be friendly in any case, as you don't know where you will meet him again. Funnily enough we met again a month ago, even at work, after not seeing each other for 6, 7 years.. (P15: EK_586; 16:16)

Over the years each individual should develop a kind of "embedded buffer" which encourages showing respect to other cultures. This helps to deal with 
emerging problems based on e.g. culturally determined different working and communication styles.

Occasionally you treat each other roughly, but you never go beyond a certain point. Great store is set by conforming with the rules, although you're very rough content wise. I would say, hurt yes, kill no, and if you hurt, not to leave scars, because we all have to change again and in the end we all depend on each other. That does not mean you don't address the issue, but you don't, I can't remember this ever happening, you don't really get personal. That you say, I won't do this because it's Mister X or mister $Y$, no, it is more businesslike. I mentioned earlier, the negative thing about the Commission is that they don't treat you as a human being, but rather as a thing. The positive effect of this is that it is not about $A$ doesn't get along with $B$ and so on, but once again we're on a factual level. (P12: EK_493; 11:11)

Another important aspect of this team norm is the search for consensus. The general approach to search for consensus is a basis requirement for efficient team work.

Often, everything is about group dynamics, there it depends on knowing where the individual interests lie, what a person's interests are and the interests of another. You don't want to, you are looking for consensus, you do not carelessly isolate anyone or ...unintelligible... exclude north-south, but you're trying to make it more abstract. Everybody has a problem at some stage, there's no one who's going to say yes and fine to everything [...]. And it's the same in meetings, this guy has been sent down from Helsinki, in order to say no, and when he returns and tells them he didn't say no, he's out of a job, or he can say, yes, I said no, but the other 14 all said yes and I was the minority and hard luck $[. .$.$] . (P17: EK_671; 048:048)$

\subsection{Moderators}

\section{Major findings}

The relations between society, organization, individual and team category are defined by moderators: task, team size, and learning process.

The task a team has to fulfil determines the optimal diversity mix within team members. The performance of a team depends on the degree of a task's responsibility assignment: Individuals who know what their task is perform better than those without a clear responsibility assignment. Team performance is also influenced by the type of task (e.g. routine versus special project).

Team size depends on the task a team has to fulfil. In multinational teams, the number of cultures within a team is a crucial success factor. In teams with a large number of cultures it is easier to develop team norms: There is not so much concentration of culturally determined norms of behaviour as it is the case when two or three cultures dominate the team.

To be continued. 
In the latter case, team members of the dominant cultures will insist on their norms of behaviour rather than on the establishment of common team norms.

The empirical analysis shows that the learning process within a team is a main moderator of the relations between the categories in the model. In learning processes members of multinational teams become aware of the various categories that influence team performance and their inherent complexity. They learn about (a) the relations between society, organization, team and individual and (b) the relations within society, organization and team. However, learning processes within teams takes time. The empirical study shows that if the organization itself sets measures (e.g. job rotation) which are not compatible with the time needed for the learning process team work might fail.

The complex relations of the society, organization, individual and team category are influenced by the following moderating variables: the task of the team, the team size including the relevance of the number of cultures in the team, and the learning process.

\subsubsection{Task}

Hackman (1987: 324) defines the task of a group as a "whole and meaningful piece of work, with a visible outcome". The task may determine performance pressure, since a goal has to be met. Rewards for achieving and sanctions for not achieving determine the influence of performance pressure on the behavior of team members and on possible outcomes. The nature of a task determines the needs of resources and skills (Jackson et al., 1995: 218). Based on the definition of the task the question has to be raised: Is there a team needed to solve the problem or is it more efficient to work alone? When deciding for the implementation of a team, an optimal qualification mix (diversity) of team members by educational and cultural background, experience, physical requirements, etc. has to be identified. Consequently, work on the task shows how efficient the team selection and implementation process was and how well the team is performing (Hackman, 1987: 324-327).

Then I worked in a third team in the Commission. That was broader in its tasks, because it included a lot of advising politicians and again we were a mixed team. It was clear right from the start that the advantage of a mixed team, because it was easier when advising politicians to spot sensibilities in the individual member states early, which results in a possible solution compared to another possible solution for a problem or does not result in one and so on. This means, it could be seen most clearly that a team with a very mixed composition certainly increased our problem solving capacity and, in particular, improves our sensitivity towards problems that can lead to different suggestions for solutions and policies. That is, you can thus reduce the time you need to react to problems [...]. (P6: EKK 3.12.03:03) 


\subsubsection{Responsibility assignment}

The responsibility assignment influences the output of a team. If each individual team member is aware of his/her task then the output will be higher.

Everybody should be fully aware of his objectives, about his role in the team and not try to shirk responsibilities. If it is not clear who has to coordinate things, this might lead to problems. Everybody should see himself in the team's output and find himself reflected individually. (P5: EK_261; 35:37)

The complexity of a task is described by the required acts and information cues and sets up the upper limits on knowledge, skills, and resources individuals need to fulfil a task (Earley \& Gibson, 2002: 149). The acceptance of the responsibility assignment and the qualitative fulfilment of the task is influenced by the complexity of the task (routine versus special project) as this defines how often the team and therefore the single team member is in contact with a hierarchically higher positioned person. This might directly influence the personal career development and is therefore determined by personal interests of a single team member (team versus personal interests). Thus, it can be assumed that the responsibility assignment is crucial for the transfer of knowledge within the team.

I have task areas, for example, where there is so much work to do which is distributed randomly, with the aim of providing equal workloads to everyone, so that no one has to struggle to do anything in particular. Then again, I could be in a department, where I know this year there are so and so many routine tasks and a project of which I know I will present to the Director General three times, where everybody is really keen to get the project and not the routine tasks assigned. (P6: EK_312; 58:58)

\subsubsection{Team size}

Team size has to be large enough to fulfill the task, meaning that sufficient resources (manpower, time), sufficient capabilities and knowledge must be available. In consensus driven teams it seems to be easier to reach consensus among a smaller than a larger group. Therefore, large multinational teams might not be as efficient as smaller teams (Hackman, 1987: 327). At least, this is a proposition also often raised in the context of the enlargement of the European Union.

\subsubsection{Number of cultures in a team}

On the other hand, it can be assumed that the larger the team and the more culturally different the members in the team are the more easily the occurrence of bilateral conflicts might be reduced. If two groups with different values and norms have to interact in one team, then the adoption of either norms A or B as team norms becomes the core of a power game with a good chance to escalate and to become a stalemate confrontation. As the number of encounters grows by $\left(n^{2}-n\right) / 2$ 
the importance of a single clash of norms decreases by $2 /\left(n^{2}-n\right)$. Beyond eight team members with diverse national backgrounds of values and norms it will be difficult for a team member to take note and assess all those clashes. Therefore, the importance of clashes becomes small enough to give room for adopting new reciprocal team norms that serve the interest of all team members. Consequently, it can be assumed that the likelihood to succeed with the establishment of new team norms is increases with diversity among team members (Fink et al., 2004b).

I have to say, in our team German-speaking countries are strongly represented, I particular, of our 8 people 3 are German, 2 are French, the secretary is Belgian, also quite francophone, and one Austrian, that is me. In our department the Romance countries are heavily represented, there are many French speakers, but on the other hand there are also German speakers, extraordinarily many German speakers. We are three Austrians, in total we are 43 people of which three are Austrian, I have never seen anything like it, that is we have a strong element of German/French colleagues in the department and this certainly influences our work. (P7: EK_357; 15:15)

\subsubsection{Learning process}

Learning processes within teams help to overcome insufficiencies in the action repertoires of individuals and the organization itself (e.g. organizational culture, organizational structure) (Stern, 1997: 70). Reflection on team processes increases awareness of team members and fosters learning processes, which in turn (in analogy to Argyris \& Schön, 1974) could help to make things right, but also to make the right things.

The learning process of individual team members and the team itself is directly influenced by power and interests of the individual team members and the particular organization. Conflicts of interest, the desire to gain or maintain power, or the wish not to subordinate oneself have an influence on team learning and consequently on team performance. Interests of individuals are influenced by the social system into which they are embedded (the contextual organization), by their personal needs, income, experience and stock of knowledge.

[...] With this adaptation, the fact that you change, I would say, because of this constant exchange and watching and partly copying behaviour and so on. But also, in order to better understand where you frequently stand with certain nationalities, you behave indeed differently, because you respect that. During the learning process you often get a bloody nose or are confused or offended or whatever. In the meantime, when a Dutchman approaches me directly and says he doesn't find that particularly good, I don't immediately get this strange feeling in the stomach, he attacks me personally, but listen first what he has to say. And I know it isn't personal and so the 
learning process and the adaptation process are really important. (P10: EK_461; 46:46)

\subsection{Recommendations for managers and researchers}

This chapter has presented results of the empirical study in the European Commission. The analysis of the interviews followed the theoretical framework which highlighted three major research aspects. These aspects allow for a deeper analysis of multinational team work and are summarized in the following. Additionally, this section aims to develop propositions for future research which are deduced from the empirical findings of multinational team work in the European Commission. The propositions concern the previously identified categories of influence on multinational team performance. Managers can use these propositions as guidelines to analyze potential issues in their teams.

- Research Aspect 1: Which categories influence the performance of multinational teams?

Research aspect 1 analyzes categories that influence the performance of multinational teams. Categories that affect multinational team performance are identified and arranged in an integrated model.

- Research Aspect 2: Are these categories related? If yes, how are they related?

The analysis of categories influencing multinational team performance derives from a complex set of influences and needs to consider the context of the particular organization.

Recent research on multinational team work investigates only a few variables in the particular categories (society, organization, individual, team and moderators) which have been identified through the interviews. As seen in the literature analysis the statistical significance of a variable might change when other variables are added. The empirical study shows that there are mutual causal relations between categories and that the categories are highly interdependent. Therefore, the model (figure 9) as presented below integrates all of the identified categories and shows its relations. However, in order to reduce complexity it does not include all the details of the data analysis. A summary of the complex relations between the various variables of each category is presented in appendix C. It shows the source of difference in each category and the characteristics of the specific source of difference within the category. Then it highlights how variables from other categories influence the category under study. Finally, it is shown if and how the specific category has an impact on a) other categories determining team performance or $b$ ) if it directly influences team performance. 
FIGURE 9: FIVE CATEGORIES DETERMINING TEAM PERFORMANCE: THE COMPLEXITY MODEL OF MULTINATIONAL TEAM PERFORMANCE

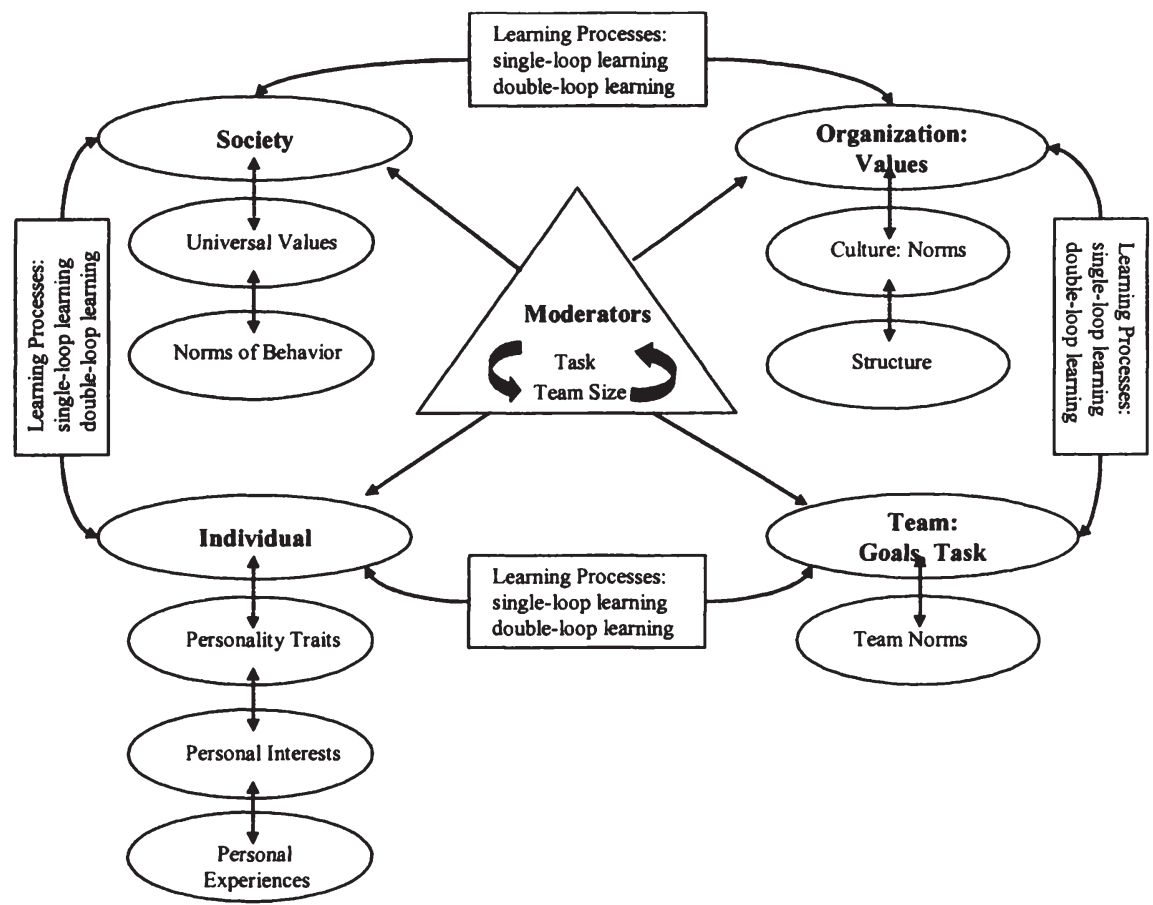

Source: Analysis of interviews

The model contains five categories of influence on multinational team performance: society (cultural values and culturally determined norms of behavior), organization (organizational culture and organizational structure), individual (personal interests and motivations, personality traits, and personal experiences, i.e. past international assignments and educational background), team (team norms) and moderators (task, team size and learning process). The model is illustrated in figure 9; its description is done clockwise starting from the left.

\section{Society}

The first category consists of factors that concern the culturally determined source of diversity within a multinational team. It highlights the relevance of cultural values and culturally determined norms of behavior for the efficient multinational team work. Whereas most of the studies in literature analyze the relation between cultural values (e.g. individualism, collectivism, power distance etc.) and 
team performance, the empirical part of this study underlines that not cultural values per se, but the experienced culturally determined differences in norms of behavior (which are indirectly reflected by cultural values) influence the output of multinational team work.

Proposition 1: In multinational teams culturally specific norms of behavior are indirectly reflected by cultural values.

Culturally determined norms of behavior: In particular, two culturally determined norms of behavior can be identified: different ways of criticism and different working styles. The diversity in these norms of behavior can be mainly explained by dividing team members in two main groups- those from the South of Europe and those from the North of Europe. Ignoring the influence of the other categories in the model, it can be said that people from the South prefer a more "indirect" way of criticism whereas those from the North are more direct in their criticism. In the way of how work is done, people from the South prefer a more process-orientated approach whereas people from the North are more goal oriented. Depending on the degree of difference, meaning where on these two sides of the working-style continuum each team member is situated, problems in the interaction might occur.

Proposition 2a: Culturally determined norms of behavior influence multinational team performance.

Proposition $2 b$ : There is an inverse relationship between culturally determined different ways of criticism and the performance of multinational teams.

Proposition 2c: There is an inverse relationship between culturally determined differences of working styles and the performance of multinational teams.

Cultural values: The empirical study shows that members of multinational teams link cultural values to personality traits. If in the team work problems occur, the personality of a person is seen as a more relevant explanation factor than differences in cultural values. The influence of cultural value dimensions on multinational team performance is overwritten by personality traits of the individual team members.

Proposition 3: In multinational teams, a fit of personality traits between team members is more important than similarities in cultural values to perform efficiently. 
Language: Another aspect of this category is language. In multinational teams the communication in a second language is an under-considered stress factor. However, in the empirical study the "language" challenge was seen more as a hindrance to multinational team performance than cultural differences per se. The need to communicate in a second language might impair the active participation in the team work. Additionally, it can reduce the ability of placing key information within the team. Speaking in a second language increases the potential of misunderstandings. This slows down the trust building process within the team, which has negative impact on team performance.

Proposition $4 a$ : Speaking in a second language is positively related to the feeling of stress.

Proposition $4 b$ : The need to speak in a second language negatively effects the individual contributions to task achievement of a team.

Proposition 4c: The communication in a second language is a potential factor for misunderstandings in multinational teams. Misunderstandings between team members are inversely related to team performance.

\section{Organization}

The second category of factors which determine the performance of multinational teams derives from the organizational context. It includes factors which can be influenced by the organization itself. It is in the hand of the organization to define and regulate these factors considering its organizational environment and strategic thoughts. Ignoring the other factors of the integrated model, this category allows the organization itself to take the right steps to establish well-performing multinational teams and to foster their development.

Organizational culture: The organizational culture of an organization is linked to the cultural values of the organizational founders and their core groups. House et al. (2004: 77-78) underline that, "if people from a given society share schemas, then the organizations within that society are likely to have structures and cultures that reflect those schemas".

Proposition 5a: Organizational culture is influenced by societal culture.

Proposition 5b: Members of multinational teams who are socialized within the predominant societal culture of the organization adapt to the organizational culture more easily.

Individuals might perceive the organizational culture in a different manner than defined by the organization itself. The empirical study puts emphasis on the perceived kind of organizational culture in contrast to the explicitly defined organiza- 
tional culture as influencing factor on team performance. The perceived kind of organizational culture might differ from department to department within the same organization.

Proposition 6a: Team members' perception of the organizational culture actually experienced in their daily work might be different from the explicitly defined organizational culture by the organization itself.

Proposition $6 b$ : In order to establish well-performing multinational teams, managers/team members have to be aware of the perceived kind of organizational culture. The organizational culture influences the establishment of a team culture (or not) and fosters the motivation to achieve a task (or not).

Culturally determined differences in norms of behavior foster the development of a kind of "culture of tolerance" within the organization under study. This might have a positive or negative impact on team performance. The feeling of working in a "low-trust culture" restrains the development of a team culture and negatively influences team performance. As the organization under study is a bureaucratic organization, another aspect of the perceived kind of organizational culture is the feeling of "being a human machine in the organization". This feeling has direct impact on the personal motivation. Results of this study show that it is a negative relation.

The explicitly defined organizational culture identified in the empirical study deals with the huge number of diverse languages in the organization. The organization has implemented what is called "Eurospeak", which is a mix between English and French.

Organizational structure: The organizational structure of an organization is an essential factor which influences the performance of multinational teams. In a bureaucratic organization hierarchical structures have an impact on the performance of teams. Based on the historical and national roots of a department, hierarchy is of particular importance (French system) or not (Anglo-Saxon system).

Another important aspect of the organizational structure is the performance appraisal system (see also: Kirkman \& Den Hartog, 2004: 250-253), i.e. the system an organization uses to reward its employees. If an organization is interested in team work, then it has to establish a reward system that considers team performance and not only individual performance. If this is not the case, this might negatively influence the establishment of a team culture and the team work. This leads us to another key factor: The implemented appraisal system must be adapted to the particular organization. According to the empirical study, problems in team work emerge when a rewarding system which is particularly used by profitorganizations is implemented in a public, bureaucratic organization. 
Proposition 7a: An inadequate performance appraisal system might have negative impacts on a) the establishment of a team culture and b) on an already existing team culture.

Proposition 7b: Performance appraisal systems need to be adapted to the needs of the particular organization.

Job rotation is a further aspect of organizational structure and the latter influences team performance. The findings of the study give evidence that a high mobility of employees might negatively influence the knowledge transfer willingness of team members as it hinders the development of a trust-based team culture.

Proposition 8a: Job Rotation might be inversely related to a clear identification with the team.

Proposition 8b: A lack of identification with the team leads to a lack of loyalty and trust within the team.

Proposition 8c: Job Rotation has negative effects on knowledge transfer among team members. However, it might allow bringing new knowledge in the team.

\section{Individual}

The third category of factors driving multinational team performance comprises sub-categories which can be influenced only by the individual team member itself. Ignoring the other categories of the model, the behaviour of the individual in multinational teams is influenced on the one hand by "non-visible" and on the other hand by "visible factors". Non-visible factors are personality, personal experiences and personal interests/motivation. Visible factors are those which are readily detectable for all team members (e.g. educational background). Personality, personal experiences and personal interests/ motivation are interactively related. However, it is quite difficult to be aware of possible overlaps of the nonvisible characteristics of the single team members. Similarities and differences in this category will become obvious not until the interaction of the individual team members.

Personality: People are socialized within a specific society and consequently, cultural values of this society support the conformity in the ways individuals think and act (Brannen et al., 2004: 46). Nevertheless, people are also individuals which are characterized by their own personality. In the literature, talking about personality means talking about personality traits, i.e. relatively stable, unique characteristics of individuals (Brannen et al., 2004: 46). It was already highlighted that in multinational teams a fit in personalities of the individual team members seems to 
be more important than similarities in cultural values. However, it cannot be ignored that these two constructs (i.e. the sociological and the psychological characteristics of an individual) are related. It is difficult to imagine that in collectivistic countries solely individuals with individual-oriented personality traits live.

Proposition 9: Personality traits of individuals in a given society are positively related to cultural values of this society.

Personal experiences: In multinational teams personal experiences are predominantly expressed in terms of past international assignments. Individuals who have already lived abroad and worked in multinational settings might integrate in multinational teams more easily. Past international assignments and working experiences in multinational teams foster the ability to understand implicit informal rules and norms in those teams. Being aware of the complexity of the influencing categories on multinational team performance allows for an efficient use of diverse knowledge of the other team members. Experts in multinational team work can further and encourage the establishment of efficient team norms as they are aware of the interrelations of the categories in the model: If one category is not considered or its influence is not taken seriously the whole model will be influenced - including team performance.

Proposition 10: Multinational team performance can be increased if there is at least one efficient multinational team work-expert in the team.

Personal interests and motivations: Personal interests and motivations of team members have an impact on efficient team work. The study underlines that the individual's career development stage influences the interest to participate more or less in team work. However, contributing to team work might not automatically mean being interested in the success of the whole team. This is influenced by individual's attitudes towards being a team- or a single player and can be implicitly affected by the organization itself (e.g. through a team-adapted job performance appraisal system). Additionally, an individual's motivation to work in a specific team, or more generally in a specific organization, is of relevance for multinational team performance. In international public organizations the feeling of contributing to something useful and important for the general public has a positive impact on team performance. 
Proposition 11a: Personal interests of team members influence multinational team performance.

Proposition 11b: Personal interests are influenced by personality traits and can be affected by the organization. Organizations might have structures which do (not) support individual's orientation towards teams (e.g. teamadapted job performance appraisal system).

Educational background: is a visible characteristic of team members in multinational teams. Depending on the task a team has to fulfill, a mix of educational backgrounds is necessary or not. The empirical study underlines the existence of communication problems not as a result of cultural differences but because of diverse educational backgrounds of team members. Additionally, it has to be considered that even if team members have the same educational background, the education might be different in various countries. This leads to misunderstandings and slows down decision-making of teams. Therefore, task is a crucial element in the team performance process, as it deals with the question of the degree of diversity needed within the team.

Proposition 12: Depending on the task, diverse educational backgrounds of team members allow for efficient problem solutions. However, diverse educational backgrounds might slow down the decision-making of teams.

\section{Moderators}

The relations between society, organization, individual and team category are defined by the moderators (task, team size, learning process).

Task: The task a team has to fulfil determines the optimal diversity mix within team members. Thus, with the definition of task the optimal degree of the diversity needed within team members or conversely the optimal degree of individuals' overlaps of the categories in the model is defined. The performance of a team depends on the degree of a task's responsibility assignment: Individuals who know what their task is perform better than those without a clear responsibility assignment. Team performance is also influenced by the type of task (e.g. routine versus special project).

Proposition 13a: The task of a team defines the needed degree of diversity in the society and individual category.

Proposition 13b: A clear task responsibility assignment is positively related to team performance. 
Team size: Team size depends on the task a team has to fulfil. According to the task the optimal team size needs to be defined. In multinational teams, the number of cultures within a team is a crucial success factor. In teams with a large number of cultures it is easier to develop team norms: There is not so much concentration of culturally determined norms of behaviour as it is the case when two or three cultures dominate the team. In the latter case, team members of the dominant cultures will insist on their norms of behaviour rather than on the establishment of separate team norms.

Proposition 14: The more cultures are represented in a team the less conflicts occur due to culturally determined norms of behaviour and the easier it is to establish efficient team norms.

Learning process: In the learning process members of multinational teams become aware of the various categories of influence on team performance and their inherent complexity. They learn about (a) the relations between the society, organization and individual category and (b) the relations between the subcategories in the categories. They use this knowledge to establish their team. In a next step, reflection on team processes increases awareness of team members and fosters learning processes, which in turn (in analogy to Argyris \& Schön 1974) could help to make things right, but also to make the right things. Learning processes within teams in a particular organization consist of single-loop and double loop-learning (Argyris, 1999). "Whenever an error is detected and corrected without questioning or altering the underlying value of the system, the learning is single-loop" (Argyris, 1999: 68). Single-loop learning is appropriate for routines, meaning that it supports to get the everyday job in a team done (Argyris, 1999: 69). Double-loop learning is characterized by learning "when mismatches are corrected by first examining and altering the governing variables and then the actions" (Argyris, 1999: 68). It is more relevant for complex issues and may even lead to adaptation of values if 'old value structures' are perceived as obsolete (Argyris \& Schön 1974). Thus, the implementation of new HR practices in the European Commission should be accompanied by a cultural and structural change in the long run.

Learning processes within teams take time. Multinational team members need time to understand one another's behaviour, to identify mutually agreeable ways of working together and to judge one another's capabilities (Ravlin et al., 2000: 40). The empirical study shows that if the organization itself sets measures (e.g. job rotation) which are not compatible with the time needed for the learning process the idea of team work might fail. 
Proposition 15a: The learning process within teams is crucial for the success of multinational teams.

Proposition 15b: Multinational teams need time to undergo learning processes.

Proposition 15c: Organizations need to be aware that their structures influence the learning process within teams.

The literature underlines that simply providing teams with the opportunities to interact does not automatically lead to the elimination of negative effects of multiculturalism (Ravlin et al., 2000: 40). To deal with these problems, teams need to perceive process-related feedback to use the learning process over time for the improvement of team interactions (Thomas, 1999).

The empirical analysis shows that the learning process over time within a team is a main moderator on the relations between the categories in the model. An active, supervised learning process facilitates the establishment of the category "team". However, the desired and really needed degree of supervision on part of the team members might depend on their personality and personal interest and their cultural background.

Proposition 16: If learning processes within teams are supervised (by the team leader, by team members themselves), the establishment of team norms is facilitated.

- Research Aspect 3: How do individuals cope with the complexity of working in multinational teams?

This research aspect addresses the analysis of coping strategies for problems inherent in the complexity of working in a multinational team. The last category of the model, i.e. team, focuses on this research aspect.

\section{Team}

This category comprises the established and used team norms. According to the empirical results team norms can be defined as the mutual consensus of all team members on how to deal with their possible diversity in the society and individual category, influenced by the characteristics of the organization and moderated by task and team size. Thus, team norms need to be established to ensure an efficient use of the particularities (diversity) of each individual. Consequently, the existence of team norms does not mean that there is an assimilation of team members which goes hand in hand with the loss of the benefits of the diversity within the team members (which is the reason why multinational teams are established). 
They are a tool to facilitate the interaction while at the same time making use of the particular knowledge of each team member based on its individual and society background and influenced by the organization.

The findings of this study show that multinational teams establish both relationship and performance-oriented team norms to increase their performance.

Proposition 17: Team norms support the use of particularities of each team member and help to deal with the complexity of multinational teams caused by diversity in the society and individual category and the organization.

Proposition 18: Performance-oriented team norms need to be complemented with relational norms to increase the benefits of multinational teams.

Mutual considerateness: This team norm is relationship oriented. Mutual considerateness is particularly influenced by the learning process within teams. Developing an "embedded" buffer, i.e. don't be harmed when something does not work like you are used to, supports mutual considerateness and is a pre-condition for the success of multinational teams. Therefore, mutual considerateness is a team norm that helps to overcome problems based on culturally determined different e.g. working and communication styles.

Proposition 19a: Mutual considerateness helps multinational team members to cope with their inherent diversity (e.g. culturally determined different working and communication styles).

Informal rules and facilitation of communication: The use of informal rules is an instrument to facilitate the communication within a team. These two norms are performance-oriented. The establishment of informal rules within teams allows for the acceleration of the information flow. In times of intensive use of information technology, communication via e-mail is quite often used to overcome hierarchical barriers.

Proposition 19b: Informal rules help to overcome organizational barriers (e.g. hierarchy) and consequently accelerate the flow of information within the team. 


\section{Empirical Findings in the European Parliament}

In contrast to the interviews in the European Commission, most of the interviews in the European Parliament were not recorded on tape. After two interviews it was recognized that only standardized sentences were uttered by the politicians. This changed when notes were taken by hand. Consequently, the transcripts are shorter than those in the European Commission. On average the interviews take between 25 and 30 minutes. According to the qualitative content analysis (Mayring, 2003) several categories could be identified as being worthwhile for the multinational team work in the European Parliament (Table 13).

Table 13: Five categories of influence on multinational team performance in the European Parliament

\begin{tabular}{|c|c|c|}
\hline Category & Sub-category & Codes \\
\hline \multirow[t]{4}{*}{ Team } & \multirow[t]{4}{*}{ Team norms } & Informal working and networking \\
\hline & & Discussion-culture \\
\hline & & Culture of compromise \\
\hline & & Mutual respect \\
\hline \multirow[t]{2}{*}{ Society } & $\begin{array}{l}\text { Culturally determined } \\
\text { norms of behavior }\end{array}$ & $\begin{array}{l}\text { Cultural differences in communication } \\
\text { styles }\end{array}$ \\
\hline & & Language proficiency \\
\hline \multirow[t]{2}{*}{ Organization } & Organizational culture & \multirow{2}{*}{$\begin{array}{l}\text { Rules of procedure of the European } \\
\text { Parliament }\end{array}$} \\
\hline & $\begin{array}{l}\text { Organizational struc- } \\
\text { ture }\end{array}$ & \\
\hline Individual & $\begin{array}{l}\text { Individual team mem- } \\
\text { ber }\end{array}$ & Educational background \\
\hline \multirow[t]{3}{*}{ Moderators } & & $\begin{array}{l}\text { Task - three fundamental powers } \\
\text { (legislative power, budgetary power and } \\
\text { supervisory power) }\end{array}$ \\
\hline & & $\begin{array}{l}\text { Rules of procedure of the European } \\
\text { Parliament }\end{array}$ \\
\hline & & Austrian versus European interests \\
\hline
\end{tabular}

Source: Analysis of interviews and analysis of rules of procedure of the European Parliament

It is important to note that team members in the European Parliament strongly emphasize the establishment of team norms as a success factor of multinational teams. Therefore, the analysis starts with team norms, then explaining the other categories: society, organization, individual and moderators. Not all of these categories can be supported with interview data. However, as team norms are explained in detail by the interview partners, they can be used to draw conclusions. Additionally, further information concerning the description of the categories can 
be gathered through an in-depth analysis of the rules of procedure of the European Parliament.

\subsection{Team}

The identified team norms are: informal working and networking, discussionculture, culture of compromise and mutual respect. These five norms are interacting.

\subsubsection{Informal working and networking}

According to the interviews, informal working and informal meetings enable a better interaction between the individual members. This norm is strongly related to networking. Both factors are influenced by trust. The trust building process is supported by informal meetings as they allow room for getting to know each other and to understand what the personal background of the counterpart is. This might lead to a better mutual understanding of the others' behaviours. If there is mutual trust the building of networks might be facilitated. The knowledge of from where to get the needed information increases the chance to efficiently (in quality and on time) fulfil a task. The interviews show that the interviewed persons are aware of the relevance of these two norms for successful team work and use them in their interactions.

This does not lead to problems as long as you listen to each other and help each other out and this only works if there's a positive climate in the group. So how can you create this positive climate? I'm the coordinator responsible for the internal committee. I make sure there are informal meetings outside working hours, so you can learn about the national backgrounds of the others. I'll give you an example: I have a colleague who is not uncomplicated, critical, opposed to his faction's position. Now, if you know him personally, you know this is so because he has problems in his own country, there is no support from his own party [...]. (P3: EP_188; 03:03)

\subsubsection{Discussion-culture}

Another main team norm is the way of how things are discussed among team members as this influences the output. In the European Parliament the culture of discussion as perceived by the interview partners can be described as objective and not based on personal attacks. The culture of discussion is influenced by the society-category, meaning that the cultural background of a person might influence the communication style. However, this relation is moderated by the organizational category: e.g. the Rules of Procedures of the European Parliament defines rules of how long each team member might talk. 
Very good, very high level also regarding the politeness shown when interacting with others. Not like on the national level, there are quarrels but to an acceptable extent. You don't dish dirt, but treat each other with respect. Of course the Italians talk longer, while a Brit gets to the point in 20 seconds. But there are restrictions on how long you can talk. (P12: EP_745; 17:17)

\subsubsection{Culture of compromise}

The interview partners identified the culture of comprise as factor for successful interactions. In the political environment compromises have to be found in order to come to a European solution. Thus, the established successful behaviour is "I support you and substitutional you support me" rather than "either you or I". This is highly influenced by the moderator "Austrian versus European interests". However, in order to efficiently achieve the Austrian aims, team members have to be aware of the game of compromises.

The European ideal is disproportionately strong, naturally some national enthusiasm also comes in. The important thing is how you approach a problem. Not, "I want this", but "how can I present my wishes to fit them into the general context". You can't have 100\%. There has to be some filter first, how much must I yield, how much do I have to accept. From Vienna you often hear, and that is very important, you have to accomplish this or that, but that's the wrong approach. (P11: EP_708; 21:21)

\subsubsection{Mutual respect}

The objective discussion culture and the culture of compromise particularly exist because of the establishment of mutual respect amongst the team members as a relevant norm to facilitate team work. These findings are consistent with the results in the European Commission. However, in the literature empirical studies dealing with the role of mutual considerateness and respect as an influencing variable on multinational team performance are more or less neglected.

[...] Thirdly, good manners are important. Only here do you notice how different we are. What gets on a Scandinavians nerves, is the minimum of politeness for a Spaniard. (P11: EP_708; 06:06)

\subsection{Society}

\subsubsection{Cultural differences in communication styles}

In accordance to the findings in the European Commission the interviewed persons in the European Parliament identified a kind of North versus South difference in the communication styles. As in the European Commission the major dif- 
ference can be seen in the "straight-to-the point" communication in the North versus an indirect communication style in the South.

When talking to the German representative I come straight to the point, without detours and pleasantries, that's the direct way. With Italians or Greeks I first engage in some small talk about the nice Greek isles, then you get to the point. It's all more general, less precise. It's simply different cultures interacting with each other. And therefore there's a code of behaviour. If a Greek has the floor, you know there will be a certain run-up until he gets to the point. It is all very positive, you learn from one another. (P3: EP_188; 13:13)

\subsubsection{Language proficiency}

The role that language plays in the multinational interactions was mentioned together with the fact that official meetings are interpreted. Within the interpretation process a lot of emotions are reduced. This might be positive as possible offending statements could be diminished through the interpreter, but in contrast also tension-loosening comments (e.g. jokes) get lost. Additionally, it has to be considered that in informal meetings at least basics in English and/or French language are necessary in order to interact successfully. If the interviewed persons have to work in a foreign language there is a perceived kind of "pressure", as also seen in the European Commission. However, mutual respect might reduce this feeling.

Language is a problem: everyone thinks he has the right to talk in his official language. It is possible, when you talk in a foreign language, for things to com across more strongly than you intend. (P5: EP_384; 21:21)

[...] However, you have to consider that, like on a national level, politics is made in the pub. You have to speak languages, after all, you represent the people who elected you...If you speak languages, you know what's behind the words, then it's easier to understand [...]. (P9: EP_472; 17:17)

\subsection{Organization and Individual}

In contrast to the European Commission the organizational category was not directly identified as an important influencing factor on team performance by the interviewed persons. However, team work is influenced by the Rules of Procedures of the European Parliament. Thus, e.g. the culture of discussion in an official meeting is influenced by the rule 120 ("allocation of speaking time") of the rules of procedure of the European Parliament. In point 4 (rule 120) it is said that "no member may speak for more than one minute on any of the following: the 
minutes, procedural motions, amendments to the final draft agenda or to the agenda" (rules of procedure of the European Parliament).

In the individual category the interview partners highlighted the relevance of the professional competence of their team colleagues in order to perform efficiently. In contrast to the European Commission they did not mention the role the so-called 'non-visible' individual variables (e.g. personality, personal experiences and personal interests) play in multinational teams. It can be assumed that the strengthened existence of multinational team norms is overlaying the differences on the individual level.

\subsection{Moderators}

The tasks of the members of the European Parliament are clearly defined by its three fundamental powers: legislative power, budgetary power and supervisory power (http://www.europarl.eu.int/presentation/default en.htm).

In contrast to the European Commission the composition of team members as well as the team size in the committees is defined by the Rules of Procedure of the European Parliament. Rule 152 (Point 1) states the following: "Members of committees and committees of inquiry shall be elected after nominations have been submitted by the political groups and the Non-attached Members. The Conference of Presidents shall submit proposals to Parliament. The composition of the committees shall, as far as possible, reflect the composition of Parliament."

As the members of the committees are elected there is no discussion possible about the optimal degree of diversity within the teams in the various committees of the European Parliament. This might explain the high degree of established team norms: Being aware that there is no other possibility than working together fosters the establishment of such norms in order to improve and facilitate the team work.

The interaction of individual members is also characterized and moderated by the consideration of Austrian interests versus European interests. Team members are caught between the devil and the deep blue sea to find a path between Austrian and European interests in the team work. This is another significant moderator as it directly leads to the establishment of the team norm "culture of compromise".

\subsection{Summary}

This chapter has presented results of the empirical study in the European Parliament. The analysis of the interviews followed the theoretical framework which highlighted three major research aspects:

- Research Aspect 1: Which categories influence the performance of multinational teams? 
- Research Aspect 2: Are these categories related? If yes, how are they related?

- Research Aspect 3: How do individuals cope with the complexity of working in multinational teams?

The collected data (which are not as profound as those in the European Commission) are related to the propositions derived from the empirical findings in the European Commission (see Table 14). In summary, the findings emphasize the relevance of context-dependent research and the role that team norms play in multinational teams. Nearly half of the propositions developed in the context of the European Commission are only similar, are different or there were no incidents reported in the European Parliament due to the diverse contexts of research (multinational teams in a bureaucratic administration versus multinational teams in a political context). However, in the society category more or less the same results as in the European Commission could be identified in the European Parliament, meaning that there is a South- versus North categorization of team members' behavior. This conclusion is inconsistent with my own findings underlining the relevance of context-dependent research particularly in the "organization" category. Additionally, it is inconsistent with Milliken \& Martins' (1996) findings that context may have an effect on whether differences are noticed and how single team members react. However, it has to be corsidered that in the European Parliament and the European Commission the same nationalities are represented. This might explain why the culturally different norms of behavior are perceived as being the same in the European Parliament and the European Commission.

The highlighting of the importance of the existence of team norms by the interview partners supports that future research should focus on this part of the complexity model of multinational team performance as it seems to be one of the most influencing factors to increase the efficiency of a multinational team.

In the analysis of the interviews it becomes clear that the methodological approach chosen for studying multinational teams in the European Parliament was not the most appropriate one. As already said before, it was not easy to approach the politicians with the narrative interview method, trying to learn about their personal experiences in multinational teams and not about predefined political statements. The interviews were highly influenced by the so called 'social desirability' bias (SD-bias). Own value identity and interests of the interview partners and the values of the political party (party platform) the interviewed persons belong to have influenced the interviews. Because of this issue, a quantitative approach might be more appropriate. Stocké (2004) shows that besides other characteristics response privacy reduces the SD bias in quantitative research. However, this may be counteract by the effect of privacy leading to the temptation to answer according to the underlying SD values within a society or more precisely the values of the political party and own interests of the respondent. 
Consequently, for future research into multinational teams in a political context the "social network analysis" seems a possible tool to learn more about the complexity of these multinational teams. Mitchell (1969) defines a social network as "a specific set of linkages among a defined set of persons, with the additional property that the characteristics of these linkages as a whole may be used to interpret the social behaviour of these persons involved." (Mitchell, 1969: 2-3). This methodological approach will support the analysis of the complex relations of the five categories of influence on multinational teams: society, organization, individual, team and moderators.

\section{Table 14: Comparing the propositions derived from the empirical analysis in the European Commission with the findings in the European Parliament}

\begin{tabular}{|c|c|c|c|}
\hline Category & Proposition & $\begin{array}{l}\text { Identical/ } \\
\text { Similar/ } \\
\text { Different/ } \\
\text { No incidents } \\
\text { reported in the } \\
\text { European } \\
\text { Parliament? }\end{array}$ & Explanation \\
\hline \multirow{3}{*}{ Society } & $\begin{array}{l}\text { Culturally determined norms } \\
\text { of behavior influence } \\
\text { multinational team } \\
\text { performance. }\end{array}$ & Identical & $\begin{array}{l}\text { The interviewed persons in the } \\
\text { European Parliament mentioned the } \\
\text { cultural differences (particularly in } \\
\text { the communication style) as a factor } \\
\text { influencing the performance } \\
\text { outcome of their teams. }\end{array}$ \\
\hline & $\begin{array}{l}\text { There is an inverse } \\
\text { relationship between } \\
\text { culturally determined ways of } \\
\text { criticism and the performance } \\
\text { of multinational teams. }\end{array}$ & Similar & $\begin{array}{l}\text { The interview partners identified a } \\
\text { kind of North versus South } \\
\text { difference in the communication } \\
\text { styles (straigth to the point versus } \\
\text { indirect communication) as a factor } \\
\text { influencing team performance. } \\
\text { Assuming that communication is } \\
\text { linked to styles of criticizing this } \\
\text { proposition can be indirectly } \\
\text { supported. }\end{array}$ \\
\hline & $\begin{array}{l}\text { There is an inverse } \\
\text { relationship between } \\
\text { culturally determined } \\
\text { differences of working styles } \\
\text { and the performance of } \\
\text { multinational teams. }\end{array}$ & $\begin{array}{l}\text { No incidents } \\
\text { reported }\end{array}$ & $\begin{array}{l}\text { This can be explained by the } \\
\text { existence of strong team norms } \\
\text { influencing the multinational team } \\
\text { work. }\end{array}$ \\
\hline & & & To be continued \\
\hline
\end{tabular}




\begin{tabular}{|c|c|c|c|}
\hline Category & Proposition & $\begin{array}{l}\text { Identical/ } \\
\text { Similar/ } \\
\text { Different/ } \\
\text { No incidents } \\
\text { reported in the } \\
\text { European } \\
\text { Parliament? }\end{array}$ & Explanation \\
\hline \multirow{4}{*}{ Society } & $\begin{array}{l}\text { In multinational teams, a fit } \\
\text { of personality traits between } \\
\text { team members is more } \\
\text { important than similarities in } \\
\text { cultural values to perform } \\
\text { efficiently. }\end{array}$ & $\begin{array}{l}\text { No incidents } \\
\text { reported }\end{array}$ & $\begin{array}{l}\text { This can be explained by the } \\
\text { existence of strong team norms } \\
\text { influencing the multinational team } \\
\text { work. }\end{array}$ \\
\hline & $\begin{array}{l}\text { Speaking in a second } \\
\text { language is positively related } \\
\text { to the feeling of stress. }\end{array}$ & Identical & $\begin{array}{l}\text { One has to be aware that official } \\
\text { meetings are interpreted. } \\
\text { Nevertheless, working in a foreign } \\
\text { language is perceived as a kind of } \\
\text { "pressure" in informal meetings. }\end{array}$ \\
\hline & $\begin{array}{l}\text { The need to speak in a second } \\
\text { language negatively effects } \\
\text { the individual contributions to } \\
\text { task achievement of a team. }\end{array}$ & Similar & $\begin{array}{l}\text { One has to be aware that official } \\
\text { meetings are interpreted. However, } \\
\text { the feeling of "pressure" when } \\
\text { speaking in a foreign language in an } \\
\text { informal meeting might negatively } \\
\text { effect the individual contributions to } \\
\text { task achievement of a team. }\end{array}$ \\
\hline & $\begin{array}{l}\text { The communication in a } \\
\text { second language is a potential } \\
\text { factor for misunderstandings } \\
\text { in multinational teams. } \\
\text { Misunderstandings between } \\
\text { team members are inversely } \\
\text { related to team performance. }\end{array}$ & Different & $\begin{array}{l}\text { This can be explained by the } \\
\text { existence of strong team norms } \\
\text { influencing the multinational team } \\
\text { work. In particular the team norm } \\
\text { "mutual respect" might reduce the } \\
\text { negative feelings related with } \\
\text { communication misunderstandings. }\end{array}$ \\
\hline Organization & \multicolumn{2}{|c|}{$\begin{array}{l}\text { The propositions concerning the role that } \\
\text { organizational context plays for the efficient } \\
\text { function of multinational teams cannot be found in } \\
\text { the empirical findings in the European Parliament. }\end{array}$} & $\begin{array}{l}\text { There were no explicit statements } \\
\text { concerning the role that } \\
\text { organizational context plays in } \\
\text { multinational teams in a political } \\
\text { environment. This underlines the } \\
\text { importance of context-dependent } \\
\text { research. Using another research } \\
\text { approach (e.g. network-analysis) } \\
\text { might help to identify relevant } \\
\text { organizational factors (in addition to } \\
\text { the Rules of Procedures of the } \\
\text { European Parliament) influencing } \\
\text { multinational team work in a } \\
\text { political context. }\end{array}$ \\
\hline & & & To be continued \\
\hline
\end{tabular}




\begin{tabular}{|c|c|c|c|}
\hline Category & Proposition & $\begin{array}{l}\text { Identical/ } \\
\text { Similar/ } \\
\text { Different/ } \\
\text { No incidents } \\
\text { reported in the } \\
\text { European } \\
\text { Parliament? }\end{array}$ & Explanation \\
\hline \multirow{4}{*}{ Individual } & $\begin{array}{l}\text { Multinational team } \\
\text { performance can be } \\
\text { increased if there is at least } \\
\text { one efficient multinational } \\
\text { team work-expert in the } \\
\text { team. }\end{array}$ & $\begin{array}{l}\text { No incidents } \\
\text { reported }\end{array}$ & \\
\hline & $\begin{array}{l}\text { Personal interests of team } \\
\text { members influence } \\
\text { multinational team } \\
\text { performance. }\end{array}$ & Similar & $\begin{array}{l}\text { This proposition can be indirectly } \\
\text { supported when considering the task } \\
\text { of a politician: He/she has to } \\
\text { represent the interests of his/her } \\
\text { country to be re-elected. } \\
\text { Consequently, he/she is caught } \\
\text { between the devel and the deep blue } \\
\text { sea to find a path between Austrian } \\
\text { and European interests in the team } \\
\text { work. }\end{array}$ \\
\hline & $\begin{array}{l}\text { Personal interests are } \\
\text { influenced by personality } \\
\text { traits and can be affected } \\
\text { by the organization. } \\
\text { Organizations might have } \\
\text { structures which do (not) } \\
\text { support individual's } \\
\text { orientation towards teams } \\
\text { (e.g. team adapted job } \\
\text { performance appraisal } \\
\text { system). }\end{array}$ & $\begin{array}{l}\text { No incidents } \\
\text { reported }\end{array}$ & \\
\hline & $\begin{array}{l}\text { Depending on the task, } \\
\text { diverse educational } \\
\text { backgrounds of team } \\
\text { members allow for } \\
\text { efficient problem solutions. } \\
\text { However, diverse } \\
\text { educational backgrounds } \\
\text { might slow down the } \\
\text { decision-making of teams. }\end{array}$ & $\begin{array}{l}\text { No incidents } \\
\text { reported }\end{array}$ & $\begin{array}{l}\text { However, the interview partners } \\
\text { highlighted the relevance of the } \\
\text { professional competence of their } \\
\text { team colleagues to perform } \\
\text { efficiently }\end{array}$ \\
\hline & & & To be continued \\
\hline
\end{tabular}




\begin{tabular}{|c|c|c|c|}
\hline Category & Proposition & $\begin{array}{l}\text { Identical/ } \\
\text { Similar/ } \\
\text { Different/ } \\
\text { No incidents } \\
\text { reported in the } \\
\text { European } \\
\text { Parliament? }\end{array}$ & Explanation \\
\hline \multirow[t]{3}{*}{ Moderators } & $\begin{array}{l}\text { The task of a team defines } \\
\text { the needed degree of } \\
\text { diversity in the society and } \\
\text { organizational category. } \\
\text { A clear task responsibility } \\
\text { assignment is positively } \\
\text { related to team } \\
\text { performance. }\end{array}$ & Different & $\begin{array}{l}\text { This underlines the importance of } \\
\text { context-dependent research: In } \\
\text { contrast to the European } \\
\text { Commission the composition and } \\
\text { size of the team is defined by the } \\
\text { Rules of Procedures of the European } \\
\text { Parliament: There is no discussion } \\
\text { possible about the optimal degree of } \\
\text { diversity within the teams in the } \\
\text { various committees of the European } \\
\text { Parliament. }\end{array}$ \\
\hline & $\begin{array}{l}\text { The more cultures are } \\
\text { represented in a team the } \\
\text { less conflicts occur due to } \\
\text { culturally determined } \\
\text { norms of behavior and the } \\
\text { easier it is to establish } \\
\text { efficient team norms. }\end{array}$ & Similar & $\begin{array}{l}\text { According to the possible large } \\
\text { number of cultures within a team in } \\
\text { the European Parliament (i.e. } 25 \\
\text { cultures possible) and the strong } \\
\text { emphasis on team norms that are } \\
\text { established to support multinational } \\
\text { team work, one can assume that this } \\
\text { proposition is similar in the } \\
\text { European Parliament.. }\end{array}$ \\
\hline & $\begin{array}{l}\text { The learning process } \\
\text { within teams is crucial for } \\
\text { the success of } \\
\text { multinational teams. }\end{array}$ & Similar & $\begin{array}{l}\text { It can be assumed that the existence } \\
\text { of efficient team norms is based on a } \\
\text { learning process. The existence of } \\
\text { efficient team norms is positively } \\
\text { related to team performance. }\end{array}$ \\
\hline Team & $\begin{array}{l}\text { Team norms support the } \\
\text { use of particularities of } \\
\text { each team member and } \\
\text { help to deal with the } \\
\text { complexity of } \\
\text { multinational teams caused } \\
\text { by diversity in the society } \\
\text { and individual category } \\
\text { and the organization. }\end{array}$ & Identical & $\begin{array}{l}\text { The establishment of team norms } \\
\text { was much more highlighted than in } \\
\text { the European Commission. The } \\
\text { organization and individual category } \\
\text { of the complex model of } \\
\text { multinational teams were more or } \\
\text { less not explicitly mentioned by the } \\
\text { interview partners. Therefore, it can } \\
\text { be assumed that the existence of } \\
\text { well-established team norms, like it } \\
\text { seems to be the case in the European } \\
\text { Parliament outweighs the influence } \\
\text { of organization and individual } \\
\text { differences on multinational team } \\
\text { work. }\end{array}$ \\
\hline & & & To be continued \\
\hline
\end{tabular}




\begin{tabular}{|c|c|c|c|}
\hline Category & Proposition & $\begin{array}{l}\text { Identical/ } \\
\text { Similar/ } \\
\text { Different/ } \\
\text { No incidents } \\
\text { reported in the } \\
\text { European } \\
\text { Parliament? }\end{array}$ & Explanation \\
\hline \multirow{3}{*}{ Team } & $\begin{array}{l}\text { Performance-oriented team } \\
\text { norms need to be } \\
\text { complemented with } \\
\text { relational norms to increase } \\
\text { the benefits of } \\
\text { multinational teams. }\end{array}$ & Identical & $\begin{array}{l}\text { In the European Parliament "mutual } \\
\text { respect" is established as a relational } \\
\text { norm. The norms "discussion- } \\
\text { culture", "culture of compromise" } \\
\text { and "informal working and } \\
\text { networking" are established as } \\
\text { performance-oriented team norms. }\end{array}$ \\
\hline & $\begin{array}{l}\text { Mutual considerateness } \\
\text { helps multinational team } \\
\text { members to cope with their } \\
\text { inherent diversity (e.g. } \\
\text { culturally determined } \\
\text { different working and } \\
\text { communication styles). }\end{array}$ & Identical & $\begin{array}{l}\text { The objective discussion culture and } \\
\text { the culture of compromise in the } \\
\text { European Parliament particularly } \\
\text { exist because of the establishment of } \\
\text { mutual respect amongst the team } \\
\text { members as a relevant norm to } \\
\text { facilitate team work. }\end{array}$ \\
\hline & $\begin{array}{l}\text { Informal rules help to } \\
\text { overcome organizational } \\
\text { barriers (e.g. hierarchy) } \\
\text { and consequently } \\
\text { accelerate the flow of } \\
\text { information within the } \\
\text { team. }\end{array}$ & Similar & $\begin{array}{l}\text { According to the interviews, } \\
\text { informal working and informal } \\
\text { meetings enable a better interaction } \\
\text { between the individual members. } \\
\text { The knowledge of from where to get } \\
\text { the needed information increases the } \\
\text { chance to efficiently (in quality and } \\
\text { in time) fulfil a task. }\end{array}$ \\
\hline
\end{tabular}

Source: Analysis of interviews 


\section{General Conclusions}

This chapter concludes the study of multinational teams in the European Commission and the European Parliament. The first section develops practical advice for organizations and team members, based on the results of this study. The second part of this chapter gives recommendations for future research

\subsection{Managerial Implications}

This study emphasizes the complexity of multinational teams. In this chapter, according to the findings of the empirical part of the study, managerial implications for successful multinational teams in the European Commission and the European Parliament will be discussed.

Members and leaders of multinational teams (i.e. in this study employees in the European Commission and politicians in the European Parliament) have to be aware that diversity within teams is not automatically an asset. It enhances the complexity of team work. Therefore, efficient problem solutions within such teams can only be found when being aware of the complexity inherent in multinational teams. A model of the type presented in figure 9 allows for understanding the real complexity of multinational teams. An effective consideration of all categories (and their interrelations) results in team performance. However, disregarding one of the categories (i.e. society, organization, individual, team and moderators) might result in worse performance and might - in the worst case - lead to a non-achievement of the desired objectives. Thus, making managerial efforts to solve problems in one category is highly influenced by the other categories (see Appendix $\mathrm{C}$ for an overview of the complex relations of the relevant categories in the European Commission).

With the conclusions of the empirical part of the study in mind, specific actions will now be discussed which the author believes will help team members/leaders in the European Commission and the European Parliament to work in / manage multinational teams more efficiently. According to the identified categories the managerial implications are organized as follows:

- How to manage cultural differences?

- How to manage 'efficient' multinational team norms?

- What are 'efficient' multinational team norms?

- What role does the team implementation process play?

- What role does the team development process play?

- How to manage the "individual category" and what role does the organizational context play? 


\section{How to manage cultural differences?}

According to the findings in the European Commission and the European Parliament working successfully in multinational teams implies being aware of the culturally determined norms of behavior (CDNB), which all team members bring into the team. As seen in both institutions (where individuals from 25 different cultures work together) the influence of CDNB on the team performance is strongly linked to the numbers of cultures within a team. If there are only two or three cultures within a team, team members and team leaders really have to worry about cultural standards. A kind of power-game might emerge about what norms of behavior (e.g. working, communication, and discussion styles) will be established in the team. It can be assumed that the larger the team and the more culturally different the members in the team are, the more easily the importance of bilateral conflicts might be reduced. Consequently, the larger the number of cultures the less conflict might occur due to culturally determined norms of behavior. This is an important benefit of multinational teams compared to bi- or tricultural teams, as the importance of single clashes becomes small enough to give room for adopting new reciprocal multinational team norms that serve the interest of all team members. The empirical findings in the European Parliament emphasize the existence of multinational team norms in order to overcome the influences that differences in e.g. the individual category might have on team performance. Team leaders have to analyze and support the analysis of differences and similarities in CDNB. They should present them to the team members by some kind of mirror images, i.e. how do I see the other team members, and how do they see me. This is the basis for the development of a common strategy, e.g. a mutual consent about the norms of behavior within the team.

In the empirical analysis it becomes obvious that the efficient management of cultural differences is strongly related to the establishment and development of efficient multinational team norms.

\section{How to manage 'efficient' multinational team norms?}

- What are 'efficient' multinational team norms?

Efficient team norms support team performance. The establishment of team norms does not automatically imply that these team norms are goal oriented, i.e. serving the task achievement. Team leaders and team members have to be aware that a mix of relation-oriented (e.g. mutual considerateness) and performance oriented norms (e.g. informal rules, facilitation of communication, culture of compromise) is needed for efficient multinational team performance. In order to establish 'efficient' multinational team norms, a clear definition of the role of each team member is necessary. In the European Commission, individuals who know what their task is perform better than those without a clear responsibility assignment. Additionally, the overall goal the team needs to achieve has to be defined. 
Being aware of what are efficient team norms is the first step towards a more efficient team performance, taking the right action in order to establish such team norms is the next step.

- The establishment of 'efficient' multinational team norms and the team implementation process

Since it is known that wrong perceptions could have a detrimental impact on future team performance, it is suggested to team leaders/ members that they should be aware of the perceptions within their team. This influences the way of how team members cooperate and how much effort they invest to achieve the goals of the team. In their studies, Ely \& Thomas (2001) and Richard et al. (2003) underline the importance that team members perceive differences as a valuable source. To maximize the chances of successful multinational team work, team leaders should use the team implementation process to provide team members with relevant information about each other so that 'bad feelings' and 'bad' stereotypes cannot emerge and not negatively influence the team process. When with the team implementation process team members get information (context specific stereotypes) that override their prevailing general stereotypes, then there is an improved chance of success. Team implementation therefore has to provide new knowledge, which can be easily grasped and enlarges the available repertoire of modes of behavior of all individual team members. This has a positive impact on the level of satisfaction of individuals and, finally, contributes to team success.

- How to manage the team implementation process to support the development of 'efficient' multinational team norms?

With team implementation a 'qualification profile' of each team member should be made available to all team members and it should be explained why this mix of personalities, qualifications and nationalities would contribute to team success. In the European Commission and the European Parliament individuals from 25 cultural backgrounds work together. Consequently, various settings of cultural combinations are possible within a team. Therefore, the 'qualification profile' should include as a starting point the cultural values inherent to the national backgrounds of team members as a kind of cultural distance-map. Team members have to be made aware that "the map is not the territory, it is simply a picture of the territory" (Brannen et al., 2004: 29). Team members should discuss their perceptions of the national culture they belong to and position themselves in relation to the information provided about their national cultural values. The next step to establish efficient multinational team norms is to go beyond cultural values. It is recommended that team leaders give team members room to discuss and explain to each other (a) what are their perceptions of each others cultures and (b) what are their specific approaches to work styles: communication, negotiation, decision making, progress monitoring, and conflict resolutions. 
This process aims to prepare for the establishment of efficient multinational team norms. It should be supported by the use of established intercultural trainings to figure out what perceptions and what kind of CDNBs are important for each team member individually and therefore should be expressed at the beginning of the team formation process.

- How to manage the team development process to support the development of 'efficient' multinational team norms?

Team members/ leaders who are conscious of team norms which in similar contexts proved successful in the past, and understand the process of how new multinational team norms emerge, can positively influence the development of team norms and thereby contribute to the success of teams. Experienced team members who are aware of the particular needs of multinational teams can be helpful to transfer previously applied team norms, which proved successful, to other teams.

Providing teams with the opportunities to interact does not automatically lead to the elimination of possible negative effects of multinationality (cf. for a multicultural context: Ravlin et al., 2000: 40). To deal with these issues, teams need process-related feedback to unleash learning processes for the improvement of team interactions over time (Thomas, 1999). Therefore, it is of importance that this process is monitored and moderated by team leaders or by external consultants.

How to manage the 'individual category' and what role does the 'organizational context' play?

The establishment of efficient team norms is highly influenced by the individual team member and the organization in which the team is implemented. It can be assumed that the team norms established in a bureaucratic administration or a political environment might not be the most suitable for multinational teams in e.g. a private company.

Although team members' behavior is influenced by general cultural values of the society in which they were socialized, they are all individuals. Individuals are characterized by so-called 'non-visible characteristics', i.e. personality traits, personal interests and perceptions. Personal interests (like e.g. in the European Commission the individual stage of career development) influence the decision of being a single- or a team-player. However, this behavior can be affected by the organization itself. It is of particular importance that organizations offer structures which foster the existence of teams: The use of e.g. a reward system which is more individual than team oriented will have negative effects on the establishment of efficient team norms as seen in the European Commission.

It is not easy to become aware of the non-visible characteristics of team members. State of the art personality tests (like e.g. the Global Personality Inventory Test) help to figure out the personality characteristics within teams. The optimal 
degree of diversity in personality traits has to be defined depending on the task a team has to fulfill. It has to be decided if a mix of personalities or an overlap of personalities within the team enables more efficient performance. Additionally, the existence of strong team norms helps to deal with the issues inherent in the differences of the non-visible characteristics of team members as seen in the European Parliament.

\section{Summary}

According to the complexity of multinational teams it is not possible to offer a nostrum for efficient multinational team work in the European Commission and the European Parliament. However, it can be recommended that individuals who have already experienced this complexity should be appointed "knowledge managers" in multinational teams. Experienced team members have the ability to understand implicit informal rules and norms in multinational teams. They support the efficient use of diverse (culturally based) knowledge of other team members. Last but not least they further and encourage the establishment of efficient team norms. Therefore, at least one multinational-team expert should be within the team in order to achieve the tasks.

Multinational team experts might use the complexity model of multinational team work to explain the complex relations between the five categories of influence (society, organization, individual, team and moderators) to the other team members. The aim of this model is not to terrify multinational teams about the complexity they have to handle, but to provide a kind of check-list supporting the analysis of strengths and weaknesses of multinational teams to foster their performance. Team members/leaders who bear in mind that taking managerial action in one category will always influence the other categories are able to undertake a straightforward analysis of opportunities and challenges within multinational teams.

\subsection{Implications for future research}

The aim of this study was to analyse the complexity of multinational teams in a public-organization context. This setting was chosen as only a few researchers (e.g. Elron et al., 2003) have analyzed teams in a non-profit context so far. Additionally, the European Commission and the European Parliament are research settings where (at least now) almost all of the European nationalities are working together in one organization.

The following conclusions can be drawn from the results of the study and the research process:

- One has to be aware of the needed interdisciplinary research approach when studying multinational team performance. Although e.g. sociology and psychology present different theoretical levels of analysis, the study shows 
that both of them are related and that their relation is essential to explain the research topic.

- In contrast to quantitative research, qualitative data allows for the analysis of social processes. This was crucial for the success of this study as the influential categories on team performance appear in team processes.

Like in any research project, time and manpower limited the results of this study. Consequently, data collection was limited to Austrian team members. This was also caused by methodological issues: In recent research, it was shown that interviewers who are from the same culture than the interview partners achieve better results than interviewers who are from a different culture than the interview partner (Fink et al., 2004a: 12).

Reproducing this study with team members from other countries of the European Union may allow for the refinement of the model. It is assumed that team members from other cultures might emphasize other sub-categories within the main categories of the model than the Austrian interview partners did.

The complexity of the model allows for the presentation of the interdependency of the main categories. Case studies and longitudinal studies might help to understand in more detail the underlying relations between the sub-categories of the model and the inherent processes. It has to be pointed out that results can only present a static view of influencing categories on multinational team performance. With the enlargement of the European Union team members from diverse cultures will join the teams in the European Commission and the European Parliament. This might influence e.g. culturally determined norms of behaviour within the teams.

According to the findings of this study it seems to be interesting for follow-up research to elaborate among other things the following selected research aspects:

- What are the most influential categories of multinational team performance in various organizations (e.g. profit- versus non profit organizations)?

- What role do culturally determined norms of behaviour play in multinational teams?

- How do team members perceive the organizational culture? Is there a gap between the perceived organizational culture and the explicitly defined organizational culture?

- What role does organizational structure, e.g. performance appraisal system, play in multinational teams?

- What kinds of team norms are established? Are there differences in the establishment of team norms according to the organizational context (e.g. profitversus non-profit organizations)?

- How do teams establish team norms? Are they explicitly defined?

- Do teams whose team learning process is supervised establish more efficient team norms than those whose learning process is not supervised? Does 
the desired and actually needed degree of supervision on part of the team members depend on their personality and personal interest and their cultural background? If yes, which individual and cultural characteristics need supervision (or do not need it)?

- What can be learnt from the complexity of multinational teams for other fields of international management (i.e. post-merger-integration phase comparison with team process phases)?

Being aware of its limitations, it is the aim of this study to contribute to the area of multinational team research. It encourages future investigations in this field of research by exploring the complexity and by showing the relations of five categories of influence on multinational team performance: society, organization, individual, team and moderators. 


\section{Bibliography}

Adler, N.J. (1997). International Dimensions of Organizational Behavior, $3^{\text {rd }}$ edition. Cincinnati, Ohio.

Argyris, C. (1999). On organizational learning, $2^{\text {nd }}$ edition. Mass.

Argyris, C., \& Schön, D. (1974). Theory in Practice: Increasing Professional Effectiveness. San Francisco.

Arthur, W., \& Bennett, W. (1995). The international assignee: The relative importance of factors perceived to contribute to success. Personnel Psychology, Vol. 48: 99-114.

Atteslander, P. (ed.) (2000). Methoden der empirischen Sozialforschung, $9^{\text {th }}$ edition. Berlin.

Bakir, A., Landis, D., \& Noguchi, K. (2004). Looking into studies of heterogenous small groups: An analysis of the research findings, in: Landis, D., Bennett, J., \& Bennett, N. (eds.). Handbook of intercultural training, $3^{\text {rd }}$ edition. Thousand Oaks, CA.

Baron, H., Gibbons, P., MacIver, R., \& Nyfield, G. (2000). Conscientiousness and managerial performance. Journal of Occupational and Organizational Psychology, Vol. 73: 171-180.

Barsade, S.G., Ward, A.J., Turner, J.D., \& Sonnenfeld, J.A. (2000). To your heart's content: a model of affective diversity in top management teams. Administrative Science Quarterly, Vol. 45: 802-836.

Baugh, S.G., \& Graen, G.B. (1997). Effects on team gender and racial composition on perceptions of team performance in cross-functional teams. Group \& Organization Management, Vol. 22 (3): 366-383.

Beersma, B., Hollenbeck, J.R., Humphrey, S.E., Moon, H., Conlon, D.E., \& Ilgen, D.R. (2003). Cooperation, competition, and team performance: toward a contingency approach. Academy of Management Journal, Vol. 46 (5): 572-590.

Bennett, B. (2003). Job rotation. Training Strategies for Tomorrow, Vol. 17 (4): 7-9.

Bernart, Y., \& Krapp S. (1998). Das narrative Interview. Ein Leitfaden zur rekonstruktiven Auswertung. (Forschung, Statistik \& Methoden, Bd. 2). Landau. 
Bewley, T. (2002). Interviews as a valid empirical tool in economics. Journal of Socio-Economics, Vol. 31: 343-353.

Bhawuk, D.P.S., \& Brislin, R. (1992). The measurement of intercultural sensitivity using the concepts of individualism and collectivism. International Journal of Intercultural Relations, Vol. 16: 413-436.

Black, S., Mendenhall, M., \& Oddou, G. (1991). Toward a comprehensive model of international adjustment: an integration of multiple theoretical perspectives. Academy of Management Journal, Vol. 16 (2): 291-317.

Bochner, St. (1994). Cross-cultural differences in the self concept: a test of Hofstede's Individualism/Collectivism Distinction. Journal of Cross-Cultural Psychology, Vol. 25 (2): 273-283.

Boeije, H. (2002). A purposeful approach to the constant comparative method in the analysis of qualitative interviews. Quality and Quantity, Vol. 36: 391-409.

Bortz, J., \& Döring, N. (2002). Forschungsmethoden und Evaluation für Humanund Sozialwissenschaftler, $3^{\text {rd }}$ edition. Berlin.

Bulletin Statistique (2004). Le personnel de la commission (Direction general du personnel et de l'administration, Janvier 2004.

Brannen, Y.M., Gómez, C., Peterson, M.F., Romani, L., Sagiv, L., \& Wu, P.C. (2004). People in global organizations: culture, personality and social dynamics, in: Lane, H.W., Maznevski, M.L., Mendenhall, M.E., \& McNett, J. (2004). The Blackwell Handbook of Global Management: A guide to managing complexity. Malden.

Brass, P. (1979). Elite groups, symbol manipulation and ethnic identity among the Muslim of South Asia, in: Taylo, D., \& Yapp, M. (eds.). Political Identity of South Asia. London, pp. 35-27.

Brück, F. (1999). Anwendbarkeit von bestehenden Methoden und Instrumentarien zur Bewältigung interkultureller Differenzen im österreichischen Management Kulturvergleich Österreich - Deutschland - Schweiz. Unpublished dissertation, Wirtschaftsuniversität Wien 1999.

Brüsemeister, T. (2000). Qualitative Forschung: Ein Überblick. Wiesbaden.

Bucher, A. (1994). Einführung in die empirische Sozialwissenschaft: ein Arbeitsbuch für TheologInnen. Stuttgart. 
Budäus, D. (2002). Public und Nonprofit Management. Linz.

Buss, A.H. (1989). Personality as traits. American Psychologist, Vol. 44: 13781388.

Buss, D.M. (1991). Evolutionary personality psychology, in: Rosenzweig, M.R. \& Porter, L.W. (eds.). Annual Review of Psychology, Vol. 42: 459-492.

Caligiuri, P. (2000). Selecting Expatriates for Personality Characteristics: A moderating effect of personality on the relationship between host national contact and cross-cultural adjustment. Management International Review, Vol. 40: 61-80.

Caligiuri, P. (2000a). The Big Five personality characteristics as predictors of expatriate's desire to terminate the assignment and supervisor-rated performance. Personnel Psychology, Vol. 53: 67-86.

Caligiuri, P., Jacobs, R., \& Farr, J. (2000). The attitudinal and behavioral openness scale: scale development and construct validation, International Journal of Intercultural Relations, Vol. 24 (1): 27-46.

Cartwright, S., \& Cooper, C.L. (1992). Mergers \& Acquisitions: the human factor. Oxford.

Chatman, A., \& Flynn, F. (2001). The influence of demographic heterogeneity on the emergence and consequences of cooperative norms in work teams. Academy of Management Journal, Vol. 44 (5): 956-974.

Chatman, J.A. (1991). Matching People and Organizations: Selection and Socialization in Public Accounting Firms. Administrative Science Quarterly, Vol. 36 (3): 459-484.

Chattopadhyay, P. (1999). Beyond direct and symmetrical effects: The influence of demographic dissimilarity on organizational citizenship behaviour. Academy of Management Journal, Vol. 42 (3): 273-288.

Chen, Ch., Chen, X.P., \& Meindl, J. (1998). How can cooperation be fostered? The cultural effects of individualism-collectivism. Academy of Management Review, Vol. 23 (2): 285-304.

Chen, X.P., Triandis, H.C., Kim, U., Carnevale, P.J., de Dreu, C., Gelfand ,M.J., van der Vliert, E., Robert, C., Iwao, S., Wasti, S.A., Ohbuchi, K.I., Probst, T., Schmitz, P.G., Kashima, E., Dragonas, T., \& Chan, D. (2001). Culture and deception in business negotiations: A multilevel analysis. International Journal of Cross-Cultural Management, Vol. 1 (1): 73-90. 
Cinnirella, M. (1997). Towards a European identity? Interactions between the national and European social identities manifested by university students in Britain and Italy. British Journal of Social Psychology, Vol. 36 (1): 19-31.

Cohen, W.M., \& Levinthal, D.A. (1990). Absorptive capacity: A new perspective on learning and innovation. Administrative Science Quarterly, Vol. 35: 128-152.

Costa, A.C. (2003). Understanding the nature and the antecedents of trust within work teams, in: Nooteboom, B., \& Six, F. (2003). The trust process in organizations: Empirical studies of the determinants and the process of trust development. Cheltenham, UK, pp. 105-124.

Costa, P.T., \& McCrae, R.R. (1992). Four ways five factors are basic. Personality and Individual Differences, Vol. 13: 653-665.

Cui, G., \& Awa, N. (1992). Measuring intercultural effectiveness: an integrative approach. International Journal of Intercultural Relations, Vol. 16: 311-328.

Cui, G., \& Berg van den, S. (1991). Testing the construct validity of intercultural effectiveness. International Journal of Intercultural Relations, Vol. 15: 227-241.

Dann, S. (1996). Public sector reform and the long-term public servant. The International Journal of Public Sector Management, Vol. 9 (2): 28-35.

Dermath, L. (2002). Epistemological Culture Theory: A Micro Theory of the Origin and Maintenance of Culture. Sociological Theory, Vol. 20 (2): 209- 226.

Dermath, L. (1993). Knowledge-Based Affect: Cognitive Origins of „Good“and „Bad“. Social Psychology Quarterly, Vol. 56 (2): 136-147.

Desjeux, D. (1987). Stratégies paysannes en Afrique Noire, le Congo: essai sur la gestion de l'incertitude. Paris.

Duarte, D.L., \& Synder, N.T. (1999). Mastering virtual teams: Strategies, tools and techniques that succeed. San Francisco.

Dunkel, A. (2001). Handlungswirksamkeit von Kulturstandards: Eine qualitativempirische Analyse am Beispiel Österreich, Deutschland und Spanien. Unpublished dissertation, Wirtschaftsuniversität Wien.

Earley, P.Ch., \& Erez, M. (eds.) (1997). The transplanted executive: Why do you need to understand how workers in other countries see the world differently. New York. 
Earley, P.Ch., \& Gibson, C.B. (eds.) (2002). Multinational work teams: A new perspective. Mahwah, NJ.

Earley, Ch. P., \& Mosakowski, E. (2000). Creating hybrid team cultures: an empirical test of transnational team functioning. Academy of Management Journal, Vol. 43 (1): 26-49.

Edmondson, A. (2003). Framing for learning: Lessons in successful technology implementation. California Management Review, Vol. 45 (2): 34-54.

Elron, E. (1997). Top management teams within multinational corporations: effects of cultural heterogeneity. Leadership Quarterly, Vol. 8 (4): 393-412.

Elron, E., Halevy, N., Ari, E.B., \& Shamir, B. (2003). Cooperation and coordination across cultures in the peacekeeping forces: Individual and organizational integration mechanisms, in: Britt, T.W., \& Adler, A.B. (eds.). The Psychology of the Peacekeeper: Lessons from the Field. Westport.

Ely, R.J., \& Thomas, D.A. (2001). Cultural diversity at work: the effects of diversity perspectives on work group processes and outcomes. Administrative Science Quarterly, Vol. 46: 229-273.

Erny, P. (1987). L'enfant et son milieu en Afrique noire: essai sur l'éducation traditionelle. Paris.

Feely, A.J., \& Harzing, A.W. (2003). Language management in multinational companies. Cross Cultural Management, Vol. 10 (2): 37-52.

Feldman, D. (1984). The development and enforcement of group norms. Academy of Management Review, Vol. 9 (1): 47-53.

Fink, G. (2002). Issues of international intercultural research: The narrative interview process. Presentation at PDW Academy of Management.

Fink, G., Kölling, M., \& Neyer, A.K. (2004a). Research on intercultural management interaction: the cultural standard method. Unpublished Paper, Wirtschaftsuniversität Wien.

Fink, G., \& Meierewert, S. (2004). Issues of time in international, intercultural management; East and Central Europe in the perspective of Austrian managers. Journal for East European Management Studies, Vol. 9 (1): 61-84.

Fink, G., \& Meierewert, S. (eds.) (2001). Interkulturelles Management - Österreichische Perspektiven. Wien. 
Fink, G., Neyer, A.K., Kölling, M. (2004c). The cultural standards research and its implications for multinational team management: Experiences from German and Austrian managers. Unpublished Paper, Wirtschaftsuniversität Wien.

Fink, G., Neyer, A.K., Kölling, M. (2004d). Going beyond cultural values to efficiently manage multinational teams. Paper submitted to the Journal of International Management.

Fink, G., Neyer, A.K., Kölling, M., \& Meierewert, S. (2004b). An Integrative Model of Multinational Team Performance. Europe Institute Working Paper 60. Wirtschaftsuniversität Wien, October 2004.

Flexner, S.B., \& Hauk, L. C. (1987). The Random House Dictionary of the English Language, $2^{\text {nd }}$ edition. New York.

Flick, U., Karlsdorff von, E., \& Steinke, I. (2000). Qualitative Forschung - Ein Handbuch. Hamburg.

Flynn, F.J., Chatman, J.A., \& Spataro, S.E. (2001). Getting to know you: the influence of personality on impressions and performance demographically different people in organisations. Administrative Science Quarterly, Vol. 46: 414-442.

Garcia-Prieto, P., Bellard, E., \& Schneider, S.C. (2003). Experiencing diversity, conflict, and emotions in teams. Applied Psychology: An international review, Vol. 52 (3): 413-440.

Gibson, C.B., Zellmer-Bruhn, M.E., \& Schwab, D. P. (2003). Team effectiveness in multinational organizations: Evaluation across contexts. Group \& Organization Management, 28 (4): 444-475.

Gomèz, C., Kirkman, B., \& Shapiro, D. (2000). The impact of collectivism and in-group/out-group membership in the evaluation of generosity of team members. Academy of Management Journal, Vol. 43 (6): 1097-1 106.

Gudykunst, W., Hammer, M., \& Wiseman, R. (1978). Dimensions of intercultural effectiveness: An explorative study. International Journal of Intercultural Relations, Winter 1978.

Guigo, D. (1994). Ethnologie des hommes: des usines et des bureaux. Paris.

Gupta, A.K., \& Govindarajan, V. (2000). Knowledge flows within multinational corporations. Strategic Management Journal, Vol. 21 (4): 473-496. 
Gupta, V., Hanges, P. J., \& Dorfman, P. (2002). Cultural clusters: methodology and findings, Journal of World Business, Vol. 37: 11-15.

Hackman, J.R. (1987). The design of work teams, in: Lorsch, J.W. (ed.). Handbook of organizational behavior. London.

Hall, E.T., \& Hall, M.R. (2000). Understanding cultural differences: keys to success in West Germany, France and the United States, $11^{\text {th }}$ edition.Yarmouth.

Hall E., \& Hall M. (1990). Understanding cultural differences: keys to success in West Germany, France and the United States. Yarmouth.

Hambrick, D.C., Canney Davison, S., Snell, S.A., \& Snow, C.C. (1998). When groups consists of multiple nationalities: towards a new understanding of the implications. Organization Studies, Vol. 19 (2): 181-205.

Harrison, J.K., Chadwick, M., \& Scales, M. (1996). The relationship between cross-cultural adjustment and the personality variables of self-efficacy and selfmonitoring. International Journal of Intercultural Relations, Vol. 20 (2): 167-188.

Harrison, R. (1972). Understanding your organization's character. Harvard Business Review, May-June 1972: 119-128.

Hassard, J. (1996). Images of time in work and organization, in: Clegg, S.R., Hardy, C., \& Nord, W.E. (eds.). Handbook of Organisation Studies. London, pp. 581-598.

Hermanowicz, J.C. (2002). The great interview: 25 strategies for studying people in bed. Qualitative Sociology, Vol. 25 (4): 479-499.

Hofner Saphiere, D.M. (1996). Productive behaviours of global business teams. International Journal of Intercultural Relations, Vol. 20 (2): 227-259.

Hofstede, G. (2001). Lokales Denken, globales Handeln, Interkulturelle Zusammenarbeit und globales Management, $2^{\text {nd }}$ edition. München.

Hofstede, G. (1993). Culture's Consequences: International differences in workrelated values. Newbury Park/CA.

Hofstede, G. (1980). Culture's Consequences: International differences in workrelated values. Newsbury Park/CA.

Holden, N.J. (2002). Cross-Cultural Management: A Knowledge Management Perspective. Harlow. 
House, R., Hanges, P., Javidan, M., Dorfman, P., \& Gutpa, V. (eds.) (2004). Culture, leadership, and organizationas: The GLOBE study of 62 societies. Thousand Oaks.

House, R., Javidan, M., Hanges, P., \& Dorfman, P. (2002). Understanding cultures and implicit leadership theories across the globe: an introduction to project GLOBE. Journal of World Business, Vol. 37: 3-10.

House, R., Javidan, M., \& Dorfman, P. (2001). Project Globe: an Introduction. Applied Psychology: An International Review, Vol. 50 (4): 489 - 505.

Hughes, O.E. (2003). Public Management \& Administration. New York.

Jackson, S.E., Joshi, A., \& Erhardt, N. L. (2003). Recent research on team and organizational diversity: SWOT analysis and implications. Journal of Management, Vol. 29 (6): 801-83.

Jackson, S.E., May, K.E., \& Whitney, K. (1995). Understanding the dynamics of diversity in decision-making teams, in: Guzzo, R.A., Salas, E. et al. (eds.): Team effectiveness and decision making in organizations. San Francisco, pp. 204-261.

Jehn, K., Northcraft, G.B., \& Neale, M.A. (1999). Why differences make a difference: a field study of diversity, conflict, and performance workgroup. Administrative Science Quarterly, Vol. 44: 741-763.

Jiménez, A., Górniak, J., Kosic, A., Kiss, P., \& Kandulla, M. (2004). European and National identities in EU's old and new member states: ethnic, civic, instrumental and symbolic components. European Integration online Papers: Vol. 8 (11). http://eiop.or.at/eiop/texte/2004-011a.htm.

Joshi, A., Labianca, G., \& Caligiuri, P. (2002). Getting along long distance: understanding conflicts in a multinational team through network analysis. Journal of World Business, Vol. 37: 277-284.

Judge, T., Higgins, Ch., Thoresen, C., \& Barrick, M. (1999). The Big five personality traits, general mental ability and career success across the life span. Personnel Psychology, Vol. 52: 621-652.

Kersbergen, K. V. (1997). Double Allegiance in European Integration: Publics, Nation-States, and Social Policy. European University Institute Working Paper 97/15. http://www.iue.it/RSCAS/WP-Texts/97 15.html. 
Kiffin-Petersen, S.A., \& Cordery, J.L. (2003). Trust, individualism and job characteristics as predictors of employee preference for teamwork. International Journal of Human Resource Management, Vol. 14 (1): 93-116.

Kirchler, E., Meier-Pesti, K., \& Hofmann, E. (eds.) (2004). Menschenbilder in Organisationen: Arbeits- und Organisationspsychologie 5. Wien.

Kirkman, B. \& Den Hartog, D. (2004). Performance Management in global teams, in: Lane, H.W., Maznevski, M.L., Mendenhall, M.E., \& McNett, J. (eds.). The Blackwell Handbook of Global Management: A guide to managing complexity. Malden, pp. 227-250.

Kirkman, B., Gibson, C.B., \& Shapiro, D.L. (2001). "Exporting teams": Enhancing the implementation and effectiveness of work teams in global affiliates. Organizational Dynamics, Vol. 30 (1): 12-29.

Kirkman B., \& Shapiro D. (2001). The Impact of Team Members' Cultural Values on Productivity, Cooperation and Empowerment in Self-Managing Work Teams. Journal of Cross-Cultural Psychology, Vol. 32 (5): 597-617.

Kirkman, B., \& Shapiro, D. (2001a). The impact of culture value on job satisfaction and organizational commitment in self-managing work teams: The mediating role of employee resistance. Academy of Management Journal, Vol. 44 (3): 557570 .

Kluckhohn, C. (1951). Values and value-orientations in the theory of action: An exploration in definition and classification, in: Parsons, T., \& Shils, E. (eds.). Toward a general theory of action. Cambridge, pp. 388-433.

Kluckhohn, F.R., \& Strodtbeck, F.L. (1961). Variations in Value Orientations, New York.

Kolb, D. (1984). Experiential Learning: experience as a Source of Learning and Development. Upper Saddle River.

Kölbl, C. (2001). Rekonstruktion der Forschungspraxis- eine Antwort auf die Frage, was ein Einführungstext in qualitative Methoden bringen soll. Forum Qualitative Sozialforschung/ Forum: Qualitative Social Research (Online Journal), Nr. 2/2001. Verfügbar über: http://qualitative-research.net

Kölling, M. (2004). Interkulturelles Wissensmanagement Deutschland Ost und West. Unpublished Dissertation, Wirtschaftsuniversität Wien, Vienna. 
Kuckartz, U. (1999). Computerunterstützte Analyse qualitativer Daten: Eine Einführung in Methoden und Arbeitstechniken. Opladen.

Lamnek, S. (2000). Sozialforschung in Theorie und Praxis. Zum Verhältnis von qualitativer und quantitativer Forschung, in: Clemens, W., \& Strübing, J. (eds.): Empirische Sozialforschung und gesellschaftliche Praxis: Bedingungen und Formen angewandter Forschung in den Sozialwissenschaften. Opladen, pp. 23-46.

Lamnek, S. (1995). Qualitative Sozialforschung, Band 1: Methodologie, München.

Lane, H.W., Maznevski, M.L., \& Mendenhall, M.E. (2004). Globalization: Hercules meets Buddha, in: Lane, H.W., Maznevski, M.L., Mendenhall, M.E., \& McNett, J. (eds.). The Blackwell Handbook of Global Management: A guide to managing complexity. Malden, pp. 3-25.

Latein, B. (1996). Über den Umgang mit kritischen Interaktionen in der interkulturellen Begegnung. Regensburg.

Lehmann, M. (2003a). Don't Forget to Observe The Organization and the Cadre. Paper presented at Conference on "The Opening of Systems Theory", Copenhagen, May 23-25, 2003.

Lehmann, M. (2003b). Annäherung von Managementtechniken durch wirtschaftliche Transformation und Erweiterung der EU? Vortrag im Europakolloquium, Europainstitut der Wirtschaftsuniversität Wien, 15.12.03

Mancini, G.F. (1998). Europe: the Case for Statehood. Harvard Jean Monnet Working paper 6/98. http://www.jeanmonnetprogram.org/papers/98/98-6-.html.

Marschan, R., Welch, D., \& Welch, L. (1997). Language: The forgotten factor in multinational management. European Management Journal, Vol. 15 (5): 591-598.

Mayring, P. (2003). Qualitative Inhaltsanalyse: Grundlagen und Techniken. Weinheim, Basel.

Mayring, P. (2002). Eine Einführung in die qualitative Sozialforschung: Eine Anleitung zum qualitativen Denken. Weinheim, Basel.

Mayring, P. (2000a). Qualitative Content Analysis. Forum Qualitative Sozialforschung (Online Journal), Vol. 1 (2). Verfügbar über: http://qualitativeresearch.net/fqs/fqs-e/2-00inhalt-e.htm. Abgerufen am: 07.03.2003. 
Mayring, P. (2000b). Qualitative Inhaltsanalyse. Grundlagen und Techniken, $7^{\text {th }}$ revised edition. Weinheim.

Mayring, P (1999). Einführung in die qualitative Sozialforschung. Eine Anleitung zum qualitativen Denken, $4^{\text {th }}$ revised edition. Weinheim.

Mayring, P. (1996). Einführung in die qualitative Sozialforschung: Eine Einleitung zu qualitativem Denken, $3^{\text {rd }}$ revised edition. Weinheim.

Mayring, P. (1993). Einführung in die qualitative Sozialforschung. Eine Anleitung zum qualitativen Denken, $2^{\text {nd }}$ revised edition. Weinheim.

Mazey, S. (1992). Conception and Evolution of the High Authority's Administrative Services (1952-1956): From Supranational Principles to Mulinational Practices, in: Heyen, E.V. (ed.). Yearbook of European Administrative History 4: Early European Community Administration. Baden Baden, pp. 31-47.

Maznevski, M.L., \& Peterson, M.F. (1997). Societal values, social interpretation, and multinational teams, in: Granrose, Ch. (ed.). Cross-cultural work groups. Thousand Oaks.

McHugh, M. \& Bennett, H. (1999). Dream on: team work from the confines of the bureaucratic cage. Strategic Change, Vol. 8 (4): 189-203.

Merten, K. (1983). Inhaltsanalyse. Einführung in die Theorie, Methode und Praxis. Opladen.

Milliken, F.J., \& Martins, L.L. (1996). Searching for common threads: understanding the multiple effects of diversity in organizational groups. Academy of Management Review, Vol. 21 (2): 402-433.

Mitchell, J.C. (ed.) (1969). Social Networks in Urban Situations: Analysis of Personal Relationships in Central African Towns. Manchester.

Mruck, K., \& Mey, G. (2000). Qualitative Sozialforschung in Deutschland. Forum Qualitative Sozialforschung/ Forum: Qualitative Social Research (Online Journal), Nr. 1/2000. Verfügbar über: http://qualitative-research.net.

Mutabazi, E., \& Derr, C.B. (2003). The management of multicultural teams: the experience of afro-occidental teams. Cahiers de recherché (Numéro 13), EM Lyon, France. 
Neumann, G.A., Wagner, S.H., \& Christiansen, N.D. (1999). The relationship between work-team personality composition and the job performance of teams. Group and Organization Management, Vol. 24 (1): 28-45.

Neyer, A.K. (2004). The complexity of multinational teams in the European Commission. An explorative analysis from Austrian point of view. Paper presented at $8^{\text {th }}$ international workshop on teamworking (IWOT), organized by European Institute for Advanced Studies in Management, September 16-17, 2004, Trier, Germany.

Neyer, A.K., \& Kölling, M. (2003). Redefining cultural standards. A metaanalysis of 650 interviews, in: Fink, G., Neyer, A.K., \& Reichel, W. (eds.). Theory and methods in the study of intercultural knowledge and interaction. Studien des Instituts für den Donauraum und Mitteleuropa, Nr. 4 (2003).

Nugent, N. (2001). The European Commission. Tavistock and Rochdale.

Oguri, M., \& Gudykunst, W.B. (2002). The influence of self construals and communication styles on sojourners' psychological and sociocultural adjustment. International Journal of Intercultural Relations, Vol. 26: 577-593.

Ortega, J. (2001). Job rotation as a learning mechanism. Management Science, Vol. 47 (10): 1361-1370.

Østerud, Ø. (1999). Globalisenringen og nasjonalstaten. Oslo.

Oudenhoven, J.P., \& Van der Zee, K. (2002). Predicting multinational effectiveness of international students: the Multinational Personality Questionnaire. International Journal of Intercultural Relations, Vol. 26: 679-694.

Oudenhoven, J.P., Van der Zee, K., \& Van Kooten, M. (2001). Successful adaptation strategies according expatriates. International Journal of Intercultural Relations, Vol. 25: 467-482.

Parker, B., \& McEvoy, G.M. (1993). Initial examination of a model of intercultural adjustment. International Journal of Intercultural Relations, Vol. 17: 355379.

Parker, R., \& Bradley, L. (2000). Organisational culture in the public sector: Evidence from six organisations. The International Journal of Public Sector Management, Vol. 13 (2/3): 125-141.

Parkinson, C.N. (1992). Parkinsons Gesetz und andere Studien über die Verwaltung. Düsseldorf. 
Parsons, T. (1951). The Social System. Glencoe, IL.

Parsons, T., \& Shils, E. (1962). Values, Motives and System of Action, in: Parsons, T \& Shils, E. (eds.). Toward a General Theory of Action. Cambridge.

Patton, M.Q. (1997). Utilization-focused evaluation: the new century text. Thousand Oaks, CA.

Peterson, M.F. (1993). Embedded organizational events and the new situationalism. Unpublished manuscript, Texas Tech University, Institute for Leadership and Management Research, Lubbock.

Popitz, H. (1980). Die normative Konstruktion von Gesellschaft. Tübingen.

Probst, T.M., Carnevale, P.J., \& Triandis, H.C. (1999). Cultural values in intergroup and single group social dilemmas. Organizational Behaviour and Human Decision Process, Vol. 77 (3): 171-191.

Randel, A.E. (2003). The salience of culture in multinational teams and its relation to team citizenship behaviour. International Journal of Cross Cultural Management, Vol. 3 (1): 27-44.

Ravlin, D.C., Thomas, C.T., \& Ilsev, A. (2000). Beliefs about values, status, and legitimacy in multicultural groups: influences on intragroup conflict, in: Earley, P.Ch., \& Singh, H. (eds.). Innovations in international cross-cultural management. Thousand Oaks.

Reforming the Commission - A White Paper (Part 1), 2000.

Richard, O.C. (2000). Racial diversity, business strategy, and firm performance: a resource-based view. Academy of Management Journal, Vol. 43 (2): 164-177.

Richard, O., McMillan, A., Chadwick, K., \& Dwyer, S. (2003). Employing an innovation strategy in racially diverse workforces. Group \& Organization Management, Vol. 28 (1): 107-126.

Rokeach, M. (1973). The nature of human values. New York.

Ruben, B., \& Kealey, D. (1979). Behavioural assessment of communication competency and the prediction of cross-cultural adaptation. International Journal of Intercultural Relations, Vol. 3: 15-47.

Rules of the Procedure of the European Parliament. Online: 14 October 2003. 
Salk, J., \& Brannen, M.Y. (2000). National culture, networks, and individual influence in a multinational management team. Academy of Management Journal, Vol. 43 (2): 191-202.

Sarin, S., \& McDermott, C. (2003). The effect of team leader characteristics on learning, knowledge application, and performance of cross-functional new product development teams. Decision Sciences, Vol. 34 (4): 707-739.

Schedler, K., \& Proeller, I. (eds.) (2003). New Public Management. Bern.

Schein, E.H. (1992). Organizational culture and leaderhip. San Francisco.

Schmit, M., Kihm, J., \& Robie, Ch. (2000). Development of a global measure of personality. Personnel Psychology, Vol. 53: 153-193.

Schwartz, S.H. (1992). Universals in the Content and Structure of Values: Theoretical Advances and Empirical Test in 20 Countries. Advances in Experimental Social Psychology, Vol. 23: 1-65.

Schwartz, S.H., \& Bilsky, W. (1990). Toward a theory of the universal content and structure of values: Extension and cross-cultural replications. Journal of Personality and Social Psychology, Vol. 58: 878-891.

Schwartz, S.H., \& Bilsky, W. (1987). Toward a psychological structure of human values. Journal of Personality and Social Psychology, Vol. 53: 550-562.

Shafritz, J.M., \& Ott, St.J. (1987). Classics of Organization Theory. Chicago.

Skinner, D., Tagg, C., \& Holloway, J. (2000). Managers and Research: The Pros and Cons of Qualitative Approaches. Management Learning, Vol. 31 (2): 163179.

Smith, A. D. (1999). Myths and Memories of the Nation. Oxford, UK.

Smith, A. D. (1995). Nations and Nationalism in a Global Era. Cambridge, UK.

Smith, A. D. (1992). National identity and the idea of European Unity. International Affairs, Vol. 68 (1): 55-76.

Smith, P.B., \& Peterson, M.F. (1988). Leadership, Organizations and Culture: An event management model. London.

Stern, E. (1997). Crisis and learning: a conceptual balance sheet. Journal of Contingencies and Crisis Management, Vol. 5 (2): 69-86. 
Stocké, V. (2004). The interdependence of determinants for the strength and direction of social desirability bias in racial attitude surveys. Sonderforschungsbereich 504: No. 04-14. Universität Mannheim.

Thomas, A. (2003). Interkulturelle Kompetenz - Grundlagen, Probleme und Konzepte. Erwägen Wissen Ethik, Vol. 14 (1): 137-150.

Thomas, A. (ed.). (2003a). Psychologie interkulturellen Handelns. $2^{\text {nd }}$ edition. Göttingen.

Thomas, A. (ed.) (1996). Psychologie interkulturellen Handelns, Göttingen.

Thomas, A. (ed.) (1993). Kulturvergleichende Psychologie, Eine Einführung. Göttingen.

Thomas, D.C. (1999). Cultural diversity and work group effectiveness: An experimental study. Journal of Cross Cultural Psychology, Vol. 30: 242-263.

Tjosvold, D., Hui, Ch., Ding, D.Z., \& Hu, J. (2003). Conflict values and team relationships: conflict's contribution to team effectiveness and citizenship in China. Journal of Organizational Behaviour, Vol. 24: 69-88.

Triandis, H.C. (1995). Individualism and Collectivism. Boulder, CO.

Trompenaars, F. (1993). Handbuch Globales Managen. Wie man kulturelle Unterschiede im Geschäftsleben versteht. Düsseldorf.

Trompenaars, F., \& Hampden-Turner, C. (1997). Riding the waves of culture: Understanding Cultural Diversity in Business, $2^{\text {nd }}$ edition. London.

Van de Vijver, F., \& Tanzer, N.K. (1997). Bias and equivalend in cross-cultural assessment: an overview. European Review of Applied Psychology, Vol. 47 (4): 263-279.

Ward, C., Bochner, St., \& Furnham, A. (2001). The psychology of the culture shock. Hove UK.

Watson, E.W., Johnson, L., \& Merritt, D. (1998). Team orientation, selforientation, and diversity in task groups. Group \& Organization Management, Vol. 23 (2): 161-188. 
Watson, W., Johnson, L., Kumar, K., \& Critelli, J. (1998a). Process gain and process loss: comparing interpersonal processes and performance on culturally diverse and non-diverse teams across time. International Journal of Intercultural Relations, Vol. 22 (4): 409-430.

Webster online dictionary: http://www.webster-dictionary.org

Weerd-Nederhof, P.C., Pacitti, B.J., da Silva Gomes, J.F., \& Pearson, A.W. (2002). Tools for the improvement of organizational learning processes in innovation. Journal of Workplace Learning, Vol. 14 (7/8): 320-331.

Weiler, J. H. H. (1999). The Constitution of Europe. "Do the new Clothes have an Emperor?" and other essays on European Integration. Cambridge.

Witzel, A. (1982). Verfahren der qualitativen Sozialforschung: Überblick und Alternativen. Frankfurt am Main. 


\section{Appendix A: A short description of the European Commission}

The following description of the European Commission can be found on the official website of the European Commission [http://europa.eu.int/institutions/ comm/index en.htm (Online query: 24.08.2004)]:

"The Commission is the politically independent institution that represents and upholds the interests of the EU as a whole. It is the driving force within the EU's institutional system: it proposes legislation, policies and programmes of action and it is responsible for implementing the decisions of Parliament and the Council. The term "Commission" is used in two senses. First, it refers to the Members of the Commission - i.e. the team ("college") of men and women appointed by the member states and Parliament to run the institution and take its decisions. Secondly, the term "Commission" refers to the institution itself and to its staff.

The day-to-day work of the Commission is done by its administrative officials, experts, translators, interpreters and secretarial staff. There are approximately 24 000 of these European civil servants. That may sound a lot, but in fact it is fewer than the number of staff employed by most medium-sized city councils in Europe. Far from being faceless bureaucrats, these people are ordinary citizens from every EU country, selected through competitive examinations and working together to build a strong and successful European Union.

The European Commission has four main roles:

Proposing new legislation: Under the Treaty, the Commission has the "right of initiative". In other words, it is responsible for drawing up proposals for new European legislation, which it presents to Parliament and the Council. These proposals must aim to defend the interests of the Union and its citizens, not those of specific countries or industries. Before making any proposals, the Commission must be aware of new situations and problems developing in Europe and it must consider whether EU legislation is the best way to deal with them. That is why the Commission is in constant touch with a wide range of interest groups. It is obliged to consult two advisory bodies: the Economic and Social Committee (made up of employers' and trade unions' representatives) and the Committee of the Regions (made up of representatives of local and regional authorities). It also seeks the opinions of national parliaments and governments. The Commission will propose action at EU level only if it believes that a problem cannot be solved more efficiently by national, regional or local action. This principle of dealing with things at the lowest possible level is called the "subsidiarity principle". If, however, the Commission concludes that EU legislation is needed, then it drafts a proposal that it believes will deal with the problem effectively and satisfy the widest possible range of interests. To get the technical details right, the Commission consults the experts who make up its various committees and working groups.

Implementing EU policies and the budget: As the European Union's executive body, the Commission is responsible for managing and implementing the EU 
budget and the policies and programmes adopted by Parliament and the Council. Most of the actual work and spending is done by national and local authorities, but the Commission is responsible for supervising it. One example of a policy actively managed by the Commission is competition policy: the Commission monitors cartels and mergers, and makes sure that EU countries do not subsidise their industries in such a way as to distort competition. Examples of EU programmes managed by the Commission range from the "Interreg" and "Urban" programmes (creating cross-border partnerships between European regions, helping regenerate cities and declining urban areas) to the "Community Framework Programme" for Europe-wide research and the "Erasmus" programme of student exchanges. The Commission handles the budget under the watchful eye of the Court of Auditors. Both institutions aim to ensure good financial management. Only if it satisfied with the Court of Auditors' annual report does the European Parliament grant the Commission discharge for implementing the budget.

Enforcing European law: The Commission acts as "guardian of the Treaties". This means that the Commission, together with the Court of Justice, is responsible for making sure EU law is properly applied in all the Member States. If it finds that a particular Member State is not applying an EU law, and therefore not meeting its legal obligations, the Commission takes steps to put the situation right. First it launches a legal process called the "infringement procedure". This involves sending the Member State an official letter, saying why the Commission considers it is infringing EU law and setting a deadline for the government to send the Commission a detailed reply. If this procedure fails to put things right, the Commission must then refer the matter to the Court of Justice, which has the power to impose penalties. The Court's judgments are binding on the Member States and the European institutions.

Representing the EU on the international stage: The European Commission is an important mouthpiece for the European Union on the international stage. It enables the EU member states to speak "with one voice" in international forums such as the World Trade Organization. The Commission also has the responsibility of negotiating international agreements on behalf of the EU. One well-known example is the Cotonou Agreement, which sets out the terms of an important aid and trade partnership between the EU and developing countries in Africa, the Caribbean and the Pacific. It is up to the Commission President to decide which commissioner will be responsible for which policy area, and to reshuffle these responsibilities (if necessary) during the Commission's term of office. The President, with the Commission's approval, is also entitled to demand a commissioner's resignation.

The "college" of commissioners meets once a week, usually on Wednesdays in Brussels. Each item on the agenda is presented by the commissioner responsible for that policy area, and the college takes a collective decision on it. The Commission's staff is organized into departments, known as "Directorates-General" (DGs) 
and "services" (such as the Legal Service). Each DG is responsible for a particular policy area and is headed by a Director-General who is answerable to one of the commissioners. It is the DGs that actually devise and draft the Commission's legislative proposals, but these proposals become official only when "adopted" by the College at its weekly meeting. The procedure is roughly as follows. Suppose, for example, that the Commission sees a need for EU legislation to prevent pollution of Europe's rivers. The Directorate-General for the Environment will draw up a proposal, based on extensive consultations with European industry and farmers, with environment ministries in the Member States and with environmental organizations. The proposed legislation will then be discussed with all relevant Commission departments and amended if necessary. It will then be checked by the Legal Service and approved by the commissioners' "cabinets" (personal political staff). Once the proposal is fully ready, the Secretary-General will put it on the agenda for a forthcoming Commission meeting. At this meeting, the Environment Commissioner will explain to his or her colleagues why this legislation is being proposed, and they will then discuss it. If there is agreement, the College will "adopt" the proposal and the document will be sent to Council and the European Parliament for their consideration. If there is disagreement among the commissioners, the President will ask them to vote on it. If a majority is in favour, the proposal will be adopted. Thereafter it will have the unconditional support of all the Commission members." 


\section{Appendix B: A short description of the European Parliament}

The following description of the European Parliament can be found on the official website of the European Parliament [http://europa.eu.int/institutions/ parliament/ index_en.htm] (Online query: 24.08.2004)]:

"The members of the European Parliament (MEPs) sit not in national blocks but in Europe-wide political groups that bring together all the main political parties operating in the EU member states. Parliamentary elections are held every five years, and every EU citizen who is registered as a voter is entitled to vote. So Parliament expresses the democratic will of the Union's 374 million citizens, and it represents their interests in discussions with the other EU institutions.

The Parliament has three main roles:

It shares with the Council the power to legislate. The most common procedure for adopting (i.e. passing) EU legislation is "co-decision" (see the section on Decisionmaking in the European Union). This places the European Parliament and the Council on an equal footing and the laws passed using this procedure are joint acts of the Council and Parliament. It applies to legislation in a wide range of fields. On a range of other proposals Parliament must be consulted, and its approval is required for certain important political or institutional decisions. Parliament also provides impetus for new legislation by examining the Commission's annual work programme, considering what new laws would be appropriate and asking the Commission to put forward proposals.

It exercises democratic supervision over all EU institutions, and in particular the Commission. Parliament exercises democratic supervision over the other European institutions. It does so in several ways. First, when a new Commission is to be appointed, Parliament interviews all the prospective new members and President of the Commission (nominated by the member states). They cannot be appointed without Parliament's approval. Second, the Commission is politically answerable to Parliament, which can pass a "motion of censure" calling for its mass resignation. More generally, Parliament exercises control by regularly examining reports sent to it by the Commission (general report, reports on the implementation of the budget, the application of Community law, etc.). Moreover, MEPs regularly ask the Commission written and oral questions. The members of the Commission attend plenary sessions of Parliament and meetings of the parliamentary committees, maintaining a continual dialogue between the two institutions. Parliament also monitors the work of the Council: MEPs regularly ask the Council written and oral questions, and the President of the Council attends the plenary sessions and takes part in important debates. Parliament works closely with the Council in certain areas, such as common foreign and security policy and judicial co-operation, as well as on some issues of common interest such as asylum and immigration policy and measures to combat drug abuse, fraud and international crime. The Council Presidency keeps Parliament informed on all these subjects. Parliament can also exercise democratic control by examining petitions from citi- 
zens and setting up temporary committees of inquiry. Finally, Parliament provides input to every EU summit (the European Council meetings). At the opening of each summit, the President of Parliament is invited to express Parliament's views and concerns about topical issues and the items on the European Council's agenda. It shares with the Council authority over the EU budget and can therefore influence EU spending. Parliament debates it in two successive readings, and it does not come into force until it has been signed by the President of Parliament. Parliament's Committee on Budgetary Control (COCOBU) monitors how the budget is spent, and each year Parliament decides whether to approve the Commission's handling of the budget for the previous financial year. This approval process is technically known as "granting a discharge".

Parliament's work is divided into two main stages:

Preparing for the plenary session: This is done by the MEPs in the various parliamentary committees that specialise in particular areas of EU activity. The issues for debate are also discussed by the political groups.

The plenary session itself: Plenary sessions, attended by all MEPs, are normally held in Strasbourg (one week per month) and sometimes in Brussels (two days). At these sessions, Parliament examines proposed legislation and votes on amendments before coming to a decision on the text as a whole." 


\section{Appendix C: Overview of the findings in the European Commis- sion}

\begin{tabular}{|c|c|c|c|c|}
\hline Category & Subcategory & Characteristics & Influenced by & Impact on \\
\hline \multirow{4}{*}{ Society } & $\begin{array}{l}\text { General cultural } \\
\text { differences } \\
\text { versus } \\
\text { personality }\end{array}$ & $\begin{array}{l}\text { Values. } \\
\text { Personality traits. }\end{array}$ & $\begin{array}{l}\text { Personality traits. } \\
\text { Past international } \\
\text { assignments. } \\
\text { Team size: number of } \\
\text { cultures in team. }\end{array}$ & $\begin{array}{l}\text { Stereotyping. } \\
\text { Prejudices. } \\
\text { Culturally based in- } \\
\text { group versus out- } \\
\text { group thinking. }\end{array}$ \\
\hline & \multirow[b]{2}{*}{$\begin{array}{l}\text { Culturally } \\
\text { determined } \\
\text { norms of } \\
\text { behaviour: } \\
\text { North-versus } \\
\text { South }\end{array}$} & Types of criticism & $\begin{array}{l}\text { Communication } \\
\text { style. } \\
\text { Team norms. } \\
\end{array}$ & $\begin{array}{l}\text { Discussion within } \\
\text { the team. } \\
\text { Solution finding. }\end{array}$ \\
\hline & & $\begin{array}{l}\text { Different working } \\
\text { styles: goal- versus } \\
\text { process-orientation }\end{array}$ & $\begin{array}{l}\text { Communication style } \\
\text { (straight to the point } \\
\text { versus personal } \\
\text { relationship } \\
\text { oriented). } \\
\text { Time pressure. } \\
\text { Team norms. }\end{array}$ & $\begin{array}{l}\text { In time fulfilment of } \\
\text { the task. } \\
\text { "Bad feeling": } \\
\text { things not } \\
\text { happening in the } \\
\text { "right way" } \\
\text { Frustration. } \\
\text { Personal motivation. }\end{array}$ \\
\hline & $\begin{array}{l}\text { Language } \\
\text { proficiency }\end{array}$ & $\begin{array}{l}\text { Stress } \\
\text { Hindrance for } \\
\text { second language } \\
\text { speaker } \\
\text { Inability to } \\
\text { participate }\end{array}$ & $\begin{array}{l}\text { Use and } \\
\text { interpretation of } \\
\text { words. } \\
\text { Sense of humor. }\end{array}$ & $\begin{array}{l}\text { Misunderstandings - } \\
\text { Trust building. } \\
\text { Presentation and } \\
\text { enforcement of own } \\
\text { ideas. } \\
\text { Placing of key } \\
\text { information within } \\
\text { the team. }\end{array}$ \\
\hline \multirow{3}{*}{$\begin{array}{l}\text { Organization: } \\
\text { Organizational } \\
\text { Culture }\end{array}$} & \multirow[t]{2}{*}{$\begin{array}{l}\text { "Perceived kind } \\
\text { of } \\
\text { organizational } \\
\text { culture" }\end{array}$} & $\begin{array}{l}\text { Culture of } \\
\text { tolerance }\end{array}$ & $\begin{array}{l}\text { High level of } \\
\text { diversity on the } \\
\text { cultural and } \\
\text { individual level. }\end{array}$ & $\begin{array}{l}\text { Trust building } \\
\text { within the team. } \\
\text { Increased team } \\
\text { efficiency. } \\
\text { Establishment of } \\
\text { efficient team } \\
\text { norms. }\end{array}$ \\
\hline & & $\begin{array}{l}\text { "Being a human } \\
\text { machine in the } \\
\text { organization" }\end{array}$ & $\begin{array}{l}\text { Type of organization } \\
\text { (bureaucracy). } \\
\text { Hierarchy. } \\
\text { Personal interests }\end{array}$ & $\begin{array}{l}\text { Personal motivation. } \\
\text { Team performance. }\end{array}$ \\
\hline & $\begin{array}{l}\text { "Explicitly" } \\
\text { defined } \\
\text { organizational } \\
\text { culture }\end{array}$ & Eurospeak & $\begin{array}{l}\text { Mix of diverse } \\
\text { languages. }\end{array}$ & $\begin{array}{l}\text { Building up } \\
\text { common } \\
\text { "organizational" } \\
\text { identity. }\end{array}$ \\
\hline
\end{tabular}




\begin{tabular}{|c|c|c|c|c|}
\hline Category & Subcategory & Characteristics & Influenced by & Impact on \\
\hline \multirow{3}{*}{$\begin{array}{l}\text { Organization: } \\
\text { Organizational } \\
\text { structure }\end{array}$} & Hierarchy & $\begin{array}{l}\text { French versus } \\
\text { Anglo-Saxon } \\
\text { system }\end{array}$ & $\begin{array}{l}\text { Type of Directorate- } \\
\text { General (type of } \\
\text { department). } \\
\text { Organizational } \\
\text { history. } \\
\text { Personal interests - } \\
\text { power. }\end{array}$ & $\begin{array}{l}\text { Leadership-style. } \\
\text { Knowlegde transfer. } \\
\text { In time fulfilment of } \\
\text { tasks. }\end{array}$ \\
\hline & $\begin{array}{l}\text { Performance } \\
\text { Appraisal }\end{array}$ & $\begin{array}{l}\text { Career } \\
\text { development } \\
\text { review }\end{array}$ & $\begin{array}{l}\text { Promotion: personal } \\
\text { interests (single- } \\
\text { versus team player). } \\
\text { Clear goal definition } \\
\text { and objective } \\
\text { evaluation of goal } \\
\text { achievements. } \\
\text { Adequate } \\
\text { performance } \\
\text { appraisal (team vs. } \\
\text { individual evaluation, } \\
\text { kind of organization). }\end{array}$ & $\begin{array}{l}\text { Trust building } \\
\text { process within the } \\
\text { team. } \\
\text { Degree of individual } \\
\text { frustration. } \\
\text { Possible negative } \\
\text { influences on } \\
\text { existing team } \\
\text { culture. } \\
\text { Team performance. }\end{array}$ \\
\hline & Mobility & Job rotation & $\begin{array}{l}\text { Time lack for team } \\
\text { building phases -> } \\
\text { Not enough time for } \\
\text { building trust. }\end{array}$ & $\begin{array}{l}\text { Negative effects on } \\
\text { knowledge } \\
\text { management. } \\
\text { Lack of } \\
\text { identification with } \\
\text { team. }\end{array}$ \\
\hline \multirow[b]{2}{*}{ Individual } & Personality traits & \multicolumn{2}{|c|}{ Personal experiences } & $\begin{array}{l}\text { Trust building. } \\
\text { Team effectiveness. }\end{array}$ \\
\hline & $\begin{array}{l}\text { Personal } \\
\text { Experiences }\end{array}$ & $\begin{array}{l}\text { Past international } \\
\text { assignments }\end{array}$ & $\begin{array}{l}\text { Personality traits (e.g. } \\
\text { empathy). } \\
\text { Ability to } \\
\text { communicate in } \\
\text { foreign languages }\end{array}$ & $\begin{array}{l}\text { Easier integration in } \\
\text { multinational team. } \\
\text { Ability to } \\
\text { understand implicit } \\
\text { informal rules and } \\
\text { norms in } \\
\text { multinational teams. } \\
\text { Efficient use of } \\
\text { diverse (culturally } \\
\text { based) knowledge } \\
\text { of the other team } \\
\text { members. } \\
\text { Further and } \\
\text { encourage the } \\
\text { establishment of } \\
\text { efficient team } \\
\text { norms. }\end{array}$ \\
\hline \multicolumn{5}{|r|}{ To be continued } \\
\hline
\end{tabular}




\begin{tabular}{|c|c|c|c|c|}
\hline Category & Subcategory & Characteristics & Influenced by & Impact on \\
\hline \multirow{3}{*}{ Individual } & $\begin{array}{l}\text { Personal } \\
\text { Interests/ } \\
\text { Motivations }\end{array}$ & \multicolumn{2}{|c|}{$\begin{array}{l}\text { Stage of career development. } \\
\text { Team versus single player. } \\
\text { Particular reasons for working in an } \\
\text { institution (e.g. feeling of , doing } \\
\text { something useful“). }\end{array}$} & Efficient team work. \\
\hline & \multicolumn{2}{|c|}{ Educational Background } & $\begin{array}{l}\text { Task. } \\
\text { Mix of knowledge, } \\
\text { skills, and } \\
\text { approaches. } \\
\text { Team norms. }\end{array}$ & $\begin{array}{l}\text { Efficient problem } \\
\text { solutions. }\end{array}$ \\
\hline & Team Leader & $\begin{array}{l}\text { Leadership-style } \\
\text { and power }\end{array}$ & $\begin{array}{l}\text { Task-oriented } \\
\text { delegation of work. } \\
\text { Transfer of relevant } \\
\text { information to the } \\
\text { team members. } \\
\text { Hierarchy. } \\
\text { Personal interests. } \\
\text { Personality traits. }\end{array}$ & $\begin{array}{l}\text { Motivation. } \\
\text { Mutual knowledge } \\
\text { transfer. } \\
\text { Effective } \\
\text { leader/team member } \\
\text { interaction. } \\
\text { Level of } \\
\text { satisfaction. } \\
\text { Establishment of a } \\
\text { team culture. } \\
\text { Trust building. }\end{array}$ \\
\hline \multirow{4}{*}{ Team } & \multirow{4}{*}{ Team Norms } & Informal rules & $\begin{array}{l}\text { Organizational } \\
\text { culture. } \\
\text { Culturally } \\
\text { determined norms of } \\
\text { behaviour. } \\
\text { Personal interests. }\end{array}$ & $\begin{array}{l}\text { Dealing with } \\
\text { hierarchy. } \\
\text { Acceleration of } \\
\text { information process. }\end{array}$ \\
\hline & & $\begin{array}{l}\text { Facilitation of } \\
\text { communication }\end{array}$ & $\begin{array}{l}\text { Kind of organization } \\
\text { (e.g. bureaucratic). } \\
\text { Information } \\
\text { technology. } \\
\text { Personal interests - } \\
\text { power. }\end{array}$ & $\begin{array}{l}\text { Overcoming } \\
\text { hierarchical barriers. }\end{array}$ \\
\hline & & \multirow[t]{2}{*}{$\begin{array}{l}\text { Mutual } \\
\text { considerateness }\end{array}$} & $\begin{array}{l}\text { Embedded (cultural) } \\
\text { buffer. } \\
\text { Showing respect. } \\
\text { Personal interests. }\end{array}$ & $\begin{array}{l}\text { Dealing with } \\
\text { differences on the } \\
\text { individual and } \\
\text { cultural level. } \\
\text { Task achievement. }\end{array}$ \\
\hline & & & Search for consensus. & Task achievement. \\
\hline & & & & To be continued \\
\hline
\end{tabular}




\begin{tabular}{|c|c|c|c|c|}
\hline Category & Subcategory & Characteristics & Influenced by & Impact on \\
\hline \multirow{5}{*}{ Moderators } & \multirow[t]{3}{*}{ Task } & Task - general & \multirow[t]{2}{*}{ Type of task. } & $\begin{array}{l}\text { Degree of diversity } \\
\text { mix: working with } \\
\text { people form diverse } \\
\text { cultures with } \\
\text { invisible and visible } \\
\text { individual } \\
\text { characteristics. } \\
\text { Task fulfillment. } \\
\text { Performance } \\
\text { measurement } \\
\text { (performance } \\
\text { appraisal). }\end{array}$ \\
\hline & & $\begin{array}{l}\text { Responsibility } \\
\text { assignment }\end{array}$ & & $\begin{array}{l}\text { Higher performance } \\
\text { output } \\
\text { (organizational } \\
\text { level). } \\
\text { Satisfaction on } \\
\text { individual level. }\end{array}$ \\
\hline & & $\begin{array}{l}\text { Nature of task: } \\
\text { Routine versus } \\
\text { "special" project }\end{array}$ & $\begin{array}{l}\text { Personal interests. } \\
\text { Personal motivation. } \\
\text { Hierarchical } \\
\text { structure. } \\
\text { Performance } \\
\text { appraisal. }\end{array}$ & $\begin{array}{l}\text { Higher performance } \\
\text { output. }\end{array}$ \\
\hline & Team Size & $\begin{array}{l}\text { Number of cultures } \\
\text { within a team }\end{array}$ & $\begin{array}{l}\text { Degree of diversity } \\
\text { mix: working with } \\
\text { people form diverse } \\
\text { cultures with } \\
\text { invisible and visible } \\
\text { individual } \\
\text { characteristics. } \\
\text { Task. }\end{array}$ & $\begin{array}{l}\text { Working style - } \\
\text { culturally based } \\
\text { norms of behavior. } \\
\text { Communication. } \\
\text { Relevance of } \\
\text { cultural differences. }\end{array}$ \\
\hline & Learning proces & & $\begin{array}{l}\text { Becoming aware of } \\
\text { various categoriesl of } \\
\text { influence on efficient } \\
\text { team work (society, } \\
\text { organization, } \\
\text { individual, team). }\end{array}$ & $\begin{array}{l}\text { Establishment of } \\
\text { efficient team } \\
\text { norms. } \\
\text { Society, } \\
\text { organization, } \\
\text { individual and team } \\
\text { category. }\end{array}$ \\
\hline $\begin{array}{l}\text { Excursus: } \\
\text { Knowledge } \\
\text { Management }\end{array}$ & $\begin{array}{l}\text { Knowledge } \\
\text { Management }\end{array}$ & $\begin{array}{l}\text { Knowledge } \\
\text { Transfer }\end{array}$ & $\begin{array}{l}\text { Job rotation. } \\
\text { Performance } \\
\text { appraisal system } \\
\text { Information systems } \\
\text { Personal interests. }\end{array}$ & $\begin{array}{l}\text { Trust building. } \\
\text { Efficient problem } \\
\text { solutions. } \\
\text { Team performance. }\end{array}$ \\
\hline
\end{tabular}




\section{Forschungsergebnisse der Wirtschaftsuniversität Wien}

Herausgeber: Wirtschaftsuniversität Wien vertreten durch a.o. Univ. Prof. Dr. Barbara Sporn

Band 1 Stefan Felder: Frequenzallokation in der Telekommunikation. Ökonomische Analyse der Vergabe von Frequenzen unter besonderer Berücksichtigung der UMTS-Auktionen. 2004.

Band 2 Thomas Haller: Marketing im liberalisierten Strommarkt. Kommunikation und Produktplanung im Privatkundenmarkt. 2005.

Band 3 Alexander Stremitzer: Agency Theory: Methodology, Analysis. A Structured Approach to Writing Contracts. 2005.

Band 4 Günther Sedlacek: Analyse der Studiendauer und des Studienabbruch-Risikos. Unter Verwendung der statistischen Methoden der Ereignisanalyse. 2004.

Band 5 Monika Knassmüller: Unternehmensleitbilder im Vergleich. Sinn- und Bedeutungsrahmen deutschsprachiger Unternehmensleitbilder - Versuch einer empirischen (Re-)Konstruktion. 2005.

Band 6 Matthias Fink: Erfolgsfaktor Selbstverpflichtung bei vertrauensbasierten Kooperationen. Mit einem empirischen Befund. 2005.

Band 7 Michael Gerhard Kraft: Ökonomie zwischen Wissenschaft und Ethik. Eine dogmenthistorische Untersuchung von Léon M.E. Walras bis Milton Friedman. 2005.

Band 8 Ingrid Zechmeister: Mental Health Care Financing in the Process of Change. Challenges and Approaches for Austria. 2005.

Band 9 Sarah Meisenberger: Strukturierte Organisationen und Wissen. 2005.

Band 10 Anne-Katrin Neyer: Multinational teams in the European Commission and the European Parliament. 2005.

www.peterlang.de 